Chapman University

Chapman University Digital Commons

$5-2022$

\title{
Higher Education Housing Professionals and Disability: A Grounded Theory Exploration of Resident Directors' Understandings of Disability
}

Christopher Toutain

Chapman University, ctoutain@chapman.edu

Follow this and additional works at: https://digitalcommons.chapman.edu/education_dissertations

Part of the Disability and Equity in Education Commons

\section{Recommended Citation}

Toutain, C. (2022). Higher education housing professionals and disability: A grounded theory exploration of resident directors' understandings of disability [Doctoral dissertation, Chapman University]. Chapman University Digital Commons. https://doi.org/10.36837/chapman.000339

This Dissertation is brought to you for free and open access by the Dissertations and Theses at Chapman University Digital Commons. It has been accepted for inclusion in Education (PhD) Dissertations by an authorized administrator of Chapman University Digital Commons. For more information, please contact laughtin@chapman.edu. 


\title{
Higher Education Housing Professionals and Disability: A Grounded Theory Exploration of Resident Directors' Understandings of Disability
}

\author{
A Dissertation by \\ Christopher Toutain \\ Chapman University \\ Orange, CA \\ Attallah College of Educational Studies \\ Submitted in partial fulfillment of the requirements for the degree of \\ Doctor of Philosophy in Education
}

May 2022

Committee in charge:

Scot Danforth, Ph.D., Chair

Meghan Cosier, Ph.D.

Whitney McIntyre Miller, Ph.D.

Charlie Potts, Ph.D. 
The dissertation of Christopher Toutain is approved.

\section{Scot Danforth}

Scot Danforth, Ph.D., Chair

Meghan Cosier

Meghan Cosier, Ph.D.

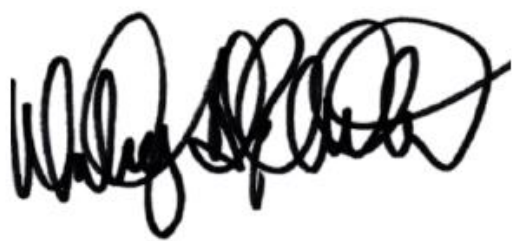

Whitney McIntyre Miller, Ph.D.

\section{Lawrence Charles Potts}

Charlie Potts, Ed.D.

January, 2022 
Higher Education Housing Professionals and Disability: A Grounded Theory Exploration of Resident Directors' Understandings of Disability

Copyright (C) 2022

by Christopher Toutain 


\section{ACKNOWLEDGEMENTS}

I am incredibly fortunate to have the opportunity to pursue a doctoral degree. The process has been formative and enriching. I am grateful for the family, friends, mentors, and colleagues who have supported me and assisted in making this journey possible.

First, I would like to thank my dissertation committee. To my committee chair and advisor, Dr. Scot Danforth, thank you for mentorship, feedback, and encouragement throughout the doctoral program. Your ongoing support has been invaluable. Thank you, Dr. Whitney McIntyre Miller, for your guidance as I engaged in my grounded theory analysis. Thank you, Dr. Meghan Cosier, for supporting me as I honed my critical voice, with an eye towards intersectionality. Thank you, Dr. Charlie Potts, for serving as a professional role model in Student Affairs, and a trusted expert on the context of this study.

Second, I would like to thank the academic and professional colleagues and peers who have supported me over the past several years. Whether in classes generating and exchanging ideas, or out of class, asking about my progress and providing constant encouragement, these connections provided me with the energy to maintain forward progress in the program.

Lastly, I would like to thank my family and friends who not only provided support, but gave of themselves so that I could pursue the doctoral program. Thank you for checking in, sharing excitement at program milestones, and keeping me motivated. Thank you, Mom and Dad, for instilling in me a value for education and helping me find a path in which it remains a constant. Finally, thank you, Ashley. Your unwavering support has only been matched by the tremendous amount of work you took on so that I could undertake this academic journey. 


\begin{abstract}
Higher Education Housing Professionals and Disability: A Grounded Theory Exploration of Resident Directors' Understandings of Disability

by Christopher Toutain
\end{abstract}

The residential experiences of students with disabilities in higher education play a pivotal role in their overall campus education. However, little is known about the ways in which the staff who manage and support these residential environments understand and work with issues and concepts of disability. Utilizing constructivist grounded theory, this study examines the ways in which resident directors think about and work with disability within their positions of residential management. The study also explores the ways in which resident directors think about and understand disability as a component of diversity, the steps that resident directors take in working with students with disabilities, and the support they provide their student staff in fostering residential communities inclusive of students with disabilities. The findings suggest that resident directors' work related to disabilities and disability identity is marked by tensions between individual understandings of disability and institutional systems and job expectations. Suggestions are provided for ways to better support resident directors as they navigate conflict between personal beliefs and positional responsibilities. 


\section{TABLE OF CONTENTS}

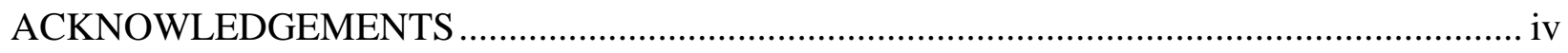

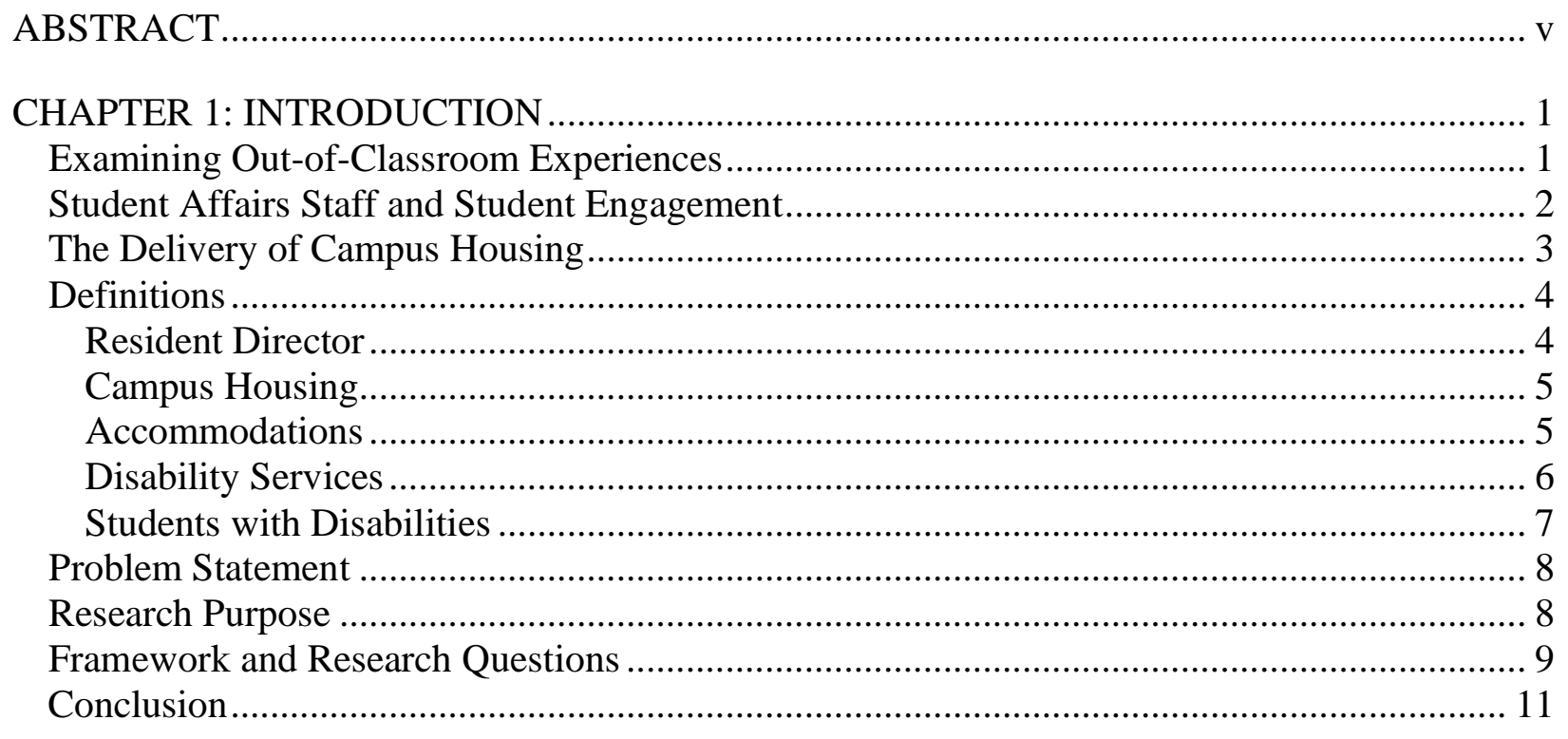

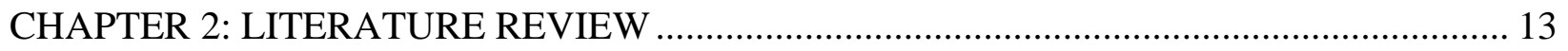

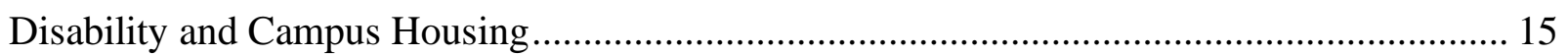

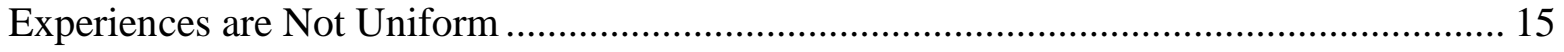

Importance of Housing Accommodations ........................................................................ 18

Aspects of Daily Living Across the Campus Environment............................................... 21

Disability and Campus Engagement ………………............................................................ 22

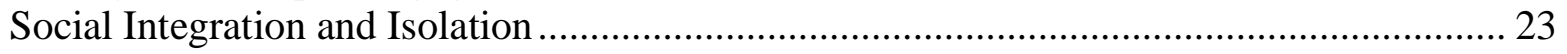

Social Pressures and Stigma ....................................................................................... 26

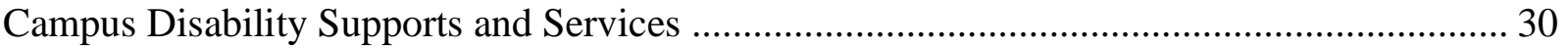

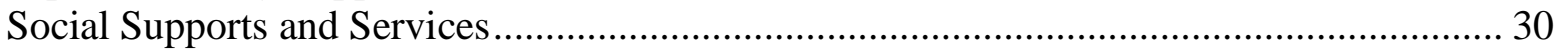

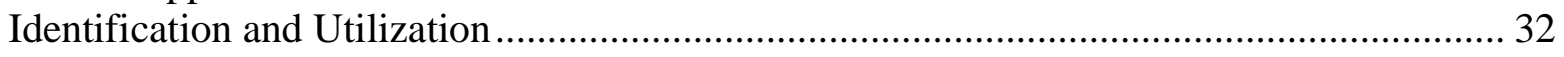

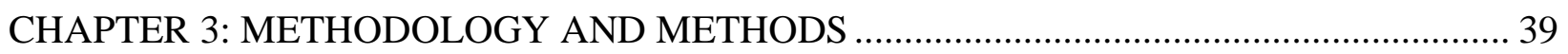

Methodological Approach and Rationale …………………................................................ 39

History of Grounded Theory ……………………....................................................... 39

Constructivist Grounded Theory ……….......................................................................... 41

Grounded Theory Methodology and Methods .................................................................... 42

Asking Grounded Theory Questions ………………..................................................... 42

Gathering Grounded Theory Data …………………..................................................... 44

Conducting Grounded Theory Coding ........................................................................... 45

Theoretical Sensitivity and Memo-Writing ..................................................................... 47

Theoretical Sampling and Category Saturation ................................................................... 49

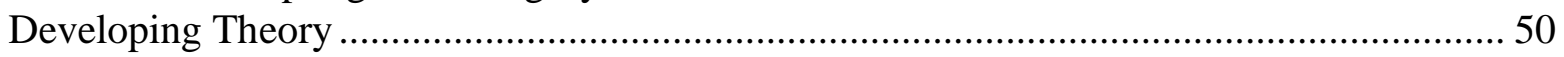

Applying Constructivist Grounded Theory to RD Understandings of Disability ......................5 51

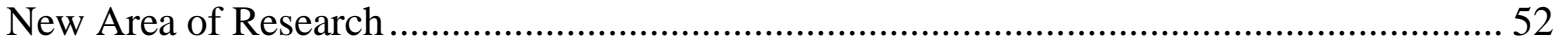




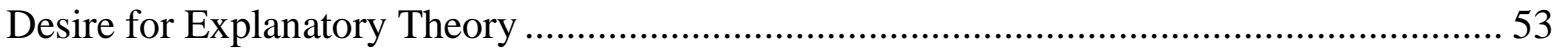

The Processes Imbedded within the Resident Director Position ............................................ 53

Constructivist Approaches to RDs and Disability Studies .................................................. 55

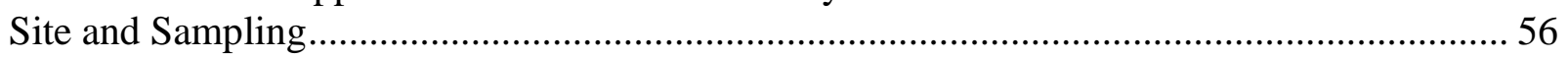

Access, Role, Reciprocity, Trust, and Rapport ……………............................................ 59

Role

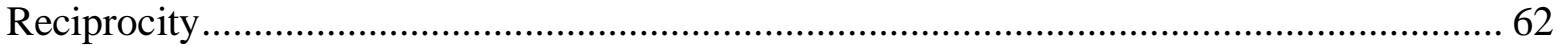

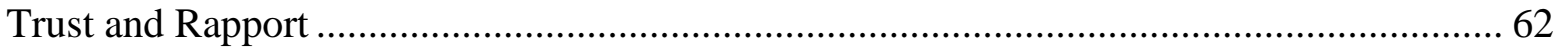

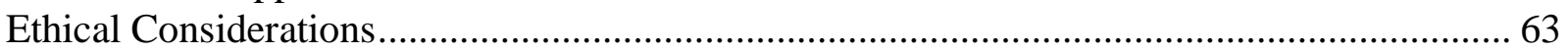

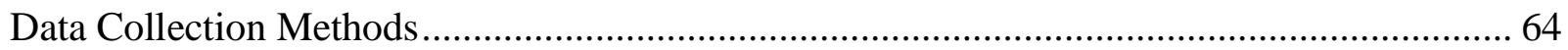

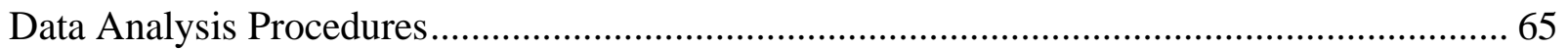

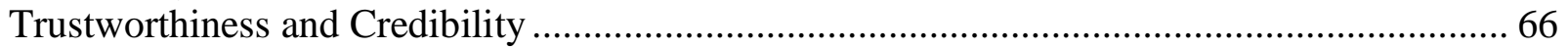

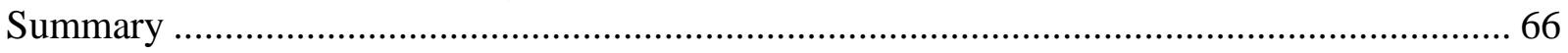

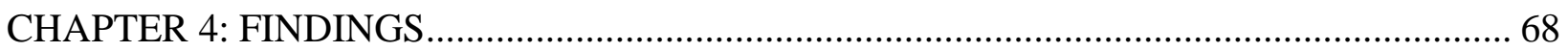

Developing an Understanding of the Breadth and Individualization of Disability ................... 68

Learning from Personal Experiences....................................................................... 70

Avoiding Assumptions ............................................................................................ 72

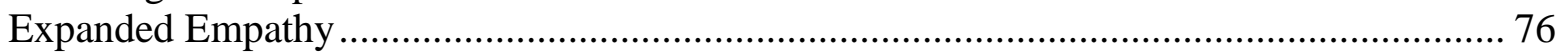

Addressing Disability Reactively .................................................................................... 79

Distinguishing Between Accommodation and Inclusion ..................................................... 81

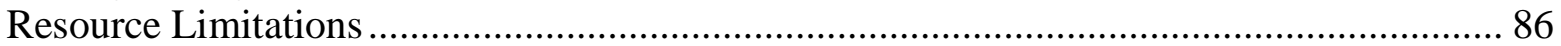

Tension Between Stated Needs and Documentation Requirements ....................................... 89

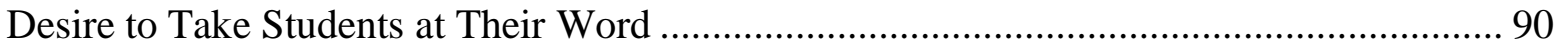

Legal Requirements ....................................................................................................... 95

Assisting Students Through the DS Process......................................................................... 97

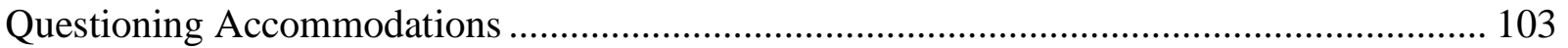

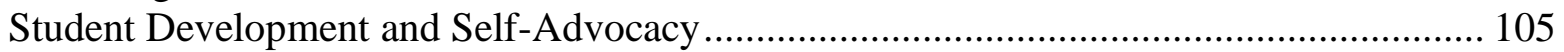

Accommodations and RA Employment ........................................................................... 109

Identity Privilege and Limited Resources ....................................................................... 111

Generalists Operating Between Silos of Expertise …………............................................. 115

Autonomy Within My Building ..................................................................................... 117

Specialized Knowledge of Disability is Not Needed ...................................................... 121

Managing Legal Liability by Following Instruction ......................................................... 124

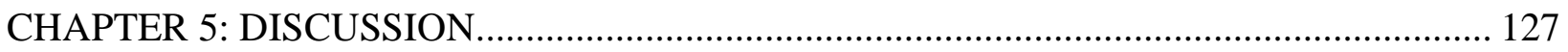

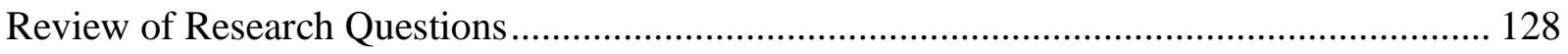

Framing Active Tensions Across Identified Themes .......................................................... 128

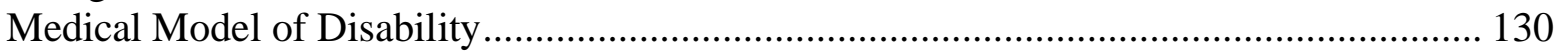

Social Model of Disability .......................................................................................... 132

Systems and Structures of Student Affairs in Higher Education.......................................... 134

Tensions of Community and Diversity ............................................................................ 137

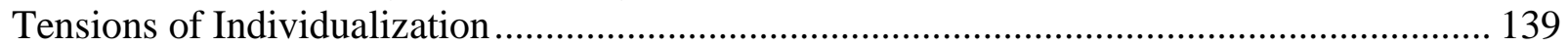

Tensions of Residence Life Learning Outcomes ............................................................... 141

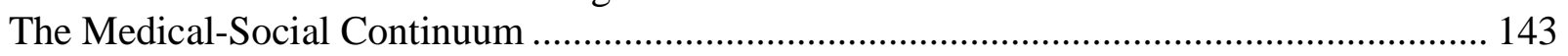

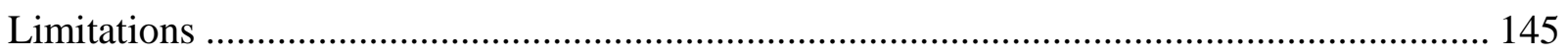

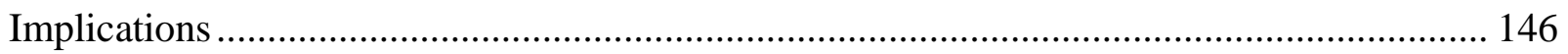




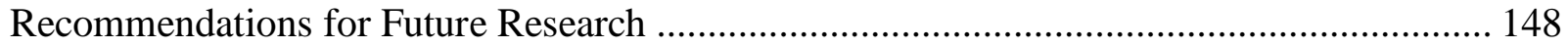

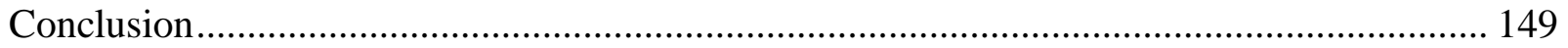

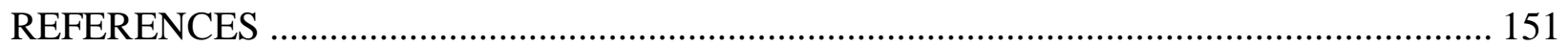

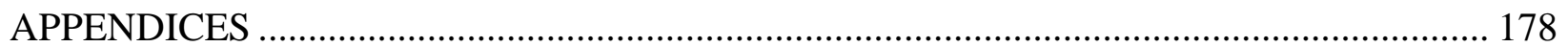




\section{CHAPTER 1: INTRODUCTION}

The number of students with disabilities enrolled in postsecondary education in the United States has risen over the past several decades (Newman et al., 2010; Snyder \& Dillow, 2010; Snyder et al., 2019). Scholars have attributed this increase, in part, to legislation that requires colleges and universities to provide disability-related accommodations for students who disclose their disabilities to their institutions (Lynch \& Gussel, 2011). However, as postsecondary enrollment has increased, an achievement gap at four-year colleges and universities appears to persist between students with disabilities and their non-disabled peers. A body of literature has grown out of attempts to understand this gap, and better support students with disabilities in higher education. Researchers have approached this problem in a number of ways, including explorations of the campus experiences of students with disabilities (e.g., Hong, 2015; Leake \& Stodden, 2014; Shepler \& Woosley, 2012), the provision of academic accommodations (e.g., Ketterlin-Geller \& Johnstone, 2006; Marshak et al., 2010), the attitudes and actions of faculty and staff (e.g., Lombardi et al., 2013; Murray et al., 2009; Sniatecki et al., 2015), and the implications of systemic ableism in systems of higher education (e.g., Brown \&

Leigh, 2018; Hutcheon \& Wolbring, 2012; Kattari, 2015). These studies have largely focused on college and university academic environments. In contrast, less attention has been paid to the out-of-class aspects of disability in higher education.

\section{Examining Out-of-Classroom Experiences}

Out-of-classroom student experiences include a broad array of student life systems, both formal and informal, ranging from structured student-leadership opportunities, to daily peer interactions (Kuh, 1995; Terenzini et al., 1995). These out-of-class activities, experiences, and behaviors have been examined by researchers interested in understanding the role they play in 
student success (Kuh et al., 2007). Early scholarship in this area suggested that various forms of campus engagement had relationships with student persistence and success (Terenzini et al., 1999).

Among various aspects of the out-of-class experiences of students with disabilities, oncampus housing has been identified as a positive factor in student persistence (Mamiseishvili \& Koch, 2011). More recently, critical scholars have questioned previous studies of student engagement, and called for the reexamination of the assumptions upon which this research has been grounded (e.g., Quaye et al., 2020). Scholars have brought attention to systems of higher education and the ways in which they support or undercut on-campus opportunities on for traditionally marginalized students. They have also questioned the metrics by which traditional notions of engagement, persistence, or success are assessed. Consistent with this approach, consideration has recently been given to issues of disability in higher education, as a component of diversity that has been historically marginalized by postsecondary systems (Evans et al., 2017).

\section{Student Affairs Staff and Student Engagement}

One way in which research on student engagement can take a critical perspective is by interrogating the systems of daily life that dictate individual experiences. Student affairs administrators play a central role in the construction and maintenance of these systems. From the staff members who advise student clubs and organizations, to administrators who provide intervention and services to students in crisis, student affairs staff play a direct role in the ways that students experience their campuses; and whether those experiences support all students, or reinforce systems of marginalization. The on-campus experiences of students with disabilities have been explored through a diversity lens in a variety of ways. For example, some researchers 
have studied the intersectional experiences of disability with race/ethnicity (Pearson \& Samura, 2017) and gender and sexuality (Miller et al., 2017) within systems of higher education.

Meanwhile, others have investigated similar systems, with an eye towards the ways in which disability is, or is not, treated as a component of institutional diversity (Gabel et al., 2017; O’Neil

Green et al., 2017). However, one component of the student experience in which this literature remains sparse is that of housing and residential life. The present qualitative study sought to investigate the ways in which residence life professional staff understand disability.

\section{The Delivery of Campus Housing}

Colleges and universities have long histories of providing housing for their students (Nuss, 2003). Institutions vary in the type of housing they provide, as well as in the makeup of their campus populations that reside in their buildings (Shushok et al., 2011). Beyond providing a physical space for students to live, many colleges and universities facilitate residential education programs through their residence halls. Student affairs housing professionals strive to construct vibrant living environments for students; designed to facilitate learning and development in compliment to the academic experience (Eanes \& Perillo, 2015). The intentionality of housing professionals in the creation of educational experiences in residence halls is central to the primary question that was explored in this research project. In addition to understanding disability in housing professionals' work with specific students or situations, this study aimed to explore larger concepts of disability access and equity by exploring the ways in which residence life staff think about and work with disability throughout their delivery of the residential program.

Research has suggested that the awareness and responsiveness of residence life staff has implications for the campus experiences of students with disabilities (Wilke et al., 2020). 
However, the literature on the perspectives and understandings of these staff members remains quite limited (Vacarro \& Kimball, 2019). Of the various staff who contribute to the operation of college and university housing, the resident director (RD) role is of central importance to this study. RDs work as full-time, live-in professional staff members in residence halls. The role is one that is recognized as crucial to the successful creation of engaging, educational, and developmentally supportive communities (Belch \& Mueller, 2003). Additionally, RDs supervise student resident assistants, who are often residents' first points of contact and support in the residence halls (Berg \& Brown, 2019). Despite the important and unique role played by RDs, it is not one that has been rigorously studied regarding issues of disability.

\section{Definitions}

There are multiple terms and concepts that are discussed throughout this study that require clarification. Several of these definitions are important because of the lack of uniform language within student affairs in higher education. Although the field has best practices, guiding documents, and national associations (e.g., Association on Higher Education and Disability, n.d.; Council for the Advancement of Standards in Higher Education, 2015; Eanes \& Perillo, 2015) institutions retain a great deal of flexibility in the titling of positions and departments.

\section{Resident Director}

For the purposes of this study, $R D$ is used to reference the full-time, live-in professional staff members who supervise student resident assistants and who are responsible for the overall operation of the residential programs and students within the building or buildings to which they are assigned. The title used for these professionals varies from campus to campus, and may include, among other terms, resident director, residence director, hall director, or area 
coordinator. For ease of understanding, $\mathrm{RD}$ is used throughout this study to refer to any of these positions, provided that the job responsibilities met the position as described above.

\section{Campus Housing}

The literature on student housing in higher education generally utilizes housing in reference to the physical spaces in which students reside, and residence life when discussing the programmatic aspects of student life in residence halls (e.g., Wilke et al., 2019). Like the variety of RD titles, residence life departments have different names at different institutions - residence life, residential life, campus life and housing, or housing and community life, represent only a few examples. Likewise, a given campus may title the office responsible for the physical residence halls housing, housing facilities, or housing operations. To further complicate these terms, some institutions are organized such that a housing office and a residence life office are one in the same, while at other institutions they are distinct offices within a larger division, or in some cases separate offices in different divisions entirely. For the purposes of this study, residence life refers to the department or office responsible for the student-focused programmatic operations of the residence halls, while housing refers to the office responsible for the physical buildings. However, from a student perspective, these offices may likely be indistinguishable (Wilke et al., 2019). Therefore, while housing and residence life are used to discuss various offices or types of administrative work or responsibilities, campus housing is used to describe the overall experience of student life in college and university residences.

\section{Accommodations}

Throughout this study, the word accommodation is used as it relates to the provision of accessible educational spaces for students with disabilities. Specifically, it is used to reference the legal concept of the provision of equal access to education, as defined by disability 
legislation (Americans with Disabilities Act of 1990; Rehabilitation Act of 1973). Outside of this legislative framework, this word is used in ways that intersect with the topic of this study but have different meanings. First, within a disability context in higher education, accommodations may be discussed in things that people do to support students with disabilities outside of the formal accommodations process. For example, a student who is not registered with the disability services office on campus may request that an RD read an incident report aloud in a meeting, so that the student is better able to understand it; the RD may do so, however, this is not an accommodation in the legal sense, but rather a situation in which an is RD working with a student to meet their needs. To not confuse these types of informal actions, the word accommodation will be used solely as it relates to the formal disability services process.

Second, in the college and university housing context, the word is also informally used to discuss residence hall amenities. A discussion of whether a particular residence hall has single rooms, doubles, suited apartments with shared bathrooms, etc., may be referred to as a matter of accommodations. Here too, due to the disability focus of this study, other language will be used in such cases, and accommodation will be reserved to reference matters of formal disability services provision.

\section{Disability Services}

Disability accommodations in higher education are provided to students in individualized ways through offices that are responsible for documenting disabilities, and identifying and implementing accommodations (Rothstein, 2015). The purpose of these offices is to facilitate access to the educational environment for students with disabilities (Meyer et al., n.d.). The staff within these offices facilitate access by engaging in processes with students that are designed to identify and document students' functional limitations; and facilitate accommodations that are 
designed to afford educational access to students with disabilities, equal to that of their nondisabled peers. These processes are highly individualized, and based the information that is shared by students, as well as the contextual factors of the educational setting within which the accommodations are being requested.

Similar to the previous definitions of offices and positions, colleges and universities have a great deal of flexibility in the location and titling of these offices (Harbour, 2009; Kroeger \& Kraus, 2017). A cursory review of college and university directories is likely to identify disability services, disability resource services, accessibility services, or accessible education as only a few of the varied departmental names. For clarity, and to maintain the anonymity of the RDs involved, these offices, and the administrators who work within them, will be referenced throughout this study as disability services (DS) offices and administrators.

\section{Students with Disabilities}

Lastly, students with disabilities is defined as those students who self-identify as such. Neither medical documentation nor registration with a campus disability services office are a required component of this identification. The rationale behind this definition is twofold. First, it is consistent with the Disability Studies perspective that served as a critical framework for this study. Second, previous research has investigated the social stigma that is associated with disability disclosure (e.g., Barnard-Brak et al., 2010; Salzer et al., 2008; Stein, 2013; Wood, 2017). Such stigma may exist for students and among communities regardless of whether students formally register with disability services offices. In exploring the ways that RDs understand disability, this study interrogated how RDs work with and think about students with disabilities, regardless of whether they have formally disclosed their disabilities to their institutions. Defining students with disabilities in this way allowed for an exploration of the ways 
that RDs thought about and worked with issues of disability beyond those of which they were formally notified through official institutional channels.

\section{Problem Statement}

The dearth of research regarding disability and campus housing requires attention. Davidson and Bauman (2013) argued for the importance of this research in a special edition of The Journal of College and University Student Housing, yet the available literature on the topic remains minimal. Wilke et al. (2019) noted that the responses of residential staff played a substantial role in the student experience. However, as highlighted by Vaccaro and Kimball (2019), staff perspectives continue to be an under-researched area of the field. If the residential experience is crucial to the educational mission of institutions, it stands that the understandings of disability held by the staff who are responsible for the delivery of campus housing should be more thoroughly explored in support of the full engagement in, and benefit from, the residential experience for students with disabilities. Such a problem statement represents a very large thread of potential research. The present study aimed only to take a step in addressing this problem.

\section{Research Purpose}

The purpose of this study was to explore RDs' understandings of disability. Within the broad spectrum of higher education, this study focused on the experiences of RDs at small and medium, private, not-for-profit, four-year colleges and universities with liberal arts traditions, that house at least twenty-five percent of enrolled undergraduate students in campus housing and are located on the West Coast of the United States. The twenty-five percent threshold was identified based on the Carnegie Classification of Institutions of Higher Education (2018). The Carnegie Classifications combined with institutional mission statements likewise guided the definition of liberal arts traditions. 
The reason for focusing the study in these ways was to support an understanding of the topic based on similarly situated RD experiences. The specific institutional characteristics selected for this study were driven by the type of institution with which I am most familiar as a student affairs administrator. Such familiarity required that I be both cautious and intentional regarding the ways in which I guarded against potential interpretive bias (Charmaz, 2014). However, it also supported my ability to better understand the institutional contexts within which I sought to explore RD understandings of disability.

\section{Framework and Research Questions}

The study was conducted using constructivist grounded theory (Charmaz, 2014). The methodology was identified because the study aimed to explore the processes by which RDs understand disability in their work. Additionally, the dearth of prior research in the area of student affairs administrators and disability broadly, and residence life and housing staff specifically, rendered constructivist grounded theory appropriate. Disability Studies provided a critical framework for this study. Disability Studies is an interdisciplinary field that developed in opposition to traditional notions of disability (Davis, 2013). Disability Studies is discussed in greater depth in the methodology section of this dissertation. It is important to note that in using Disability Studies as a critical framework, the study began from a standpoint that framed issues of disability as issues of diversity and social power and control. Multiple student affairs practitioner organizations have identified diversity and social justice as core commitments of the profession (Eanes \& Perillo, 2015). However, scholars have also noted higher education's own history of approaching disability from an individualized, policy-driven perspective, rather than from one of diversity and inclusion (Leake \& Stodden, 2014). Utilizing Disability Studies as a critical framework called for consideration of the potential tension between the history of 
disability in higher education, and the aspirational goals of residence life and housing departments to create accessible programs that serve all students equitably. Such a tension played out quite literally in the study, as RDs acknowledged their responsibilities for managing older residence halls, which were not built to be accessible to those with mobility limitations. Consistent with constructivist grounded theory, Disability Studies did not guide the study, but rather served as a starting point in exploring the ways in which RDs understand disability.

The purpose of this study was addressed through a systematic investigation of a primary research question that included multiple secondary questions. The primary question and subquestions for this study were:

- In what ways do RDs from small, private, liberal arts colleges and universities think about and work with issues and concepts of disability in the context of campus housing?

- In what, if any, ways do RDs consider disability identities in their creation and support of their residential communities?

○ In what, if any, ways do RDs consider disability as a component of diversity that intersects with other marginalized identities?

- In what, if any, ways do RDs work to provide accommodations to residential students with disabilities?

○ In what, if any, ways do RDs support resident assistants in working with students with disabilities?

As noted by Marshall and Rossman (2016), there are multiple perspectives from which to understand the significance of a qualitative research study. The present study sought to contribute to the academic knowledge regarding disability in higher education, and through it to support the lived experiences of housing and residence life for students with disabilities on 
college and university campuses. By attending to a gap in the literature, the study aimed to contribute to the provision of more effective support and the creation of more equitable campus housing environments for students with disabilities. A refined understanding of how RDs think about and work with issues and concepts of disability in campus housing is valuable in understanding areas of future research related to student affairs' support of students with disabilities.

The study also aimed to contribute to student affairs housing practitioners' knowledge of the ways in which RDs understand disability. Insight into these understandings supports important advances in policy and practice in college and university residential programs. Watson et al. (2013) argued that it is incumbent upon institutions of higher education to move beyond minimum policy requirements when considering the campus environment for students with disabilities. Exploring RDs' understandings of disability in a study framed by Disability Studies scholarship, supported the examination of perspectives of disability that move beyond legal definitions. Engaging the topic of disability beyond strict legal analyses may be valuable to higher education administrators - particularly those who seek to make their campuses more inclusive and equitable.

\section{Conclusion}

While an increase in students with disabilities in higher education has occurred, and research has been conducted regarding the classroom experience with respect to disability, the topic continues to be under-researched as it pertains to broader student life experiences. The potential educational and social engagement opportunities that exist in campus housing are ones that higher education has an obligation to better understand from a disability perspective so that it can better facilitate equitable experiences for students with disabilities. The present 
constructivist grounded theory study sought to contribute to this body of literature. It aimed to do so through the systematic exploration of RD understandings of disability in the context of college and university housing. 


\section{CHAPTER 2: LITERATURE REVIEW}

Campus housing in higher education is a site of ample tension for students. It is a place where social identities are formed (Haynes, 2019), and a venue for conflicts to emerge as students navigate their understandings of various identities, along with their growing understandings of campus, their academics, and the broader societies within which they exist (Jaggers \& Iverson, 2012). It is also an environment that is simultaneously a home for students while they live on campus, and a workplace, for the staff and administrators who manage and maintain the spaces and the programmatic components that are provided within them (Evans et al., 2017). Within these spaces, myriad identities, responsibilities, as well as personal and institutional goals intersect as students and staff move through daily life in these residential buildings.

These tensions are also visible when one views campus housing through a lens of disability. The residential experience simultaneously appears in the literature as something that may contribute to the persistence of students with disabilities (Mamiseishvili \& Koch, 2011) yet presents its own set of barriers and challenges (Camarena \& Sarigiani, 2009). Unfortunately, the available research at the intersection of campus housing and disability is relatively sparse. Therefore, in considering the literature relevant to a study of RD understandings of disability one must look beyond those studies set in a campus housing context. The following chapter considers the empirical scholarship related to disability and campus housing by examining three distinct areas of the larger literature on disability and higher education. The first area includes disability in higher education research that directly involved campus housing. The second area contains studies that addressed disability and social engagement in higher education. The final area is 
comprised of research that examined the provision of disability supports and services for students in higher education.

Although the focus of this study was on the understandings of RDs, the literature discussed in this chapter primarily revolves around the campus experiences of students with disabilities in higher education. The focus of the literature review is appropriate for this study for multiple reasons. One is the absence of literature regarding student affairs staff on the topic of disability beyond disability services offices. Another is that much of the literature that has explored topics of disability in the context of staff in higher education has done so to examine staff perspectives or attitudes regarding disabilities (e.g., Knott \& Taylor, 2014; Murray et al., 2011) The present study focused more on exploring the processes by which RDs understand and operate with respect to disability than of their attitudes. Lastly, scholars have noted that the perspectives of students with disabilities remain marginalized in the literature (Evans et al., 2017; Wilke et al., 2019). While this study was designed to explore RD understandings, it was vital in keeping with a Disability Studies frame that the perspectives and experiences of students with disabilities be a focal point of this literature review.

I gathered the literature included in this review through several systematic searches. Keyword searches were performed in the EBSCO database using combinations of the following words or phrases: disability, students with disabilities, residence life, housing, social integration, disability services, higher education, and postsecondary education. The searches were not limited by a date range. However, most of the results were published between 2010 and 2019, and nearly all results were published after 2000. These searches resulted in a combination of empirical studies (e.g., Bialka et al., 2017; Wilke et al., 2019), theses and dissertations, and practitioner-focused white papers and other non-empirical works (e.g., Miele et al., 2018; 
Watson et al., 2013). I included both qualitative and quantitative social science analyses that attended to disability in higher education housing, social interactions, and out-of-classroom accommodations and services. I then culled the references of these articles, along with the reference sections of topically relevant non-empirical and non-peer-reviewed sources, to locate additional relevant research. In order to maintain the focus of this literature review on students with disabilities in campus housing, I similarly used studies that focused exclusively on the academic context (e.g., Goegan \& Harrison, 2017; Lovett et al., 2019) and the transition into or out of higher education (e.g., Roessler et al., 2009; Skaff et al., 2016) to identify additional relevant literature, but excluded them from this review. Appendix A contains a summary table of the literature included in this review.

\section{Disability and Campus Housing}

The available literature regarding students with disabilities and campus housing is limited. However, the context of daily life in college and university residence halls and apartment buildings is replete with meaningful experiences and interactions. Thus, multiple themes were identified, albeit from a relatively small number of studies.

\section{Experiences are Not Uniform}

One theme that emerged across several studies on the experiences of students with disabilities in campus housing was that these experiences do not occur in monolithic ways (Gelbar et al., 2015; Madriaga, 2010; Stumbo et al., 2010; Wilke et al., 2019). Gelbar et al. (2015) and Madriaga (2010) both studied the campus experiences of students with autism spectrum disorders. Gelbar et al. (2015) gathered survey responses from 35 individuals in the United States who had attended at least one semester of postsecondary education. Madriaga (2010) collected eight year-long life histories from higher education students across the United 
Kingdom. Both studies included individual accounts from students, some of whom found their campus housing experiences beneficial and others who found it challenging. In certain cases, the same aspect of the housing experience was found to be supportive for some, while difficult for others. For example, Madriaga reported that several students indicated that their living spaces were important places of peace and solitude. However, for another student in the same study, being housed near the entrance to the building presented constant noise in a manner that was problematic. Likewise, data gathered by Gelbar et al. (2015) indicated that 50\% of survey respondents "enjoyed living on campus" (p. 49). Some of these respondents reported benefiting from single room housing options, while others indicated that living alone further isolated them from the campus community.

Differing student perspectives about the benefits of campus housing also appeared in Stumbo et al.'s (2010) study of University of Illinois alumni with severe physical disabilities. The researchers interviewed 13 alumni who had all lived in Beckwith Hall - a university residence hall specifically created for students with personal assistance needs. Stumbo et al. reported that for some of these students, living around peers with severe physical disabilities provided them the ability to learn from others in a similar position, "and pass along useful tips and advice" (p. 13). The researchers described a positive community that developed within the residence hall for these students who shared a common campus experience. Meanwhile, the authors noted that other Beckwith Hall residents held the perspective that the consolidation of students with severe physical disabilities in Beckwith Hall further contributed to their social isolation from the rest of the campus community.

A recent study on the perspectives of college students with disabilities (Wilke et al., 2019) corroborated the notion that student residential experiences are highly unique from student 
to student. In their study of the perspectives of 24 students with disabilities from four Midwest residential liberal arts colleges, the researchers identified flexibility as a critical theme in the campus housing experience. Wilke et al. explained that students discussed the importance of flexibility particularly with respect to university policies and procedures. The authors discussed examples including room selection policies that disadvantaged students who were unable to find roommates, or housing requirements that had very narrow exemption criteria. Wilke et al. argued that at the core of student's recommendations for increased flexibility was the assertion that current institutional policies do not have the necessary flexibility to allow students to be treated as the experts on their own individual lives.

The need for increased flexibility was also addressed in a study on the postsecondary educational barriers for students with autism spectrum disorder (Anderson \& Butt, 2017). The researchers conducted interviews with 18 postsecondary students with autism spectrum disorder and one or both parents of each student. Among their broader identification of challenges for students with autism spectrum disorder in postsecondary education, Anderson and Butt identified a lack of flexible policy to be a specific impediment. One example of inflexible policy challenges they discussed involved finding that many four-year institutions tied housing to full-time student status. They described that for one student this policy, along with a lack of knowledge of the policy, resulted in the student reducing their course load to better manage academic stress, only to find that doing so meant they were no longer eligible to live on campus.

Across these studies, suggestions for increased flexibility simultaneously served as implicit assertions that the campus housing experiences of students with disabilities are not monolithic; if they were, universal policies would be more likely to meet the needs of the students involved in these studies, without the need for flexible provisions. The notion that 
students with disabilities reported varied campus housing benefits and challenges reinforces the reality that there is not a singular disabled student experience in higher education. As much should not be surprising, as there is no singular student experience in higher education.

Critical DS scholars have noted the intersectional implications of multiply marginalized identities (e.g., Annamma, 2015; Crenshaw, 1989; Leonardo \& Broderick, 2011; Mendoza et al., 2016). While the research on campus housing experiences of students with disabilities at times gathered data on student racial, ethnic, or gender, or class standing identities and characteristics (e.g., Wilke et al., 2019), these studies have done little to employ this data in their analyses. Similar treatments of various student identities were found throughout the literature addressed in this chapter. Studies discussed in following sections by Dowrick et al. (2005) and Abes and Wallace (2018) were among the few that explicitly considered multiple identities in their findings. Unfortunately, most of the studies that collected such data on student identities did little more than reference descriptive statistics and acknowledge the homogeneity of dominant identities as study limitations. Therefore, while these studies that have addressed the campus experiences of students with disabilities appear varied, it is also important to acknowledge that other aspects of student diversity may be playing roles in these varied experiences.

\section{Importance of Housing Accommodations}

The crucial role of disability accommodations was another theme found in multiple studies on campus housing and disability (Kurth \& Mellard, 2006; Stumbo et al., 2010; Vaccaro \& Kimball, 2019; Wilke et al., 2019). In the study conducted by Stumbo et al. (2010), the operation of Beckwith Hall involved a variety of physical accessibility accommodations. One of the educational barriers that was identified by the participants in this study was the inaccessibility of certain buildings or areas of campus. It appeared that the University of Illinois 
was still struggling to provide accessible spaces to Stumbo et al.'s participants while they were enrolled. However, the participants did identify the accessibility accommodations provided within Beckwith Hall as important in the facilitation of their education.

Similarly, Kurth and Mellard (2006) discussed housing accommodations as they related to educational access in their study of 108 students with disabilities from 15 different colleges. The study, which investigated perceptions of the accommodations process, focused primarily on academic accommodations. However, Kurth and Mellard noted that housing emerged as a topic of importance during focus group discussions. Similar to Stumbo et al. (2010), students in Kurth and Mellard's (2006) focus groups identified accessible housing as a factor that impacted their ability to participate fully in campus activities. Unfortunately, Kurth and Mellard noted that for many students, this was not a positive topic of discussion. The researchers explained that the focus groups discussed the ways in which the lack of accessible housing limited student participation and academic engagement.

The physical accessibility of campus housing also appeared in interviews conducted by Wilke et al. (2019). However, accommodations that involved the physical aspects of the residence halls were only one part of Wilke et al.'s consideration of accommodations. The researchers reported on student experiences regarding a range of accommodations, including emotional support animals (ESAs) and single room assignments. Wilke et al. noted that only eight of the 24 participants in this study reported utilizing accommodations. The researchers identified several themes among students who might have benefited from accommodations but chose not to request them. The reasons included a lack of knowledge about the existence of accommodations, a belief that effective accommodations were not available, and a concern regarding the social impact of accommodations on their residential experience. 
Findings from Abes and Wallace's (2018) study of intersectional disability lent additional nuance to Wilke et al.'s (2019) discussion of accommodations. Abes and Wallace (2018) explored the ways in which intersectional ableism shapes understandings of disability. They identified erasure as a central component of the experiences of multiply marginalized students with physical disabilities. Specifically, they found that disability was limited, in part, from being fully considered as a component of diversity because of the way in which it was medicalized and pathologized through the language of accommodations.

In addition to student accounts of the importance of disability-related housing accommodations, the theme also appeared in a study of staff perspectives (Vaccaro \& Kimball, 2019). Vaccaro and Kimball conducted focus groups with 31 student affairs administrators from 21 different institutions. The focus groups explored how these "student affairs professionals conceptualized their work with students with disabilities" (p. 171). Vaccaro and Kimball reported that participants identified the interactional nature of the accommodations process as a complicating factor in working with and providing accommodations for students with disabilities in residence halls. The researchers identified tensions related to accommodations provision as a central theme of their study. They noted that participants reported conflicting challenges in working with students with disabilities - being simultaneously required to account for both the needs of individual students and the needs of the larger community with respect to ESAs, single rooms, and the navigation of roommate or floormate conflicts. When considered alongside the study by Wilke et al. (2019) on the residential experiences of students with disabilities it appeared that both students and staff may struggle with the complexity of residential accommodations and the social implications for the decisions that they must make with respect to accommodations provision. 


\section{Aspects of Daily Living Across the Campus Environment}

In addition to studies that have directly addressed aspects of disability in campus housing, there are other studies that have implicated issues of housing through their broad exploration of daily living and the campus environment. Multiple studies have addressed this component of the postsecondary environment, both directly and indirectly (Cullen, 2015; Knott \& Taylor, 2014; Van Hees et al., 2015). Each of the studies that addressed daily living challenges focused on the experiences of students with autism spectrum disorders and Asperger's syndrome. The inclusion of these studies in this section of the present literature review is due to the overlap of daily living skills and residential experiences. For students who live in campus housing, many of the daily living skills addressed in the studies included in this section necessarily occur within the residential life environment. It is important to note that while the development of these daily living skills is a focus in certificate or non-degree programs for students with intellectual disabilities (Grigal et al., 2014), the literature addressed in this chapter was limited to students with disabilities enrolled in traditional credit-bearing postsecondary programs.

Cullen (2015) gathered information on experiences and perspectives from 24 students from five universities in southeastern Pennsylvania. The study focused on these students' higher educational needs. Cullen identified daily living skills as a distinct category of needs. The category included personal hygiene, self-care, and navigation of daily eating, sleeping, and transportation patterns. Similar studies have also been conducted in Belgium (Van Hees et al., 2015) and the United Kingdom (Knott \& Taylor, 2014). Van Hees et al. (2015) interviewed 23 postsecondary students. Knott and Taylor (2014) conducted a focus group with four students with Asperger's syndrome, and also conducted two focus groups with nine university staff members. Similar to Cullen (2015), Van Hees et al. (2015) identified daily living as a distinct 
aspect of postsecondary life, and one in which the students interviewed had substantial needs.

Time management, personal organization and routines were noted as being particularly

challenging. Laundry and cooking were examples of such daily living tasks that emerged as challenges for students in Knott and Taylor's (2014) study. Additionally, the researchers noted that the students in their study focused on the negative impact of sensory overload on their abilities to carry out daily living tasks. Knott and Taylor found that staff appeared to be far less familiar with such sensory impacts for this population of students and suggested that additional efforts should be made so that staff are better able to address these student concerns.

Issues of daily living clearly extend beyond the bounds of campus housing buildings or programs. However, the concerns raised regarding the needs of students with autism spectrum disorders appeared to be consistent with previously discussed research on the residential experiences of students with disabilities. Therefore, these studies were valuable in considering the ways in which individual student experiences might be supported, and how professional staff might best work with students to support their daily living needs in the campus housing context.

\section{Disability and Campus Engagement}

Campus engagement has been identified in the literature as having a relationship with residence life and housing in higher education (Astin, 1977; Graham et al., 2018; Schudde, 2011). Further, students with disabilities have identified housing as a component of their larger campus social experiences (e.g. Camarena \& Sarigiani, 2009; Stumbo et al., 2010; Vaccaro et al., 2015). The existence of this relationship renders literature on disability and campus social engagement in higher education relevant to a full consideration of disability and campus housing.

Among the literature that has examined disability in higher education, many studies have addressed the social component of the student experience. These studies have been explored in a 
variety of campus contexts. Some have focused on the social impacts of participation in specific cocurricular programs (e.g., Bialka et al., 2017; Wessel et al., 2011), while others have explored more broadly the totality of the campus social experience (e.g., Jackson et al., 2018; Olney \& Brockelman, 2003). Researchers have also noted that social contexts are complex and integral to student understandings of their campus environments (Vaccaro et al., 2019). Students arrive on college and university campuses with broad experiences that span a variety of social contexts all of which may contribute to their understanding of their postsecondary environment (Vaccaro et al., 2018). The complexity of social environments and understandings supported the consideration of research on social engagement in higher education broadly, in an effort to better understand the social experiences specific to student residential environments.

\section{Social Integration and Isolation}

Previous research has identified student social integration as a factor in persistence, retention, and graduation in higher education (Berger \& Milem, 1999; Gray et al., 2013; Tinto, 1993). Relationships have also been identified between student social engagement and belonging on campus, particularly for students with marginalized identities (Hurtado \& Carter, 1997; Strayhorn, 2012). Several researchers have expanded from these studies and found similar relationships for students with disabilities (DaDeppo, 2009; Vaccaro et al., 2015). In a study of 97 students with learning disabilities at a large four-year southwestern institution in the United States, DaDeppo (2009) found that social integration was a significant predictor of student persistence. Further, DaDeppo’s findings, based on student scores, questionnaires, and scale measures, indicated that social integration may be an even stronger predictor of persistence than academic integration among the students involved in this study. 
In contrast to DaDeppo's quantitative approach, the importance of social relationships also emerged as a central theme in a qualitative grounded theory study by Vaccaro et al. (2015). The study involved eight students with disabilities at a mid-sized public university in the eastern United States. The researchers identified social relationships as a core component of student belonging. Further, they found a reciprocal relationship between the two - such that student social relationships positively contributed to perceptions of belonging, while student sense of belonging positively supported the development of social relationships. These studies underscored the importance of social integration for students with disabilities in higher education. Unfortunately, many more studies have identified challenges or barriers surrounding the attainment of social integration among these students.

Social isolation appeared in many of the studies reviewed (Bialka et al., 2017; Colclough, 2017; Jackson et al., 2018; Knott \& Taylor, 2014; Madriaga, 2010; McLeod et al., 2019; Megivern et al., 2003; Stumbo et al., 2010). In qualitative studies such as those conducted by Bialka et al. (2017) and Stumbo et al. (2010), students with disabilities self-reported experiences of social isolation. In addition to firsthand experiences of students with disabilities, a study by McLeod et al. (2019) compared the experiences of students with disabilities to their nondisabled peers. In their large-scale quantitative study, the researchers found significantly poorer social relationship outcomes for both students with autism spectrum disorder and students with other disabilities, as compared to their neurotypical peers. The findings of this study suggested that the social isolation reported by students with disabilities in other studies may represent a set of experiences that do not occur in the same way for nondisabled higher education students.

A range of disabilities were represented across the studies that addressed social isolation. Bialka et al. (2017) and Stumbo et al. (2010) researched the experiences of students with 
physical disabilities. Bialka et al. (2017) interviewed students regarding their campus experiences related to participation in a disability-focused student organization, while Stumbo et al. (2010) examined the broad campus experiences of students who lived in a residence hall specifically for students with severe physical disabilities. One study addressed psychiatric disabilities (Megivern et al., 2003). Lastly, five studies focused on Asperger's and autism spectrum disorders (Colclough, 2017; Knott \& Taylor, 2014; Madriaga, 2010; McLeod et al., 2019; Jackson et al., 2018). Of these five studies, Colclough (2017) specifically focused on student social experiences. Madriaga (2010) examined how students navigated university physical spaces and considered the intersection of these spaces and social engagement. The remaining three groups of researchers examined broad campus experiences and identified social aspects and challenges therein (Knott \& Taylor, 2014; McLeod et al., 2019; Jackson et al., 2018).

There appeared to be three ways in which social isolation was experienced by the students in these studies. In some instances, these differences appeared to parallel differences in the types of disabilities studied. The students with physical disabilities in Stumbo et al.'s (2010) study were the only ones who reported structural barriers as a main cause of their isolation. Meanwhile, the students with physical disabilities in Bialka et al.'s (2017) study located the source of their isolation in peer stereotypes and stigma. Peer attitudes and behaviors were also identified as a primary factor in the social isolation that was reported by students with psychiatric disabilities by Megivern et al. (2003). In addition to structural barriers and peer attitudes or actions, the third factor in social isolation appeared to be student-driven, in relationships with both structural and peer barriers. Multiple studies of Asperger's and autism spectrum disorders included reports from students who knowingly engaged in their own social isolation (McLeod et al., 2019; Jackson et al., 2018). The students in these studies reported that they wanted to be 
socially engaged but isolated themselves because they found the ways in which social engagement occurred on campus to be too overwhelming. Their descriptions demonstrated an intersection of structural barriers - such as the noise and overstimulation present in the student union (Madriaga, 2010) and peer barriers - the dominance of these types of social settings as the primary ones in which their neurotypical peers routinely engaged (Colclough, 2017; Knott \& Taylor, 2014; Madriaga, 2010).

\section{Social Pressures and Stigma}

In addition to the roles that stereotypes or stigma-driven peer attitudes played in feelings of isolation among students with disabilities (Bialka et al., 2017), the presence of disability stigma and social pressures appeared in the literature with a frequency that warranted additional consideration. Scholarship on disability and stigma has a long history beyond the context of higher education (e.g. Goffman, 1963). Within higher education, it has also been frequently documented, particularly with respect to student disability disclosure decisions related to securing or utilizing academic accommodations (e.g., Denhart, 2008; Frymier \& Wanzer, 2003; Stein, 2013). Beyond the classroom environment, issues of social stigma have also appeared in research on the social environments of students with disabilities (Barnard-Brak et al., 2010; Cox et al., 2017; Hong, 2015; Marshak et al., 2010; Olney \& Brockelman, 2003; Perry \& Franklin, 2006).

Across these studies, stigma appeared to be associated with student pressures or desires to manage the disclosure of their disability. Hong's (2015) study of 16 students with varied disabilities identified social stigma as a barrier and a stressor in the higher education environment. Hong found that students experienced stress surrounding disability stigma regarding both peer and faculty responses to their disability identities, as well as their attempts to 
manage disability disclosure. The desire to avoid negative social reactions also appeared as a barrier among the 16 students interviewed by Marshak et al. (2010). Barnard-Brak et al. (2010) specifically explored questions of disability disclosure with five students with disabilities they interviewed at a large public university in the southwestern United States. They found that these students identified stigma as a reason for "downplaying or minimizing their own disability status" (p. 421). Likewise, students with autism spectrum disorders in Cox et al.'s (2017) study also reported guarded disclosure of their disability status. The researchers noted that the uncertainty of peer responses led students to disclose to peers only when "circumstances required it" (p. 79).

The presence of social stigma and pressures surrounding disability disclosure appeared to suggest an additional layer of identity management in which students with disabilities are often engaged. Olney and Brockelman (2003) discussed this layer extensively in their study of 25 students with psychiatric and cognitive disabilities at a large public university. They found that although students experienced disability identity in unique, individualized ways, there appeared to be a common process of perception and identity management in which they were engaged. The existence of such a process also appeared in Perry and Franklin's (2006) study of ten college students diagnosed with ADHD. Perry and Franklin reported that students made intentional decisions about disclosing their disability status to peers. Further, they noted that some students they spoke with had negative experiences when their disclosure to a peer led to that peer disclosing their disability identity to others without their permission. These experiences captured both the complexity and importance that is inherent in student management of their disability identities. 
Intersectional Identities. In addition to studies that specifically addressed social pressures and stigmas, a final aspect of the literature relevant to this discussion was research that has attended to the intersectional nature of students' identities and campus experiences. As previously discussed in this chapter, a body of literature has emerged that has addressed the intersectional experiences of students with disabilities in higher education who belong to multiply marginalized identity groups (Abes \& Wallace, 2018; Miller, 2015; Miller et al., 2017; Pearson \& Samura, 2017; Stapleton, 2015). These studies have explored the intersection of disability identity and race/ethnicity, gender, and sexual identities. There are several aspects that appeared across the findings of these studies that must be recognized when considering the social experiences of students with disabilities on college and university campuses.

As related to the literature on social engagement, disability disclosure, and stigma, these studies made important contributions regarding the experiential impacts of intersectionality. Abes and Wallace (2018) interviewed 13 college and university students from across the United States and found that they frequently experienced the erasure of their intersectional identities. The researchers noted that this erasure occurred in varied ways. In some instances, students reported having their disability identity erased through the medical lens of accommodations. In others, students experienced being multiply marginalized along both their disability and racial/ethnic identities. A similar notion of erasure was found by Miller (2015) in a study of 25 LGBTQ students with disabilities at a large research university. Miller reported that in addition to being strategic about identity disclosures, these students also experienced pressure to manage their identities in ways that were dictated by structures of dominant identities at the university.

Similar findings were discussed by Pearson and Sumra (2017) who studied the identity negotiations of $16 \mathrm{racial} / \mathrm{ethnic}$ minority students with disabilities in higher education. The 
researchers noted that these students were simultaneously negotiating their understandings of their identities, and the ways they were embraced or marginalized on their campuses. In some instances, this led to students recognizing the ways in which one of their identities was more socially accepted on campus than another. Other settings appeared to highlight the ways in which navigating the social implications of one marginalized identity was made more challenging due to the way students were perceived or received based on another marginalized identity.

These studies also addressed the ways in which students experienced conflicting marginalization and stigma surrounding their intersectional identities. In a study of online identity formation of 25 LGBTQ university students with disabilities, Miller (2017) explored the experiences of students who encountered marginalization of one of their intersectional identities in a space that was devoted to another one of those identities. Specifically, in this study, students reported encountering microaggressions or ableist language within their queer communities. Abes and Wallace (2018) reported similar experiences among the students in their study. One student provided a narrative of having encountered racist jokes in their queer space, and racist perspectives in their disability space. Abes and Wallace addressed the challenge that these students encountered in struggling to find spaces within their communities that viewed their intersectional identities simultaneously, as opposed to in isolation from each other.

Stapleton's (2015) study of the intersection of d/Deaf identity, racial/ethnic identity, and gender identity of seven students at one public university on the west coast of the United States identified similar experiences. Stapleton also noted that among these students, their d/Deaf identity was more developed than their racial/ethnic identities. Stapleton suggested that campus contextual factors and broad knowledge of intersectional identities across campus led to a limiting of support for identity development in ways that were intersectional. These accounts and 
realities served as an important layer of complexity when considering the ways that students navigate issues of disability disclosure, accommodations, and social stigma on their campuses.

\section{Campus Disability Supports and Services}

Higher education practitioners and researchers have noted the importance of disability accommodations, supports, and services that involve campus housing offices or programs (e.g., Bauman et al., 2013; Evans et al., 2017; Watson et al., 2013). However, as has previously been addressed in this literature review, there is minimal extant research on disability and campus housing. Accordingly, literature on supports and services that focus specifically on residence life is limited. There are many studies that have addressed academic classroom supports and services for students with disabilities (e.g., Bolt et al., 2011; Burgstahler \& Russo-Gleicher, 2015; Kim \& Lee, 2015; McKeon et al., 2013; Sniatecki et al., 2015). Meanwhile, other studies have broadly explored disability supports and services across the student experience (e.g., Aquino \& Bittinger, 2019; Dowrick et al., 2005; Francis et al., 2019; Hutcheon \& Wolbring, 2012). Given the range of functional components that comprise residence life programs, these broad campus studies were valuable in understanding aspects of disability supports and services that may have implications within campus housing.

\section{Social Supports and Services}

One area of broad campus disability-related resources that has received specific attention in the literature involves social supports for students on the autism spectrum (Anderson et al., 2018; Ashbaugh et al., 2017; Barnhill, 2016; Camarena \& Sarigiani, 2009; Smith, 2007). In studies by Anderson et al. (2018), Barnhill (2016), Camarena and Sarigiani (2009), and Smith (2007) the issue of supports appeared as either an anticipated need for students, or a challenge in and of itself. Camarena and Sarigiani (2009) interviewed 21 students with autism spectrum 
disorders and their parents. They interviewed individuals separately and compared the educational aspirations and concerns among students, mothers, and fathers. Camarena and Sarigiani identified potential interpersonal conflicts with roommates as an area about which all three groups expressed concern. They reported that this and other non-academic concerns appeared to be more pressing for all three groups than academic concerns. Additionally, they noted that parents suggested the need for supports, including staff check-ins with their students or the institutional provision of counselors to assist with these perceived challenges.

Similar to Camarena and Sarigiani, Barnhill (2016) and Smith (2007) also explored support services by gathering data from non-students. Both studies surveyed DS officers at higher education institutions. The surveys assessed the supports and services the officers' institutions provided, and what needs they believed required additional supports. Smith (2007) surveyed DS administrators regarding the support service needs of students with Asperger's syndrome. Smith identified social skills development as both an accommodation that disability service offices provided, and an area in need of additional support for students.

Similarly, Barnhill (2016) identified social skills instruction as an accommodation provided by 23 out of 30 institutions surveyed, and a support service that was provided through a variety of programs and resources. Barnhill also reported that results were mixed as to the perceived benefit of such supports and services. A study conducted by Ashbaugh et al. (2017) appeared consistent with the previously discussed perspectives on the needs and benefits of social support services for students with autism spectrum disorders. The researchers delivered a structured social skills planning intervention for three students with autism spectrum disorders. They reported that following the 10-week intervention students reported increased social engagement. While this finding is certainly limited in its generalizability, it is possible that the 
results that were obtained were in part due to a combination of a need for social skills among the student participants, and the delivery of supports that were effective within their educational environment.

In reviewing these studies, it should be noted that they all appeared to rely on a medical model of disability. Within Disability Studies, this model has been described as a pathologizing approach, which locates disability within an individual; in contrast to a social model, which understands societal systems and structures to be disabling (Shakespeare, 2013). From this standpoint the studies approached the topic of Asperger's and autism spectrum disorders with a deficit lens. In identifying the importance of social skills, these studies focused on gains that could be made by the disabled students in question; they did not appear to consider the ways that the larger campus environments could adjust to better engage and support these students. While these studies might have benefited from a consideration of a social model approach to disability (e.g., Gabel, 2010; López Gavira \& Moriña, 2015; Matthews, 2009), they nonetheless established social interactions as an area of concern for students on the autism spectrum, their families, and DS staff members.

\section{Identification and Utilization}

Unlike the K-12 environment, students with disabilities in postsecondary education in the United States decide whether to self-identify their disabilities to their institutions and register for accommodations through campus disability services offices (Wilke et al., 2019). Further, while colleges and universities are obligated to provide equal access to students with disabilities, institutions can deny accommodations that would fundamentally alter the nature of the academic program (Rothstein, 2015). The processes in which students with disabilities must engage in order to utilize disability supports and services have been examined in a variety of ways in the 
literature. The following section discusses themes that emerged from studies that addressed student self-identification and service utilization across the campus environment.

Non-Use of Accommodations. Several studies reported on student use of disability resources in ways that addressed the non-use or underutilization of services (Anderson \& Butt, 2017; Aquino \& Bittinger, 2019; Cawthon \& Cole, 2010; Dowrick et al., 2005; Kurth \& Mellard, 2006; Marshak et al., 2010; Squires et al., 2018; Wilke et al., 2019). The topic was addressed in varied form across these studies, reflecting the variety of ways in which non-use may occur. Aquino and Bittinger (2019) explored student self-identification of disability. Their analysis of a national dataset found that of 1,670 students who identified as having one or more disabilities during their first year of college, 59\% did not identify as having a disability two years later. Aquino and Bittinger's data did not include student explanations of why they un-identified. The researchers acknowledged that some un-identification might be explained by non-persistent temporary disabilities. However, they suggested that given the literature on disability and social stigma it is possible that students may have un-identified in an attempt to increase their senses of social belonging.

Concerns regarding the social implications of service utilization appeared in several studies (Kurth \& Mellard, 2006; Marshak et al., 2010; Squires et al., 2018; Wilke et al., 2019). The relationship that Aquino and Bittinger (2019) suggested between social stigma and disability identification has been directly addressed in studies that have explored student perceptions of the accommodations process (Kurth \& Mellard, 2006), and reasons students provide for not identifying as disabled or seeking accommodations (Marshak et al., 2010; Squires et al., 2018; Wilke et al., 2019). Kurth and Mellard (2006) conducted focus groups with students at 15 community and technical colleges in three different states. They reported that some students 
identified the accommodations process itself as interfering with their sense of belonging. Specifically, they noted student concern that the process of utilizing certain accommodations had the effect of disclosing a student's disability identity to the rest of their classmates. Wilke et al. (2019) reported that some students in their study also described making decisions to not utilize disability accommodations because of their concerns that those accommodations might alter their social experiences and peer interactions.

Both Kurth and Mellard (2006) and Wilke et al. (2019) addressed issues of identity concerns and peer responses as singular complex issues. Marshak et al. (2010) and Squires et al. (2018) separated their discussions into components of disability identity and social stigma. Through Marshak et al.'s (2010) interviews with 16 students with disabilities at a medium-sized state university they found that students avoided accommodations utilization both out of a desire to avoid being identified by peers as disabled, and a fear of negative social reactions. The dual concerns of identity-disclosing accommodations use and stigmatized peer responses also emerged from Squires et al. (2018) study of 45 undergraduate and graduate students with disabilities.

The social implications of these studies were also addressed by Abes and Wallace (2018). The researchers focused on the ways in which disability appears in intersectional ways that are multiply marginalizing. Their findings suggested that in addition to individual peer responses and generalized disability social stigma, there are also social constructs that weigh on students' disclosure decisions as related to the utilization of accommodations. Beyond the potential social stigma associated with disability disclosure and accommodations use, Abes and Wallace attended to the identity erasure that students attached to accommodations. They discussed the medicalization of accommodations, and identified students' experiences of accommodations 
discussions as ones that denied their disabled identities as an important part of who they were and the diversity that their disabled identities brought to the campus.

In addition to social concerns regarding accommodations and identity disclosure, concerns of accommodations appropriateness or effectiveness emerged across multiple studies (Anderson \& Butt, 2017; Cawthon \& Cole, 2010; Dowrick et al., 2005; Kurth \& Mellard, 2006; Marshak et al., 2010; West et al., 1993; Wilke et al., 2019). In some cases, effectiveness concerns took the form of student reports that the accommodations process itself was slow or inaccessible (Dowrick et al., 2005; Marshak et al., 2010). In others, students voiced frustrations that the accommodations they needed were not available, or that the available accommodation was not an appropriate fit for their needs or desires (Kurth \& Mellard, 2006; West et al., 1993; Wilke et al., 2019).

These student perspectives brought important insight to previously gathered data from Cawthon and Cole (2010) and Anderson et al. (2018) on the underutilization of services. Cawthon and Cole (2010) surveyed 110 students with disabilities at a large, public research university and found only $43 \%$ reported having interacted with the disability services office on their campus. Anderson et al. (2018) interviewed and surveyed family members of students with autism spectrum disorders and campus administrators. They reported that although students appeared to recognize that a variety of non-academic support services were available, they often delayed or opted not to utilize them, despite generally reporting that they found them helpful. In both studies the researchers suggested that student underutilization might be in part due to difficulty or dissatisfaction with services, particularly as related to availability, ease, and quality of the services. The previously discussed studies appeared to support these hypotheses, along 
with indicating that underutilization also appears to be related to concerns regarding identity management and social stigma.

Institution-Level Systems Change. Many of the studies that addressed disability supports and services beyond the academic classroom gathered data from students and staff about the challenges present in supports and services, and ways that these challenges could be addressed (Anderson \& Butt, 2017; Belch \& Marshak, 2006; Burgstahler \& Moore, 2009; Dowrick et al., 2005; Hutcheon \& Wolbring, 2012; Kimball et al., 2016; West et al., 1993; Wilke et al., 2019). Suggested improvements varied across these studies, yet all appeared to implicate the need for institutional systems support. For example, students in Wilke et al.'s (2019) study identified that increased staff training may lead staff to be more responsive to the needs to students with disabilities and may make referral processes for these students more efficient. Calls for additional staff training were also made by students with ADHD, who were interviewed by Perry and Franklin (2006). These findings were similar to suggestions that emerged from a previous study conducted by West et al. (1993), who surveyed 761 students with disabilities at postsecondary institutions in Virginia. West et al. reported that student suggestions for accommodations improvements commonly included increased disability awareness among faculty and staff and greater availability of accommodations.

These suggestions for additional training appeared consistent with data collected from staff members on their own levels of knowledge (Burgstahler \& Moore, 2009; Murray et al., 2008; Preece et al., 2007). Preece et al. (2007) conducted a national survey of academic advisors' experiences with students with disabilities. They found that training was the most frequently identified need among their participants. They also noted that the participants identified a lack of training as a barrier to supporting students with disabilities. Burgstahler and Moore (2009), who 
conducted focus groups with 72 staff from student services offices, arrived at a consistent finding, as they found that staff identified their own lack of knowledge as a problem in supporting students with disabilities. Murray et al. (2008) surveyed staff members at a large university about learning disabilities. They reported high rates of interest among staff participants for additional training on disability-related processes and procedures.

Meanwhile, participants in Dowrick et al.'s (2005) study suggested that increased coordination between campus departments may reduce the institutional disconnect that led students to encounter resistance in securing the provision of accommodations that had already been approved by the disability services office. A focus on improving coordinated efforts across departments also appeared in calls from studies that addressed staff experiences and perspectives (Belch \& Marshak, 2006; Kimball et al., 2016). Belch and Marshak (2006) gathered survey data from 62 senior student affairs officers, while Kimball et al. (2016) gathered focus group data from 31 student affairs administrators. Both studies reported that institutional policies and departmental interactions made for a complex landscape in which providing support to students with disabilities was at times found to be challenging.

While the need for additional training and challenges in interdepartmental operations may at first glance appear unrelated, they both involve high-level discussions of institutional resources, policies, and interactions. In this respect, the previously discussed suggestions for improvement appeared most frequently to be large institutional matters, rather than individual challenges. The need for systems-level improvements was clearly implicated by the students interviewed by Dowrick et al. (2005). The researchers reported that while students often expressed being supported by individual DS office staff members, they also described difficulties in securing appointments because the office was understaffed. These systems-level 
improvements were no more clearly addressed than in Hutcheon and Wolbring's (2012) study on the different forms of disability voice that appear in higher education. In a study aimed at examining ableism in higher education, the researchers interviewed students with disabilities at a university in Calgary. Hutcheon and Wolbring found higher education policies to be implicated in student data, particularly in student desires to critique a medical model of disability and to encourage institutions to explore existing policies in order to question the ways in which normalcy is defined throughout higher education.

Finally, in addition to these system-level changes that are framed solely as matters of disability, numerous intersectional research (Abes \& Wallace, 2018; Miller, 2017; Pearson \& Samura, 2017; Stapleton, 2015) have all highlighted the importance of systems-level changes that attend to issues of multiply marginalized identities. For example, a systems-level change that only addressed ableist language, but failed to consider racial or gender implications of that language, would continue to place a marginalizing burden on students who hold multiple marginalized identities within the context of their campus communities. In order for the systemschange that calls for examination of definitions of normalcy to be impactful for all students on campus, this literature suggested that it is vital that such definitions be simultaneously critiqued with respect to the ways in which understandings of identities such as race, gender, and sexual orientation are conceived of and reflected in such discussions. 


\section{CHAPTER 3: METHODOLGY and METHODS}

With the exigence and purpose for this study defined, and the relevant literature considered, the final substantive component to address prior to the findings and discussions sections of this dissertation study is of the methodology, and the specific methods that were employed based on the methodology. This chapter begins with a discussion of the constructivist grounded theory methodology that was utilized. Following this, the specific methods of the study are presented.

\section{Methodological Approach and Rationale}

The goal of this study was to contribute to the literature on students with disabilities in campus housing by exploring RD understandings of disability in their work. Given the focus on exploring these complexities with both depth and an eye towards the varied and individual experiences RDs may have, a qualitative approach was most appropriate (Marshall \& Rossman, 2016). Specifically, this study utilized a constructivist grounded theory approach (Charmaz, 2014). The questions upon which this study was based provided several reasons why grounded

theory broadly, and a constructivist approach to grounded theory specifically, was appropriate.

\section{History of Grounded Theory}

Glaser and Strauss (1967) first published their seminal work on grounded theory amidst a tradition of sociological research that greatly valued the empirical testing and validation of $a$ priori theories. Glaser and Strauss offered grounded theory as an approach in contrast to research traditions rooted in the verification of "great-man theories" (p. 10). They argued that relying exclusively on such an approach limited research in several ways. Specifically, they suggested that the generation of additional theory would be beneficial in understanding the social world. However, they noted that theory generation was, at the time, greatly limited by a preference for 
testing pre-existing theories. Additionally, they argued that limiting research to existing grand theories inevitably led to imperfect understandings of specific social situations for which the grand theories did not adequately apply.

Instead of overlaying a theoretical lens in an imperfect or inaccurate way, Glaser and Strauss advanced the idea of generating theory from the data itself, without preconceived notions of what one would find. The benefit, Glaser and Strauss argued, of this approach was that it allowed for theory to be generated in a specific context - the one from which the theory emerged, and for which it was intended to explain. Glaser and Strauss aimed to replace the notion of theory generation as the exclusive provenance of the preeminent forefathers of the field, with an understanding of it as something that through the systematic collection and analysis of data, could be more widely generated throughout the academy - albeit exclusively by trained sociologists (Bryant \& Charmaz, 2007). Glaser and Strauss (1967) further explained that a benefit of theory generation as compared to theory verification was that where verification encouraged quick jumps to determine the fit of a theory, generation invited consideration of emerging perspectives and encouraged modification and adaptation.

Scholars who have followed and advanced the work of Glaser and Strauss (1967) have presented their own summaries of the core concepts of the methodology (e.g., Birks \& Mills, 2012; Bryant \& Charmaz, 2007; Charmaz, 2008, 2014; Corbin, 2009; Parry, 1998; Urquhart et al., 2010). These various descriptions have highlighted several central concepts of grounded theory: that the purpose of the methodology is theory generation; that data are collected and analyzed simultaneously and iteratively; that prior hypotheses or theories should not guide the analysis; that categories are developed inductively and refined through the constant comparison of data and categories; and that relationships between categories lead, through theoretical 
sampling and abductive reasoning, to theory. Prior to addressing these concepts, it is first important to examine the "constructivist turn" (Charmaz, 2014, p. 12) that occurred in grounded theory in the 1990s. Of the various aspects of the historical development of grounded theory, the distinction between the postpositivist foundations of Glaser and Strauss, and the constructivist perspective advanced by Charmaz was critical to the aims of this research study, because it implicated the manner in which the central concepts of grounded theory were interpreted.

\section{Constructivist Grounded Theory}

Mills and Birks (2014) noted that Glaser and Strauss did not account for their positionality as researchers in their work, consistent with the postpositivist tradition by which

they were influenced. Instead, they were guided by the notion that objectivity could, and should, be maintained in the course of research (Corbin, 2009). Glaser and Strauss held the position that from this objective standpoint, a researcher could cordon off their personal influences from the research process, and then proceed to analyze the data in a systematic way such that an objective theory would emerge. Corbin specifically noted the presumptive objectivity imbued in the term emergence. Corbin acknowledged that while such a stance is now outdated, the principles that undergirded the approach retain their utility. Charmaz (2014) appeared to concur, noting that the constructivist turn in grounded theory "adopts the comparative, emergent, and open-ended approach of Glaser and Strauss's (1967) original statement" (p. 12).

Charmaz (2014) explained that constructivist grounded theory moves beyond the aim of objectivity. Instead, it assumes that social reality is both multiple and constructed, and that the researcher's perspectives and experiences, as well as their interactions with the data, play a role in the development of the research. This perspective contributes to Charmaz's stance that grounded theory produces theories that are interpretations of the worlds studied by researchers, 
as opposed to precise pictures of them. Stated succinctly, Charmaz noted, "research acts are not given; they are constructed" (p. 13). Charmaz (2008) also maintained that constructivist grounded theory is emergent. However, unlike earlier research positions that interpreted emergence as an objective process, Charmaz argued, "The [grounded theory] method does not stand outside the research process; it resides within it" (p. 160). For Charmaz, the difference between postpositivist versions of grounded theory, and constructivist ones, is that in constructivist grounded theory, the notion of emergence is not suggestive of a fixed objective reality. Instead, researchers construct theory that emerges not only from the data, but from the way that the researchers, with their own interpretive perspectives, interact with the data.

\section{Grounded Theory Methodology and Methods}

Grounded theory involves a combination of concepts and principles, intertwined with a systematic approach to the research process. The various components do not necessarily pair in a symmetrical fashion. For example, the theory-building purpose of the methodology has implications throughout the process, from the formulation of the research questions, to the later steps of testing emergent theory. Likewise, the constant comparative method provides a principle that is deployed across a multi-stepped coding process. However, the visibility of the process of grounded theory is one of its strengths, as compared to other, less tangible qualitative methodologies (Bryant \& Charmaz, 2007). Therefore, in acknowledgement of this visible approach, the following description attends to the steps of grounded theory methods, while simultaneously explaining the ways that the methodological foundations inform these steps.

\section{Asking Grounded Theory Questions}

Grounded theory is intended to explain a phenomenon of study (Birks \& Mills, 2012).

Over the course of a study, a grounded theorist attempts to both generate and test concepts and 
the relationships between them (Parry, 1998). As such, research questions appropriate for grounded theory studies should aim at explanation, rather than verification or confirmation. Birks and Mills (2012) noted that in addition to an explanatory purpose, grounded theory is appropriate when little is known about an area of research, or when there is a particular process at the core of the study. The idea of building up concepts and relationships inductively from the data is a logical approach in both of these circumstances: when researching a new area of study, there is little existing theory to apply to the research at hand; while seeking to understand a process, grounded theory allows for explanations to arise from the specific contexts within which the processes in question exist. In considering processes appropriate for grounded theory study, it is important to note that Birks and Mills (2012) interpreted process broadly. They described the idea of processes as based on interactions and situational responses, such that they "need not be limited to conceptions of time, phases or stages, but can be seen as occurring in all aspects of the natural, dynamic nature of life" (p. 18). The purpose of grounded theory is to make patterns visible, and to imbue them with understanding (Charmaz, 2014).

The focus on processes and patterns informs grounded theory research questions. If a researcher wanted to examine, with the most accuracy possible, the specific experiences of an individual, or small number of individuals, grounded theory would likely be inappropriate. The focus on theoretical plausibility (Charmaz, 2014) of grounded theory renders the accuracy of individual experience less crucial than in other qualitative methodologies. Charmaz noted that grounded theory weaves together, "generalizable theoretical statements that transcend specific times and places and contextual analyses of actions and events" (p. 113). As such, grounded theory questions should be those that invite answers that make meaning across individual experiences, but in ways that still acknowledge contextual relevancies. 


\section{Gathering Grounded Theory Data}

Charmaz (2014) clarified that in grounded theory, the focus on pattern development requires a substantial amount of data. It is through ample data that Charmaz argued the grounded theory researcher is able to reduce mistakes generated from instances of misleading data. The idea of offsetting misleading data might be highly problematic for certain research questions, such as those aimed at case-specific details. However, Charmaz also cautioned that this tolerance for inaccuracy must not be treated lightly. While the collection of participant accounts is deployed in service of pattern development, researchers must be open to seeing patterns not readily apparent. These patterns may ultimately be central to theory development but might easily be missed if the researcher is too cavalier in dismissing anomalies.

The process of data collection in grounded theory represents a step that is informed by several concepts that are core to the methodology. A constructivist approach to interviewing acknowledges that interviewing is more than a process of gathering an account; the interaction implicit in the interview impacts the responses the researcher elicits (Charmaz, 2014). The principle of avoiding pre-formulated ideas about the phenomenon also plays a clear role in the constructivist interview, as grounded theorists are challenged, "to create a balance between asking significant questions and forcing responses" (Charmaz, 2014, p. 95). From a constructivist standpoint it is impossible to ask questions in a way that removes the researcher from the co-construction of responses. Simultaneously, if a researcher leads an interview participant to certain responses, they are not co-constructed, but rather forced, and serve only to verify a preconceived notion held by the researcher, in contradiction with the aim of the methodology. 
While the purpose of grounded theory is to identify themes and theories that emerge from the data, existing ideas that surround the topic of study still play a role in the process. Charmaz (2014) explained that one way this occurs is through the notion of sensitizing concepts. Charmaz suggested the use of sensitizing concepts to spur initial thought around a topic. Bowen (2006) defined sensitizing concepts as interpretive tools, which researchers use to "draw attention to important features of social interaction and provide guidelines for research in specific settings" (p. 14). Of particular importance in grounded theory, is that these concepts are not allowed to dictate the study in a pre-determined way that would be inconsistent with the methodology. Instead, Charmaz (2014) suggested that these concepts be used to guide initial interest and idea development; they can serve as points of departure for a study, but should not dictate the study or serve as the end point for inquiry.

Several other central tenets of grounded theory are also implicated in the data collection process. Specifically, the concepts of simultaneous, iterative, constant comparison, and theoretical sampling (Urquhart et al., 2010) require attention when considering data collection. Given the degree to which these concepts are integral to grounded theory, they are more fully explored in the following sections of this dissertation. At the current juncture, it is sufficient to note that both of these concepts serve to drive the researcher back into the data for the purpose of developing connections between what the researcher is piecing together inductively and what the data itself is suggesting.

\section{Conducting Grounded Theory Coding}

As the grounded theory researcher gathers data, the first analytical step is to conduct initial coding of the data. Charmaz (2014) suggested that initial coding is the first venture the researcher takes to "move beyond concrete statements in the data to making analytic sense of 
stories, statements, and observations" (p. 111). Coding of the data is the process of defining what is happening in the data, so that one can begin to make sense of what it means (Charmaz, 2014). Codes provide the researcher with ideas to pursue in subsequent data collection. They also serve as the first interactive interpretation of the data. In selecting codes, the grounded theory researcher highlights certain aspects of the data, while necessarily ignoring others. The process is one of meaning-making that the researcher then continues to analyze and further scrutinize as additional iterations of data collection and coding are conducted.

Charmaz (2014) recommended that initial coding of interview data occur at the line-byline level, and in an active form through the utilization of gerunds. Charmaz argued that doing so allows the researcher to more readily see noteworthy patterns in everyday events. Coding at the line level also helps the researcher avoid applying preconceived notions to the data. Similar to previous steps in grounded theory, the meaning-making of the coding process requires that the researcher avoid forcing the data or applying preconceived frames to their analysis. By initiating coding at the line level researchers are able to begin to compare data to other data, while limiting the application of their own interpretations.

The next step of coding in grounded theory is intermediate coding (Mills \& Birks, 2012). Mills and Birks noted that depending on the type of grounded theory research, this may be referred to as selective, axial, or focused coding. From Charmaz's (2014) constructivist standpoint, focused coding calls the researcher to compare and contrast initial codes and begin to identify patterns within the data. Focused coding is again driven by the principles of iteration and comparison. Focused coding is carried out while data gathering continues, and coding may continue to inform the interview questions, as well as the way the researcher gathers data, based on the patterns that emerge. By asking what was found in the initial codes, and what patterns 
they reveal, focused codes can be developed in ways that advance the initial codes with the most "theoretical reach, direction, and centrality" (Charmaz, 2014, p. 141).

\section{Theoretical Sensitivity and Memo-Writing}

Before moving into the next step of data analysis, two additional foundational components of grounded theory must be considered. Both of these concepts are ones that Charmaz (2014) engaged in multiple phases in the process of conducting grounded theory. To that end, they exemplify the iterative nature of the methodology.

Theoretical Sensitivity. Charmaz (2014) connected focused coding with the importance of theoretical sensitivity. Mills and Birks (2014) discussed theoretical sensitivity as central to understanding researcher positionality, particularly in constructivist grounded theory. The knowledge of the researcher - their understanding of the research topic - allows them to "recognize and extract" (p. 112) relevant elements of data. Urquhart et al. (2010) cited Glaser (1978) to assert that theoretical sensitivity requires that grounded theory researchers be steeped in the field of study so that they can understand the context in which they are developing their theory. Charmaz (2014) indicated that the relationship between theoretical sensitivity and focused coding allows for the emergence of abstract concepts and the development of relationships in the data. A grounded theory study without the necessary level of theoretical sensitivity risks producing codes that are purely descriptive, and do not facilitate later abductive analyses needed for theory development.

The concept of theoretical sensitivity simultaneously invites a tension into grounded theory, between the expertise needed to adequately raise ideas through an iterative coding process, and the requirement of avoiding the application of preconceived ideas, or forcing the data (Charmaz, 2008). Birks and Mills (2012) highlighted what they found to be the 
contradictory nature of early direction on how to achieve theoretical sensitivity, and the role that a formal literature review should, or should not, play in this aim. Charmaz (2014) appeared to address this tension to some extent by framing theoretical sensitivity as itself an iterative, ongoing process. Through the constant theorizing of ideas, and by intersecting these ideas with new data, grounded theorists are invited to look at ideas from multiple perspectives, try out concepts, rethink them in different ways, and continue to do so as new notions emerge. Charmaz described this level of engagement as necessary to avoid the risk of working one's way through the data only to develop "a list of connected but under-analyzed processes" (p. 246).

Memo-Writing and the Advancement of Categories. Along with theoretical sensitivity, grounded theorists also work to avoid thin analyses through memo-writing. Memos are central to all qualitative research. Memo-writing is a reflexive tool, designed to facilitate the researcher's understanding of their own subjectivity on their analysis of the data (Birks et al., 2008). Birks et al. also noted, however, that beyond encouraging reflexivity, memos aid in the exploration of qualitative phenomenon by initiating researcher writing and analytical momentum. Charmaz (2014) similarly highlighted the importance of memos in grounded theory research. Beyond the value of memo-writing as a tool of reflexivity and productivity, Charmaz also noted that within grounded theory, memos are of particular importance because they further the constant comparison that is core to the methodology. Memo-writing provides grounded theory researchers a mode by which to treat certain codes as categories; and a way to conduct further analysis in order to develop meaning within the category or revise the category if it is not immediately coherent. According to Charmaz, "categories explicate ideas, events, or processes in data" (p. 189). Memos serve as valuable tools for researchers to develop categories by providing a space in which to repeatedly work through ideas, while continuing to collect and analyze data. 


\section{Theoretical Sampling and Category Saturation}

Theoretical sampling is another aspect of grounded theory that separates it from other forms of qualitative research. It provides researchers a methodical way to check and refine their ongoing analyses (Charmaz, 2014). Urquhart et al. (2010) argued that theoretical sampling is "the single most important contributor to the 'fit' of a theory" (p. 371). Consistent with other concepts previously discussed in this chapter, the purpose of theoretical sampling is to further strengthen grounded theory analyses in tandem with the constant comparison in which the researcher is engaged (Urquhart et al., 2010). Glaser and Strauss (1967) explained that theoretical sampling provides strength to comparative analyses by allowing researchers to select intentional samples from the field for theoretical analysis that further refines their categories.

Charmaz (2014) provided extended guidance on theoretical sampling, including important cautions to researchers about common misconceptions, clarifying, "theoretical sampling pertains only to conceptual and theoretical development of your analysis; it is not about representing a population or increasing the statistical generalizability of your results" (p. 198). The reason for this clarification is the distinction that theoretical sampling is not a sampling strategy that a researcher uses to identify participants for a study. Rather, theoretical sampling is a way to deepen analytical connections between categories.

Charmaz (2008) explained that another way grounded theory is distinguishable from other qualitative research is that it involves an analytical shift from induction to abduction. Abductive reasoning involves creating inferential accounts in attempts to explain unexpected findings. Next, the hypotheses embedded in those accounts are tested against the data as well as against other theoretical interpretations. Engaging in abductive analysis allows for categorical relationships to be more deeply explored and more robustly developed. Thorough categorical 
development is essential in moving toward the generation of themes, and finally toward building theory. Abductive reasoning and theoretical sampling also aid the grounded theory researcher in reaching category saturation. Charmaz (2014) cautioned that similar to the misperception some researchers may have around the concept of theoretical sampling, saturation is at times mistaken as a matter of a saturation of research participants' accounts. Instead, Charmaz argued that saturation should be approached as a matter of adequately filling of the gaps in categories something reached when new theoretical connections are no longer emerging.

The concepts of theoretical sampling and category saturation are not only unique to grounded theory as specific concepts. By engaging in these aspects of grounded theory, researchers simultaneously demonstrate the core of the methodology. These aspects of the research happen iteratively. They also require the researcher to constantly tack back and forth between emergent ideas and relationships, and the data itself. The memo-writing that was core to category development and analytical progress continues to be valuable in later phases as well. In this way, grounded theory is both composed of these disparate methodological components, and a result of the ways in which they are woven together throughout the research process.

\section{Developing Theory}

The goal of grounded theory is to develop answers for the questions at hand in the research. If the previously discussed components of grounded theory are thoroughly engaged by the researcher, questions of how and why may be addressed. Charmaz (2014) cautioned that in the absence of adequate memo writing, or with theoretical sampling that is underdeveloped, researchers are likely to produce theories that are analytically thin and do little more than document or describe. Without fully applying these tools, abductive reasoning is likely to be minimal, and induction alone will drive results that fail to have the theoretical reach to grasp 
questions of why or how. Corbin (2009) provided a similar caution, specific to memo writing, noting that in the absence of adequate memos, the researcher is likely to lose track of important details from the data, such that the final product lacks "density and variation" (p. 50). The notion that the quality of the final product rests upon all the preceding steps is of little surprise, particularly given the way in which these steps have been shown to intersect and implicate each other.

Beyond questions of how and why, Charmaz (2014) also discussed the specific premises on which these questions and answers are based for constructivist grounded theory. In a way that mirrors the earlier discussion of the constructivist standpoint, the generation of theory from this view produces theories that assume a position dependent upon the researcher. Without a full retracing of the description of the constructivist standpoint addressed previously in this paper, it is sufficient here to note Charmaz's caution that constructivist theory generation acknowledges that in the absence of reflexivity, theories risk reproducing either researcher or participant ideologies in ways that elide the meaning that is socially constructed within these ideologies.

\section{Applying Constructivist Grounded Theory to RD Understandings of Disability}

The purpose of grounded theory is to inductively generate knowledge up from the data at hand (Mills et al., 2014). The methodology relies on the iterative collection and analysis of data, and the constant comparison, through memo-writing and theoretical sampling, of data to emergent analysis, new data, and relevant literature (Charmaz, 2014). Connections and relationships are then hypothesized and tested, through abductive reasoning, to arrive at a theory that aids in the explanation of the phenomenon of study (Charmaz, 2014).

Birks and Mills (2012) suggested that grounded theory is particularly appropriate when there is little known about the topic of study, when explanatory theory is the desired aim of the 
research, or when there is a process likely to be explained by the research. These indicators served as guides for considering the appropriateness of grounded theory for the present study. After attending to these indicators, consideration is given to the specific fit of constructivist grounded theory for this topic, and the role of Disability Studies as it relates to the methodology.

\section{New Area of Research}

There is presently very little literature on RD understandings of disability. The attitudes, actions, and knowledge of faculty members in higher education regarding disabilities and students with disabilities have received considerable research attention (Black et al., 2014; Hong et al., 2011; Lombardi et al., 2013; Sniatecki et al., 2015). However, less research has been conducted regarding the ways in which staff members understand disability. Further, of the studies that have addressed staff members, they have primarily investigated staff perspectives and knowledge across multiple college and university functional areas (Kimball et al., 2016; Murray et al., 2008, 2011; Vacarro \& Kimball, 2019). Vaccaro and Kimball (2019) conducted an analysis of student affairs work specific to disability in the campus housing context. However, their research participants were from a number of student affairs functional areas. The study identified various cross-departmental collaborations that staff carried out to support students with disabilities in campus housing. Although an important study, the functional area diversity among the participants prevented a specific exploration into the experiences or understandings of campus housing professionals in their work with students with disabilities.

As previous research has addressed, campus housing may have a substantial impact on student experiences and educational outcomes (e.g., Mayhew et al., 2016; Schudde, 2011). Wilke et al. (2019) coupled this with the absence of literature on the campus housing experiences of students with disabilities to suggest the importance of their study. Among their findings, Wilke et 
al. identified multiple aspects of the campus experience in need of improvement. Several of these directly implicate the work of housing professionals, such as RDs. The absence of research in this area supported the use of grounded theory. The surrounding literature supported the exigence for such a grounded theory study.

\section{Desire for Explanatory Theory}

Among the potential areas identified by Wilke et al. (2019) for the improved support of students with disabilities, several directly implicated residence life staff. RDs are an integral component of residence life staff structures. Typically, RDs are responsible for the overall dayto-day management of residence halls and are the first professional points of contact for the students who live in their buildings. Additionally, RDs provide supervision to student resident assistants (RAs). Of the positions that comprise a residence life department, RAs are the paraprofessional staff likely to have the highest levels of interaction with the students who live in the buildings. Given the extent to which changes to campus housing operation or management would likely impact and/or rely on RDs, any such recommendations might be greatly informed by a theory that aids in explaining how RDs understand disability, and how they carry out their work based on these understandings. Beyond identifying what RDs do or think regarding disability, the present study sought to contribute insight into how they think about disability and how they work with students with disabilities. The desire to move the analysis beyond the descriptive, and with consideration of literature that suggests the utility of such an explanation, grounded theory appeared to be a strong fit for this study.

\section{The Processes Imbedded within the Resident Director Position}

Birks and Mills (2012) urged for a broad definition of process when considering it as a focus of grounded theory studies. When such an understanding of the term is applied to the RD 
position, multiple noteworthy processes appear. Perhaps most tangibly, are the processes that students with disabilities must engage in in order to obtain disability accommodations in their residence halls. Wilke et al. (2019) identified these processes, and the roles that residence life staff play in them. Learning how RDs understand their work as it relates to the provision of residential accommodations stood to be valuable for the improvement of these processes. A second process that is integral to the work of RDs is actually a multitude of processes: those that revolve around the academic calendar. Much of the work of RDs is cyclical in nature. RDs often play critical roles in the hiring, training, and supervising of RAs, the assigning of students to residential spaces, the opening of buildings and welcoming of students in the fall, and closing of buildings and ushering out of students in the spring. These processes begin anew each year, with a new set of students living in campus housing. Similar to the accommodations process, the ways in which RDs manage their buildings and work to create residential communities are made up of processes; the understandings of disability within these processes were ripe for grounded theory research. One final type of $\mathrm{RD}$-specific process that was valuable to explore was the process of becoming a student affairs professional. Within student affairs in higher education, for many, RD positions serve as the entry point to the field. RD positions are frequently occupied by new professionals. As such, a whole host of understandings may be developed among RDs, as they navigate what is potentially a first professional position, or an entry position along a desired career path. Navigating departmental challenges, developing relationships and collaborative opportunities, and discerning how to engage students as a professional as opposed to a paraprofessional, may all be processes woven into the RD position. Contributing to an explanation of how notions of disability impact and are impacted by these processes stood as a valuable potential addition to the literature. 


\section{Constructivist Approaches to RDs and Disability Studies}

Beyond the previously discussed reasons why grounded theory would best support a study of RD understandings of disability, a constructivist standpoint was particularly appropriate for several reasons. Constructivist grounded theorists operate from the standpoint "that both data and analyses are social constructions that reflect the conditions of their production" (Charmaz, 2014, p. 240). These assumptions are consistent with recent Disability Studies scholarship that has suggested that a socially constructed view of disability is critical in furthering the notion of disability as a component of diversity in higher education (Hadley \& Archer, 2017; Harbour et al., 2017; Shallish, 2017; Vaccaro \& Kimball, 2017).

The present study did not apply Disability Studies as a full critical theoretical approach such an application would have conflicted with the foundation of grounded theory. However, the field of Disability Studies in Education, particularly in higher education, did provide a valuable frame for the study. Disability Studies research on the dominance of the medical model of disability in higher education (e.g., Lewis, 2017), the intersection of disability with other forms of difference and marginalization (e.g., Harbour et al., 2017; Pearson \& Samura, 2017), and histories of stigma, oppression, and campus access (e.g., Barragan \& Nusbaum, 2017; Wood, 2017) were all valuable guides that Disability Studies provided as the study was conducted.

Recent developments within Disability Studies that have concentrated on intersectionality and oppression were particularly valuable concepts given the nature of this study. For example, the work of Annamma et al. (2018) and Hernández-Saca et al. (2018) offered critiques that guided the study to be mindful of the intersectionality of marginalized identities. These critiques supported the recognition that RDs do not understand students solely through a disability/ability lens; rather, race, gender, sexual identity, and socio-economic status also play roles in these 
understandings. Additionally, scholars have critiqued the oppressive role that educational systems play at these intersections of marginalized identities (e.g., Annama \& Handy, 2019; Knoll, 2009; Young, 2016). The RDs, many of whom did not identify as disabled, hold positions of power within the context of the buildings they manage. They are responsible for systems of residential community access and engagement, as well as those of student conduct and behavioral intervention. Additionally, they participated in this study from their own socially constructed and informed histories and perspectives. Therefore, critical Disability Studies scholarship that has attended to the educational implications of broad social constructs, such as the systematic oppression perpetuated through the way teachers talk about students (Young, 2016) or the maintenance of carceral logics in classroom management (Annama \& Handy, 2019), provided logical points of entry for this study. These concepts were utilized, as suggested by Charmaz (2014), as ways to initiate thinking about the ideas that emerged from the data. By approaching this research as a source of important sensitizing concepts, Disability Studies was utilized in a way that aligned topically with the focus of the study, and methodologically, with the guidelines of grounded theory.

\section{Site and Sampling}

Similar to previous grounded theory approaches to student affairs administrator understandings of disability (Vaccaro \& Kimball, 2019), this study focused on RDs in a way that was not limited to a single or small set of specific institutions. RDs from multiple institutions

were recruited for participation in the study. The decision to seek RD participation from multiple institutions was made based on the research questions for the study. In seeking to explore RD understandings of disability, gathering RD accounts from multiple institutions encouraged an analysis that was more likely to reach across institutional or departmental cultures, practices, or 
procedures. A single-institution, or multiple-institution comparative study might better highlight these elements within a campus housing department. However, these questions were not the central focus of the present study. Recruiting RD participants from multiple institutions supported an analysis that was better able to cut across department-specific elements and remain focused on the processes of understandings of disability that occurred within the RD position.

While the study was not conducted at a specific site or sites, the types of institutions from which RDs were recruited was narrowed in several ways. As discussed in the first chapter, campus housing exists across a broad spectrum of college and university sizes and types. A constructivist grounded theory approach to a study of RDs across all these institution types may be valuable, but given the array of contexts, would likely require a multi-year study that was beyond the feasible scope of this dissertation. Therefore, a decision was made to concentrate the study around small and medium, private colleges and universities, with liberal arts traditions, that house at least 25 percent of enrolled undergraduates in campus housing. Lastly, attempts were made to recruit $\mathrm{RD}$ participants from colleges and universities that met these institutional criteria and were on the West Coast of the United States. The rationale behind a regional focus was based on the way in which several relevant student affairs professional organizations operate at both national and regional levels (Association of College and University Housing Officers International, n.d.; Student Affairs Administrators in Higher Education, n.d.). Regional associations and conferences encourage collaboration and sharing of practices and procedures in ways that may support the existence of regional differences in the RD role and experience. Therefore, the geographic focus was intended to reduce potential regional variance in understandings of the RD position, in support of a grounded theory that was regionally limited, but more complete in explanatory force. 
In addition to institutional criteria that drove participant recruitment, inclusion criteria were also identified for the RDs who worked at the institutions where recruitment occurred. The inclusion requirements for RD participants in the study included that they had at least one year of full-time professional experience in an RD position at a college or university that met the previously described institutional criteria. As previously addressed, this experience may have been obtained under a variety of institution-specific job titles. For inclusion purposes, participants' experience with the position must have included live-on operational responsibilities for one or more residential buildings and the direct supervision of live-in residential student staff members.

Multiple sampling strategies were utilized over the course of this research study. The study began with a stratified purposeful sample (Marshall \& Rossman, 2016), to gather data from RDs who lived and worked in both underclass, upperclass, and mixed-class buildings, RDs who had varied levels of professional experience, and RDs who represented diverse identities, including but not limited to race/ethnicity, gender, sexual identity and dis/ability identity. However, given the realities of the timing of this dissertation study, and the overlap with an historic moment of stress and uncertainty across higher education, and campus housing in particular, due to the COVID-19 pandemic (Carlson \& Friga, 2020; Gardner, 2020; Yanni \& Taylor, 2020), snowball sampling was also implemented. After initial rounds of data gathering and analysis, and multiple rounds of iterative coding, theoretical sampling (Charmaz, 2014) was also utilized. While theoretical sampling involved returning to the literature, it also involved returning to previous participants to ask additional questions that aided in the development of emerging analysis and theoretical understanding. 


\section{Access, Role, Reciprocity, Trust, and Rapport}

There are several perceived risks involved in a study of disability within a college or university residential life program. RDs may have had concerns regarding the potential liability implicit in their participation, and the potential for the emergence of information that may suggest noncompliance with Federal regulations. Additionally, RDs may have had concerns regarding the way their understandings would be presented, particularly if they believed they were not providing appropriate levels of support to students with disabilities. As a result of these potential challenges, the way in which I as a researcher conceived of reciprocity and sought to build trust and rapport was of great importance.

\section{Access}

Since the study did not take place at a specific college or university, access and entry for the study occurred differently than it would have for a case study or other institution-specific research design. However, there remained multiple gatekeepers who were involved in the recruitment of participants. It was necessary to consider the way in which these gatekeepers were appropriately addressed.

There were multiple stakeholders who were in positions that stood to heighten the credibility of this study and support the recruitment of participants. The leadership of campus housing departments at the institutions that fit the inclusion criteria for the study were an important set of gatekeepers. While they did not serve as gatekeepers as they would have in an institution-specific study, they were certainly important stakeholders, and my recruitment efforts were better supported through their buy-in. For this reason, I reached out to both individual department leaders, as well as regional professional groups. I requested meetings as opportunities to explain the study and answer any questions or address any concerns they had regarding the 
study. Having their support was important, particularly considering the pandemic circumstances under which the study was conducted. Multiple departmental leaders indicated that they planned to encourage their RDs to participate in the study. Such shows of departmental support were important given the extent to which the pandemic stretched thin the available time and bandwidth available among student affairs staff generally, and campus housing administrators in particular.

\section{Role}

Consistent with constructivist grounded theory, as the researcher in the study I was involved in the co-construction of meaning with the research participants (Charmaz, 2014). My presence in the research also did not stop at the meaning-making that occurred with participants. Instead, I appeared throughout the research project, and had an influence on the creation of meaning, throughout the analytical process. My constructivist positionality is consistent with the Disability Studies concepts that were utilized in this study. It would have been likely impossible, and obviously incongruent, to attempt to position myself as an objective reader outside of the data collection or analysis, while simultaneously relying upon the research of a field that was developed in response to singular objective standpoints and has a long history of reframing disability as a matter of multiple perspectives and socially co-constructed understandings.

In addition to being positioned as a co-constructor of meaning, I was positioned in the research as someone with a professional background in student affairs generally, and in campus housing, specifically. I also have regularly worked with both RDs and students with disabilities. I have found myself drawn as a researcher to consider aspects of disability in the higher education co-curriculum in large part because I have encountered instances in my professional role in which it appeared that the field of student affairs could better meet the needs of students with 
disabilities on college and university campuses. Further, I approach research involving campus housing with my own prior experience as an RD. My background in residence life was something that I needed to attend to as I interpreted the data - to make sure I was mindful of the ways in which my own prior experiences were impacting my analysis and co-construction of meaning. However, these experiences were also valuable, as they assisted in my ability to engage RDs by being able to speak knowledgably and authentically about the RD role.

Lastly, I approached this study from the position of someone who does not presently identify as disabled. Within Disability Studies there are discussions of how research regarding disability is carried out and what, if any, bounds should be applied to the identities of those conducting the research (Kitchin, 2000). I attempted to be aware of the need for emancipatory research regarding disability. Part of my attempt to ask questions that were aimed at the ways in which large systems operate was that I hoped to create knowledge alongside individuals with disabilities in ways that impact the systems from which ableist structures arose. Intentional consideration of systems of marginalization and disability was supported by Disability Studies considerations previously outlined. Further, I engaged this scholarship with emerging discussions of student affairs research on student development theories. Abes and Wallace (2020) have asked important questions regarding the oppressive nature of student development theories that place an overreliance on student shifts from dependence to independence. Abes and Wallace offered critical disability theory as a frame to highlight the ways in which systems normalize ablebodied-ness; hiding the interdependent nature of those with dominant identities while framing it as dependence among those with marginalized identities. The overlap of these questions with the presence of student development that appeared in both their research and this dissertation 
provided a valuable touchpoint in support of maintaining a focus on systems throughout the research.

\section{Reciprocity}

Making a commitment to those involved in my study regarding the ways in which I engaged with and supported them was of great importance. As a researcher, I seek to contribute to socially constructed understandings of the world. Further, as a student affairs practitioner, I have a firm commitment to the support and constant improvement of equitable spaces for higher education. To this end, I view reciprocity as a practice in which I engaged throughout the study.

The primary form of reciprocity in this study appeared in my commitment to share my findings with the professional staff members involved in the study, and their related professional associations. As previously addressed, discussing this form of reciprocity ahead of time was necessary in gaining participant access and trust. My commitment to reciprocity is not only derived from my own personal values as a researcher, but also from a practical requirement for reciprocity that I anticipated would be necessary to successfully recruit RD participants.

\section{Trust and Rapport}

It was important that I worked to establish trust and rapport with those involved in my study. In addition to developing the trust of departmental stakeholders, the trust of, and rapport with, the RDs with whom I spoke was crucial to my ability to gather robust data. When meeting with RDs, I spent time discussing the ways in which data were to be collected, analyzed, and conveyed in my research. Being up front not only about what I was seeking to understand, but also my plan to share findings was important. It was, and continues to remain possible, that I will present data related to the RDs at conferences they also attend. Therefore, I explained my intention of presenting quotes from participants in denaturalized form (Olive et al., 2005). I 
believed this explanation was important in establishing RD's trust that their naturalized language would not be shared in ways that may be perceived to cast judgements on their professional abilities. Fortunately, this plan was consistent with the denaturalized approaches that Oliver et al. (2005) have identified as typical of grounded theory methodologies. Additionally, I spent time at the beginning of each interview describing the ways that I would anonymize the data. I explained that I would replace names of specific residence halls, DS offices, or other identifying campus components that would have connected RD responses to specific institutions in ways that would have compromised their anonymity.

In addition to establishing trust with the RDs, I also took care in developing rapport with them. I built rapport primarily through spending time talking with each RD at the beginning of the interviews. Before moving into content related to the study, I was intentional to check in with the participants about how they were doing generally, and the unique situations and stresses they were navigating in residence life during a global pandemic. Doing so also allowed me to establish with the RDs my own background and experience as an RD, which appeared to support the RDs' willingness to discuss specialized aspects of their roles and work with disability in greater detail than they may have otherwise.

\section{Ethical Considerations}

The absence of any deception in the study design, along with the utilization of informed consent when working with research participants address only the most obvious of ethical considerations (Marshall \& Rossman, 2016). There were other considerations that were more complex, and potentially less apparent, which I kept in mind throughout the present study. One of these was the way in which I engaged previously discussed departmental leadership. Since this study was not institution-specific, I was able to identify those institutions that fit the study, 
and then use their websites to collect names and email addresses of RDs who might have fit the inclusion criteria, and contact those individuals directly. However, engaging departmental leadership also supported RD response to my recruitment outreach. In so doing, I needed to be mindful with respect to departmental leadership that they not exert their positional influence over the RDs in ways that would have pressured participation in the study. It was crucial that I was very explicit in discussing with departmental leadership how they share my study with their employees in ways that were ethically sound.

\section{Data Collection Methods}

The primary method of data collection for this study was through conducting interviews with RDs. Each RD participated in one interview. The interviews were semi-structured in nature (Marshall \& Rossman, 2016), with questions for each participant that focused on their consideration of disability identities and disability intersectionality in their creation and support of their residential communities, the ways in which they worked to provide accommodations to residential students with disabilities, and the ways in which they supported resident assistants in working with students with disabilities. The interviews took place remotely, via video conference. There was a total of 32 RDs who participated in the study, from 17 different colleges and universities. A table of pseudonyms and demographic information for the RDs is included in Appendix D. A summary of additional institutional characteristics of the 17 colleges and universities is presented in Appendix E. The average interview length was 84 minutes, with lengths that ranged from 50 to 98 minutes. An audio recording was made of each interview. Following the interviews, the audio files were initially transcribed by uploading to a cloud-based transcription program. The initial transcripts were then reviewed alongside the audio recordings, and edits were made for accuracy. 
A semi-structured interview guide is included in Appendix F. Grounded theory calls for the simultaneous and iterative analysis of data (Charmaz, 2014). As a result of this iterative and cyclical process, the semi-structured interview guide was adapted as interviews progressed, to be responsive to memo writing, preliminary analysis, and development of emergent tentative ideas. The modifications made to the interview guide are highlighted in the second version of the guide that is included in Appendix F. Modifying the guide allowed for the interviews to continue in ways that were responsive to these emergent ideas. In addition to interviews, field notes and researcher memos were also created throughout the research study. Memos are particularly important to grounded theory because they support the iterative analysis that moves the research from multiple rounds of coding towards the development of theory (Charmaz, 2014).

\section{Data Analysis Procedures}

Consistent with a constructivist grounded theory approach as previously discussed, the analysis of data commenced and continued alongside the collection of the interview data (Charmaz, 2014). The process involved three levels of coding: initial coding, focused coding, and theoretical coding (Mills et al., 2014). The initial coding was carried out using gerunds. It was conducted at the level of lines or phrases and sought to identify and name each (Marshall \& Rossman, 2016). Next, focused coding was utilized to relate the initial codes to one another and then led to the creation of categories. Memo writing, which occurred throughout the study, was specifically employed to further this step. Following the creation of categories, theoretical sampling was utilized to test for theoretical saturation of concepts in the analysis (Charmaz, 2014). The categories, combined with theoretical sampling, were then connected to develop themes (Charmaz, 2014). Lastly, theoretical coding was carried out to conduct a theoretical 
integration of the themes that emerged from the data (Mills et al., 2014). An example of the coding progression, from transcript through to theoretical coding, is included in Appendix G.

\section{Trustworthiness and Credibility}

The trustworthiness and credibility of the grounded theory that emerged in this study rests in large part on the correct and detailed application of the methodology and methods previously discussed in this section. As suggested by Mills et al. (2014), the memoing that was conducted throughout the data collection and analysis phases of the study assisted in documenting the fit and rigor of each phase of the research process. In addition to memoing on the data collection process, thematic and theoretical memos (Marshall \& Rossman, 2016) lend credibility to the grounded theory that developed by encouraging constant reflexivity and analytical testing of the ideas that emerged as categories were combined into themes, and themes were intersected to create the grounded theory.

Triangulation was also conducted in support of the trustworthiness and credibility of the findings. As discussed by Marshall and Rossman (2016), triangulation supports that the research has captured the authentic perspectives and experiences of participants. Triangulation was conducted throughout the later portions of the analysis, by reviewing the available literature as ideas were abductively generated. Thematic components were also triangulated through conversations with RDs and other campus housing professionals - to assess whether the analysis was coherent given their experiences in the field.

\section{Summary}

In his recent book on the state of American higher education, Alexander Astin (2016) suggested that the future of colleges and universities might include explicit tracking and measuring of many of the out-of-class and affective experiences that college students have while 
enrolled at these institutions. The more these components are measured, and codified as core to institutional missions, the more they need to be considered from a standpoint of equity and access. The present dissertation sought to investigate one thread of this broad topic, by exploring how RDs understand disability in the context of their work at small and medium private colleges and universities on the West Coast of the United States. By taking a constructivist grounded theory approach that was cognizant of the surrounding literature, and carried out in an intentional, and systematic way, the study stands to contribute to what is known about a set of processes that are foundational to the residential experiences of students with disabilities. The study also stands to contribute to the educational research community by uncovering how these processes and understandings are conceived and experienced. Given the critical Disability Studies frame of this study, it is also well positioned to contribute to student affairs professionals' ongoing institutional discussions of educational equity and access in the higher education co-curriculum. 


\section{CHAPTER 4: FINDINGS}

The study revealed that the RDs think about disability, and work with concepts and issues related to disability, in ways that are marked by active tension. These tensions were found to exist particularly at points of conflict between individual RDs and the RD role and responsibilities. The RDs experienced tensions as they navigated their own understandings of disability within the context of their job responsibilities and the larger institutional systems within which they worked. Across the interviews, RDs consistently shared perspectives, thoughts, or opinions that demonstrated understandings of disability that were simultaneously informed by, and pulled in, multiple competing directions. These tensions were visible across a variety of ways in which the RDs spoke about their interactions with students with disabilities, their support of RAs in the creation of inclusive residential communities, and their participation in institutional administrative systems. Through a constructivist grounded theory analysis, five themes emerged from the data. The themes included (1) RD development of their understandings of disability, (2) reactive approaches to disability, (3) tensions between students' needs and accommodations requirements, (4) questions of accommodations, and (5) siloed disability expertise. These themes are presented in this chapter, along with descriptions of the component parts of the themes.

\section{Developing an Understanding of the Breadth and Individualization of Disability}

When asked to describe or define disability, the RDs spoke about disability in ways that were often rooted in their own past experiences. For some, these past experiences involved interactions with individuals with disabilities. For others, their past experiences were notable for them due to an absence of experience or interaction with disability. Many of the RDs defined disability as some type of impairment or inability, relative to the expectations of normate society. 
Most of the RDs discussed physical impairments before other forms of disability. There were, however, some RDs like Elizabeth, who pointed to prior trainings or experiences that they believed led them to make quicker associations with a broader range of disabilities:

Prior to coming back into higher ed, I was a special education teacher for four years. So, I understand the intricacies. That disabilities can be physical, they can be mental, they can be emotional, they can be visible, they can be invisible.

Other RDs identified a personal connection to a particular disability. Gwen described her understanding of invisible disabilities as a function of her relationship to her brother's experiences with dysgraphia. Across the RDs, however, responses like Gwen's and Elizabeth's were infrequent. More often, the RDs explained that they thought about physical disability first, or primarily, because it was the only form of disability with which they were familiar. They attributed this limited familiarity to past experiences that rarely included interactions with individuals with disabilities. Several of the RDs posited that their lack of past experiences was a function of the exclusion of those with disabilities from general education environments and social taboo or stigma surrounding discussions of disability.

The RDs described their understandings of disability as an area of knowledge or awareness that had expanded over time. RDs attributed this expansion to their individual experiences. When discussing the ways in which their understandings of disability may have changed during their time in the RD position, they overwhelmingly stated that they did not believe that their definitions had fundamentally changed. Rather, they explained that through their work with individual students they had developed a more expansive understanding of what might constitute disability and the ways in which it might appear. Maeve shared that her 
understanding grew through professional development in which she engaged as an RD. Maeve elaborated on how this led to an expanded definition of disability:

I think that [my RD experience] has really changed my understanding of what disability looks like. It definitely broadened it, even in terms of when I was speaking to you about temporary disability in terms of my athletes getting hurt. I don't think before I studied inclusive design I would have considered that a disability. I would have seen a student who comes in who's in a wheelchair $24 / 7$ - that person is disabled. I wouldn't have looked at an athlete who's on crutches for two weeks and said that person is disabled. So I think that, that the specific book and some of the other research that I did on that topic of inclusive design really opened my eyes to see the more accurate definition of disability.

Within this theme, three salient aspects of RDs' understandings of the breadth and individualization of disability appeared. Learning from personal experiences captured the RD focus on their own experiences working with and learning from students with disabilities in the RD role as leading to greater personal understandings of disability. Through these experiences, RDs described developing understandings of the importance of avoiding assumptions about what a particular disability might mean for an individual student, or what a particular student might find supportive. Lastly, expanded empathy emerged as an approach to working with students with disabilities that the RDs developed through their increased understandings of the individualized nature of disability.

\section{Learning from Personal Experiences}

Throughout the study, the RDs highlighted the importance that learning from personal experiences played in their understandings of disability. Within the theme of developing an understanding of disability, personal experiences appeared to be particularly salient for RDs that 
did not identify as having disabilities themselves. Similar to the previous example from Maeve, RDs described their own educational experiences as ones that were limited in the extent to which topics of disability were engaged. Aaron spoke about growing up with a definition of disability from his K-12 educational environment that was restricted to mobility differences as a result of "the way I grew up and how [disability] was talked about." Set against this background of limited personal experiences, the RD position was described as the first opportunity that many of the RDs had for meaningful interactions with students with disabilities.

RD experiences also appeared to play a central role in expanding the understandings of disability among RDs who identified as having a disability. Isa discussed this, as someone who prior to the RD role only knew of her own experience of cerebral palsy. Isa explained that while she had her own experience, it was through professional development opportunities within her residence life department that she gained a more complete understanding for the variety of ways that cerebral palsy may appear:

I've even learned more about my own disability. I think the biggest takeaway I think I could probably speak to is just the spectrum of disability. I think, in theory, we, I want to say that I knew this, but it's different when you see it every day. So in theory it's like okay well, cerebral palsy is like one example but it's like CP can look like me, or CP can look like someone who is in a wheelchair... I think just having an awareness of how it can show up and how it can present is helpful. I think mental health awareness is having an awareness of how different things present. That, for example, someone who's on the spectrum can present in many many different ways. And how people interact and how it affects people can be very different. 
Additionally, many of the RDs stated that they had learned about the definitions and legal contours of disability during graduate school, and had a theoretical knowledge of the diversity of disability. However, as Isa articulated, working with and learning from individuals in different places along spectrums of disability furthered their understandings of the varied ways in which disability may appear within their communities.

\section{Avoiding Assumptions}

Another component of the expanded understandings of disability theme involved avoiding assumptions. This aspect of the theme was closely related to the previous one of personal experience. Specifically, RDs attributed their learning from personal experiences to have frequently occurred in ways that conflicted with societal norms regarding disability. In order for them to expand their understandings of disability, they had to avoid making disabilityrelated assumptions that relied on narrow, normalizing definitions or stereotypes. In order for them to consider individualized experiences of disability, as Isa described above regarding cerebral palsy, she had to avoid assuming that it was only something that was experienced in the singular way with which she was most familiar. RDs gained a greater understanding of the diversity of disability by avoiding assumptions about the ways in which they expected disability to appear in their work. Isa described having to avoid assumptions about the way that certain disabilities may, or may not appear:

I really have to keep myself in check when I come in contact with a student who discloses, "Oh I have bipolar disorder.” Or, "I have borderline personality disorder.” Or, "I struggle with a major depressive disorder." Or anything like that. I have to keep myself in check that I'm not making assumptions as to what that means and how it manifests for a particular person. 
Many of the RDs expressed a commitment as articulated by Isa, to avoid attributing a particular set of characteristics to an individual based on their identification with a particular disability. They also noted that along with these generalizations it was important to avoid assumptions about what a student might, or might not be experiencing regarding disability. Aaron described this as his active attempts to remind himself of that which he does not know:

Knowing that I don't know $100 \%$ of what's going on for somebody - and so it may seem like everything's good, or they don't need extra accommodations or anything like that, or they can access something the way their peers do. So remembering to keep thinking about that. Reminding myself that there's so many things that I don't know.

These acknowledgements of the unknown appeared to be important because they invited the RDs to step into an understanding of disability that was highly individualized, and could more easily accept divergence from stereotypes on account of their personal recognition that more may be happening with respect to a student than that of which they were aware.

In addition to stereotypes about the nature or characterizations of specific disabilities, avoiding assumptions also appeared as the RDs discussed their understandings of what students with disabilities wanted or needed. Adrian described the importance of not pre-determining appropriate supports based on an individual student's disability:

But it's an important thing with working with students who need accommodations per their disabilities, is that just because we have a certain answer doesn't mean that that's the prescription. Each student needs to be able to live that live out their own story. And no two students have the same story, and so, you know, kind of giving them, like, Alright, here's our here's our options right you know. What looks good to you? What fits correctly? 
Adrian expanded upon this later, while stressing the importance of individualized responses:

Let the student lead you with what their story is with what their needs are let them identify their needs to you. Don't, don't, don't assume their needs. And, you know, if, if you feel like somebody is acting out right it's like. Take it, take a step, take a second to think about what does acting out mean for you and what behaviors are they actually showing that are concerning. And you know what are some, what are some ways in which you can get in contact with that student to understand the underlying issues of what you, what you're perceiving as acting out.

Similarly, Gwen explained that she found it important to learn to not dismiss a particular student request based on the assumption that she would not have found it helpful had she been in the student's position:

I had a student who had a large snake as their ESA. And it blew the central office's mind. And I had an initial reaction of, "there's going to be a huge snake living across the hall from my cats? Will it eat my cats?” That was my first reaction, and then I was like, "you know, I know that student. If they need a snake, they need a snake.” And she explained it to me one day; that it's like a living weighted blanket. The snake rests on her shoulders while she does homework. It is grounding, it is calming, and it lives for 20 to 40 years. So she was like, "why get a cat that you're going to have to mourn in 10 ? I can have the snake that lives almost forever." Yeah so I think there's just a knee jerk of, "I can't have it or I don't need it. Ergo you don't either.”

Many of the RDs also acknowledged that due to their limited experiences with disability and the effects of operating within a normalizing society, it was difficult to avoid assumptions. Assumption avoidance was articulated by many RDs as an area for active, ongoing 
improvement. While some RDs discussed the ways in which they avoided assumptions, others identified it as a developmental goal. Parker articulated this, first at a societal level:

In terms of invisible disabilities, unless we know those things, we sometimes just chalk it up to someone being not as capable. I think about like the kid in PE who has asthma and is huffing and puffing on the mile run. A PE teacher could be like, "that kid is just struggling, that kid is not doing well." And unless you know that they have asthma you're not - I mean, that's an easy mindset to have, right? So I think those are trickier spaces with some of the disabilities that aren't as easily visible. We forget. And I think especially - I would say $95 \%$ of faculty and staff members probably have an ableist perspective. And I think that has a say in a lot of how we think about things. And I think it's instances like that, where we can't see it, or we can't visibly observe it as quickly. And because we come from an ableist privileged society and structure, then we just miss it a little bit more often.

Parker returned to his previous societal example later, to share a similar experience of his own within his role:

I think that's probably one of my gym teacher moments. Where I think we jump to, "Oh, no, you're just a freshman who wasn't prepared for the first test. And now you've got your wake-up moment, and you'll be fine once I've talked to you." But I'm like, that's a little bit of a privileged perspective. And then, really, it should be more of, "what do you need?" And getting to that point of, "these are the resources and this is what I would suggest." And asking good questions. And I think it's about switching to those good questions. Figuring out more about what has a student's process looked like, and history of academics looked like, and where are the places that they struggle in their classes, and 
where the places they're not struggling? And then guiding them to different places from there.

The ways that the RDs described their efforts to avoid assumptions appeared to suggest that doing so allowed them to avoid presupposing student circumstance or need based on partial or incomplete information. By avoiding these assumptions, the RDs appeared to be more prepared to explore the needs of students with disabilities, even if those needs were inconsistent with RD expectations related to particular disabilities or accommodations. Many of the RDs spoke of their desires to treat students on individualized bases. The assumptions RDs were attempting to avoid were those that filled in knowledge gaps in ways that were not individualized. Avoiding assumptions, therefore, appeared to directly support RDs in their attempts to work with students and understand disability in individualized ways.

\section{Expanded Empathy}

Within student affairs, empathy - the ability to be aware of and attuned to another individual's understandings (Winston, 2003) - is discussed as a core competency and key to serving in helping roles, such as that of the RD (Reynolds, 2017). RDs demonstrated empathy as they discussed the ways in which they worked with students with disabilities. Further, when describing the ways in which their understandings of disability had grown through their time as RDs, they also appeared to describe that their capacity for empathy had grown as well. Expanded empathy appeared in ways that were directly connected to the other components of the theme of broad and individualized understandings of disability. RDs explained that through their work they developed a greater sense of the breadth of disability, as well as an appreciation for the highly individualized ways it appeared, or was experienced by students. Many of the RDs articulated these expanded understandings in ways that suggested a simultaneous development of 
empathy. In explaining that his definition of disability has not changed as a result of the RD position, Aaron stated:

I don't know that they have changed. Yeah, I don't know. I have a little bit more understanding and empathy than I did, just because I've learned a little bit more and have heard about more experiences that I didn't even know were experiences that people had. So yeah, I think just some more care and understanding and empathy than previously. Likewise, Emily acknowledged that hearing the personal narratives of students with disabilities through her RD role had been valuable: "more exposure helps with the empathy building, and with my like definitions of disability. Just getting kind of like a broader sense of what that looks like."

Together with the elements of personal experiences and attempts to avoid assumptions, the RDs appeared to have developed more complex understandings of disability through the RD role. Increased complexity emerged as a combination of breadth and individualization. The RDs reported working with students in ways that led to both broader understandings of what constitutes disability, as well as specific appreciations for the unique ways in which disability may appear or be experienced by individual students. Isa discussed one particular student, and the specific understandings that she developed through working to support this student:

It's made me more aware. It's made me more aware of how our spaces are set up. It's made me more aware of the human experience. I think one of the blessings and also curses of this job is that you're confronted dead in the face with human experience and a lot of really hard aspects of the human experience.... there's a student, one of the most remarkable students I've ever worked with. Star athlete, star student, super engaged his freshman year. And then he got into an accident between freshman and sophomore year 
and now uses a wheelchair and he had to completely relearn how to live his life. So it was a really beautiful thing to journey with him through that, but it's also been heartbreaking at the same time. And because my building is where we tend to suggest for folks that have physical disabilities, specifically if they use wheelchairs, I've worked with him a lot.... And I remember the first call that I ever got from that student who was like "I can't reach the elevator button because [there is a bench] in the way." And I had a gut check of like, "Oh, I wouldn't have even thought about that."

Later, Isa continued, in describing the ways that these experiences led to her being more understanding when confronted with new disability-related student needs or circumstances: Having an awareness of how different things present. For example, someone who's on the spectrum. That can present in many, many different ways. And how people interact and how it affects people can be very different.... I think in theory, I knew that. But in working with students of different abilities, or students who are neurodiverse, always keeping an awareness of how this presents in one person might present completely differently in another person. And being open to continuing to learn.

Through their experiences with individual students with disabilities, particularly those in which the students did not match the stereotypical expectations the RDs may have had, the RDs appeared to expand their capacities to provide empathetic support to these students. The RDs described being better prepared to understand the experiences of their students because of past encounters with individual circumstances of disability. These circumstances invited the RDs to avoid relying upon disability-related assumptions, and instead to think about student support in ways that were grounded in individual student situations. 


\section{Addressing Disability Reactively}

A desire among the RDs to be more proactive in their disability-related work emerged as they discussed opportunities for improving student support. Some RDs identified the potential for increased resource sharing, while others contemplated changes to programs or services. Corey described an interest in communicating with students before students raised concerns: I think a lot of our students are really hurting and really struggling and I don't think that we do a proactive job of talking about that and how to best support them. I think it's more so you tell us what you need, and we'll get you accommodations, as opposed to, "Here are some things you may be struggling with and here are the resources that we have." Corey's statement underscored the reactive interactions that RDs reported at the core of their work with students with disabilities.

The theme of addressing disability reactively appeared with two distinct components. One was distinguishing between accommodation and inclusion. When the RDs discussed the supports they provided related to disability in their residential communities, the extent to which

they were perceived as proactive or reactive appeared related to whether the RDs were approaching disability as a limitation in need of accommodation, or as an identity that warranted inclusion within the community. The other was resource limitations. As entry level employees, the RDs described myriad ways in which they perceived their abilities to be proactive in support of students with disabilities to be directly connected to individually, departmentally, or institutionally-limited resources.

Prior to examining the components of this theme, it is important to note that a reactive approach to disability was found in a way that was intertwined with RD understandings of their roles as entry-level positions within hierarchical institutional systems, in which they had limited 
positional authority. The RDs frequently discussed instances in which they were not part of decision-making discussions, and were separated from the leadership circles in which many decisions were made. Furthermore, they noted that within Student Affairs, the RD position is one in which individuals remain for a relatively short period of time. As a result, it appeared that the RDs' perceived role limitations that invited them to view themselves as cogs in a much larger machine; a machine they had little ability to influence. These sentiments emerged in ways that were not limited to topics of disability. They appeared as the RDs discussed their relationships with their colleges and universities, and the broad understandings they had of institutional systems and hierarchies. Megan and Gwen provided clear examples of this sentiment. As Megan described the importance of work-life balance, she said:

I work nine to five and I will go to staff meetings and I will respond to duty calls. I am not paid more to work more than 40 hours and I constantly say, "Capitalism, you won't get me." Even though it does... Be loyal to your students, find your people. But when you find that dream job or when it's time to go, it's time to go.... Be loyal to the people but not loyal to the institution, because you don't owe the institution more than your 40 hours.

Gwen described a limited ability to make change, related to departmental leaders who tend to have longer tenures in their positions:

I have minimal autonomy over department policy. And I've been here a minute, I can voice dissent. But at the end of the day it's the live-off pro staff who are making the final call... I think the RDs can be say "This is really not working." Or, "This is really frustrating to our students." And then the central staff can take that and marinate on it, and then just do whatever. The same way that student populations refresh, live-in 
professional staff refresh really frequently. So if you just wait a little bit, you're going to outlive my complaints, as an institution.

These perspectives highlighted the institutional layers within which RDs operate. The existence of these layers is important to acknowledge in a discussion of a reactive approach to issues of disability, because it is a contextual factor that the RDs navigate across numerous aspects of their work.

When viewed through this context, there remains a theme surrounding RD responses to disability, and the extent to which these responses frequently appeared to be reactive. The RDs primarily responded to individual instances of student issues regarding disability. Rarely were these individualized responses discussed in ways that suggested proactive examination of departmental or institutional systems. However, as outlined above, such an analysis must be considered within the broader context of RD position and the college and university systems within which RDs operate. The following elements of this theme are analyzed from a standpoint that understands reactive approaches as those that respond to issues as or after they arise, in ways that are consistent with these present systems, structures, and limitations. In contrast, proactive approaches are those that attempt action prior to issues arising. Proactive approaches strive to reframe systems and structures, so as to change environments in order to avoid the creation of conditions which might otherwise contribute to the emergence of issues or challenges.

\section{Distinguishing Between Accommodation and Inclusion}

RDs described their work with students with disabilities as highly reactive. Many of the RDs described disability as something that was not prioritized during advanced departmental planning. In discussing opportunities for interaction between residence life and the DS office on her campus, Brooke explained: 
I think we can create a better dialogue between our two spaces. But, we're really not. I think that goes back to the reactive piece. We only are meeting to react to something, not to plan or to be proactive about potential somethings.

In the absence of advanced planning, RDs explained that most of their work with students with disabilities involved responding to student concerns. When confronted with these concerns, RDs directed students to the DS office, or implemented approved accommodations for students based on notification from the DS office. Noelle spoke about this aspect of her role as one of the places in which she had the least autonomy:

Accommodations are a kind of rigid process. There's a lot of red tape. A lot of "Here's what you need to do, here's who you need to talk to, and then," you know. There's not a lot of autonomy there when we're providing accommodations. It's pretty ironed out between the director of residence life and the director of disability services. So we just fulfill whatever accommodations have been decided. But if the student says "These actually aren't working for me," we don't really have the autonomy to change that. They would have to go back and talk to disability services and change the accommodations. Then they'd have to talk to housing and residence life again. So there's not a lot of autonomy to just change accommodations.

Noelle's explanation highlighted a similar interdepartmental relationship between residence life and the DS office on her campus as was pointed out by Brooke. It also provided a description of the reactive nature of responding to accommodation requests and instructions. RDs described a facilitative role with respect to accommodations. However, it was facilitation that was predicated upon responding to student needs reactively, as they arose. The reactive role that the RDs played in working with their DS offices was consistent with their broader understanding of the RD role 
in their respective institutional hierarchies. Many of the RDs expressed a desire for increased opportunities for collaboration or creative problem solving alongside their DS office. They simultaneously indicated that opportunities for this type of collaboration or idea exchange would need to be set by departmental leadership; and as a result, the RDs were limited in their available agency to create such opportunities themselves.

A small number of RDs hypothesized about proactive approaches to accommodations. Many RDs were familiar with Universal Design, and identified opportunities to incorporate principles of Universal Design into residence life planning. These RDs identified opportunities for proactive considerations of disability in the residence halls. Buildings with elevators, greater numbers of single rooms or in-unit kitchens, warm lighting in hallways rather than fluorescent bulbs, or accessible lounge furniture were all identified as components of residence hall planning that would proactively support students with disabilities. However, the RDs who noted these possibilities also indicated that they had not had opportunities to engage in residence hall planning conversations. Specifically, they explained that as entry level administrators, they were not part of building management decisions that involved capital planning or facility budgets. As Rose described when talking about the accessibility of the hall she supervised, "if I wanted to add ramps that would need to go through my supervisor. And she would need to find the money for it.... That's above my head. It's above my paygrade."

In contrast to a reactive approach to accommodations, RDs discussed more proactive ways of thinking about disability when they considered it through a lens of inclusion. Overall, these approaches appeared less frequently throughout the study than the reactive aspects of their work. The RDs spoke about inclusion particularly in terms of the supervisory support they 
provided to RAs regarding community programming. Kevin elaborated on the ways that he tries to call his RAs to be mindful in their program planning:

I don't know that the department talks too much about programming. But I talk about it with my staff. We have these signature programs for our halls. None of mine are very accessible. So we're tweaking that a bit. For my traditional hall we do a Halloween themed carnival game type thing. But none of the carnival games are very easily accessible. And so this year we made sure we had things like coloring and cookie decorating, and other things that people could sit down and engage with that weren't so physical. The apartment-style building I oversee is a little more accessible. It's a giant end of the year celebration. That's pretty ADA friendly. But there's also a bouncy house and lawn games. Again, things not everyone can engage with. And so currently we're doing a lot of thinking about, "Okay, we may still have a bouncy house. But if someone can't participate in this, what else are we doing so that they're going to have just as much of a beneficial and fun experience at this program?" I think it's just doing a lot more thinking through ahead of time, of what this experience is going to look like.

Other RDs shared similar examples of working with RAs to make sure that movie nights included captions, that guest speakers used microphones, and that events were held in accessible buildings. The ways that RDs spoke about this aspect of their work highlighted a proactive approach to disability that emerged when attention was paid to overall event inclusion. Maeve captured this sentiment as she contemplated an inclusive approach to disability as something that is important for the development of more proactive supports for students: 
How can we be proactive and not wait and say, "Oh, well because we have a student with this type of disability, then we will do this," but just do this particular thing in advance, no matter what type of students we have?

The approach that Maeve encouraged was found with frequency among RDs as they focused on inclusion. However, this focus on inclusion was often separate from reacting to individual student needs. Instead, the RDs described supporting RAs in their program-planning, without knowledge of the specific students who might attend the program in question.

A consequence of the disconnect of proactive approaches from particular students with disabilities is that it creates space for the consideration of disability without requiring student disclosure. However, it may also limit the types of disabilities that are addressed in this manner. In their discussions of RA programming support, the RDs frequently acknowledged severe allergies, visible physical disabilities, and concerns regarding student anxiety and difficulties with social interactions. They referenced the importance of meeting a variety of dietary needs at programs, as well as making content available in multiple formats, and providing a mix of activities - having programs with both physical and non-physical components, or options for both introvert and extrovert-friendly levels of engagement. Despite such attention being undoubtedly valuable, it did appear that this approach may not have encouraged the RDs to consider or plan for students with chronic illnesses or disabilities that involved predictable or unpredictable flare-ups. The ways in which the RDs spoke about proactive approaches to programming appeared more focused on disabilities that would not have prevented students from arriving to the program in the first place. While these discussions appeared as only a small portion of the ways in which RDs worked with disability in their role, they were more proactive than when disability was considered through an accommodations-focused lens. 


\section{Resource Limitations}

Another component that appeared connected to RDs' reactive approaches to disability involved resource availability. As previously addressed, although the RDs seemed to work with students with disabilities in primarily reactive ways, they also identified desires to be more proactive. As they spoke about the tension between these two approaches, it appeared that resource limitations played an important role in whether and to what extent RDs identified and considered opportunities for proactive support of students with disabilities. The resources that they discussed were not only financial. They also included residence hall amenities and building capacity, as well as human resources - such as RA open-mindedness and departmental knowledge. As an example, numerous RDs referenced the importance of the historical knowledge their directors held, and the value it played in navigating institutional political environments.

RDs discussed their responsibilities for the management of residential buildings - which were often old, and had numerous inaccessible features. Several RDs explained that they worked with their facility departments to update or adapt various elements within the buildings on an asneeded basis, in response to students' accommodations. The RDs also described specific residential spaces, either in their buildings or buildings managed by their coworkers, which were specifically designed or retrofitted, and then set aside or otherwise designated as spaces for students with physical disabilities. Joshua was one of many RDs who referred to these as "ADA rooms." The RDs framed the existence of these rooms in part as a matter of compliance. They noted that although an entire building may not be accessible, options did exist for students with physical disabilities. They discussed these housing options within the context of their understandings of ADA compliance. They noted that institutional obligations regarding 
accessibility within these buildings were dictated by the code in place at the time the halls were constructed. When discussing building accessibility, Perry noted:

Some places there's no ramp or no elevator. Or there just cannot be. So, if you are a student in a wheelchair, you can live in one of two residence halls, which are our newer buildings that have elevators. And aside from that, you can't really live in any of the other buildings. We would love for you to but the reality is that you can't.... We're ADA compliant, but we were grandfathered in because of the age of our buildings. So that's kind of an issue.

The institutional compliance issues that were intertwined with these understandings were ones in which the RDs perceived themselves to have limited agency, as described by Aaron:

It'd be significant time, labor, modification to the building, and things like that. Where things go up, they start to move out of my control. I can continue to push and advocate and help the student navigate systems. But at the end of the day, it's way out of my control. Especially the more cost gets brought into it. So, if it's like, "Hey, my building doesn't have this, but I know we have other buildings on campus like that." I can go and bring that conversation forward to somebody else, but that'll quickly be like, "Yeah, we can do that if you have $\$ 50,000$ sitting around."

Aaron's example highlights the absence of RD involvement in residential facility budget decisions. It also suggests that institutional leadership does not identify disability as a highpriority issue. Aaron's indication that he would be asked if he had the money for the renovation implies that unless Aaron - or someone else - earmarked a donation specifically for that purpose, general university funds would not be made available for this project. 
In contrast, when resources were less limited, RDs appeared more able to broadly apply or implement what may have been an accommodation for a student, as a universal practice that they made available for all students. RDs described examples that ranged from providing documents to students in advance of the meeting in which they would be discussed, to asking students about their meeting preferences, to handing out print versions of presentation slides to RAs during training sessions. In all of these cases, RDs expressed desires to facilitate meaningful participation for all students; and in the absence of resource limitations, supported such participation by providing things proactively, so that students did not have to make individual requests. RDs expressed their abilities to do this on small scales and within their departments or RA teams. They indicated that it was easier on small scales, where the implications of restricted budgets or the need for interdepartmental approvals were not inhibiting factors. The RDs described having small budgets for their individual buildings, which they were able to manage themselves. They explained that these funds were primarily intended to support residential programming, but could also be used for minor facility improvements. Beyond those budgets, however, the RDs appeared to have very little, if any, input in larger departmental budget decisions. The top-down budget management that the RDs described is one that typically exists for RDs as entry-level employees in Student Affairs. It is not surprising that the RDs reported this in their discussions of disability. Simultaneously, it is a feature that one could expect to find in discussions with RDs about their roles, across a wide range of topics or issues.

The limited resources and agency that the RDs articulated regarding budget or building renovation help contextualize certain aspects of what appeared to be RDs' reactive approaches to their work related to disability. Much of the RDs' approaches to disability were bounded by the resource constraints of their departments or institutions. The RDs expressed desires to function 
proactively in what they provided to students, but were unable to do so when the things they were providing - such as a single room, or one with a roll-in shower - were in short supply. Isa captured the tension that emerged as RDs described moments of conflict between their hope for inclusion and the realities of their residential communities:

While we're within ADA compliance - I would never say we're not ADA compliant there's a difference between being compliant and being, affirming. Does that make sense? And I kind of wish we could get to this place where we're not just in compliance, but where we're going above and beyond, and our buildings are all incredibly accessible. But, I'm not on our operations planning committees.

Isa's example highlights the manner in which RDs identified their entry-level roles as factors that limited their impact on institution-level decisions. Based on their residential experiences, many of the RDs identified a desire to create communities that addressed issues of disability more proactively. However, they perceived their limited institutional authority as an inhibiting factor, which led them to respond to disability in reactive ways, dictated by the existing resources at their disposal.

\section{Tension Between Stated Needs and Documentation Requirements}

Throughout the interviews, RDs discussed the role they often play as first points of contact for students with questions about disability-related housing accommodations. Some RDs described instances in which they were approached directly by students or their parents regarding disability-related concerns. RDs also spoke about instances in which issues of disability emerged when meeting with students who the RDs reached out to following expressions of concern by faculty members. Similar accounts were also provided in cases where questions of disability arose that involved a student an RD came to know through a conduct process or roommate 
mediation. Across RD discussions of these interactions, a theme of tension emerged.

Specifically, it was a tension that RDs appeared to experience between the self-reported needs of students with disabilities and the documentation requirements of the disability accommodations processes within which the RDs worked.

Disability accommodation processes require students to formally register with the disability services office on their campus. Part of the registration process involves verifying that they have a disability; often through providing documentation from a qualified medical provider. The primary tension that the RDs expressed was rooted in their concern regarding student access to the resources necessary to meet the documentation requirements. Corey articulated this, explaining: "I have heard from many students that their biggest barrier when it comes to accommodations is feeling like they can even access the ability to get the documents they require." The theme was made up of $\mathrm{RD}$ desire to take students at their word, legal requirements and assisting students through the DS process. The desire to take students at their word was found specifically with respect to student requests for certain things outside of the accommodation process. Mac experienced this with a student asking for a single room, while Carmen described a student who came to her with a request for a specific type of chair for his desk. Legal requirements referred to RD associations of disability and disability accommodations with matters of the law and legal compliance. Finally, RDs also discussed experiences of tension as they supported their residents while the students navigated disability accommodations processes.

\section{Desire to Take Students at Their Word}

A desire to take students at their word was a complex aspect of the theme. It appeared as something that RDs considered when thinking about individual student interactions, as well as 
larger institutional systems. Expressions of frustration emerged out of RDs' inabilities to provide accommodations based on students' self-reported needs, and RD concerns that systems for accommodations approval were normalizing, or further marginalizing due to the time, energy, and access to resources that they require. Darren described this frustration relative to the additional steps that he observed students with disabilities undertake in order to secure accommodations, noting:

The person who is experiencing the sense of disrespect for their identity or their needs has to be the one who's the loudest advocate for themselves. That's quite unfortunate. I wish that wasn't the case. I wish we could just accept students at their word.

Gwen described a similar frustration, as one of the primary sources of learning in the RD role: You need to honor what other people are telling you, and it's not your place to dissect; which is I think contrary to student development. We're told to poke and see where [students] are at and push them a little bit. And [my RD experience] has kind of firmed up that there are certain experiences where it is what they say it is and you need to honor their reality, just point blank....And so it has been, like, "No, I think the student has a very clear idea of what they mean. I am hearing that. And if you're not responding to it you and I can chat more, but this student needs x y and z.”

In reflecting upon his learning and development through the RD position, Scotty demonstrated a commitment to this approach, stating:

I'm in no position to question if what folks are saying is true or what grounds or what severity. I trust the students at their word to tell me what they need. And you know if this is something that they use to get a leg up on me, then so be it. I will live with that if I'm able to help somebody. 
Across these and similar responses, RDs articulated their attempts to focus less on formal disability diagnoses, and more on what students said that they needed.

Through their concern regarding the negative impact of systems on students with disabilities, and their desire to take students at their word, the RDs appeared to be pushing against traditional bureaucratic systems that attempt to categorize needs into limited groupings for the sake of efficiency. Within Disability Studies, research has identified essentialist views of disability - treating disability as a monolithic identity, as opposed to one that intersects with other identities at the level of the individual (e.g., Carter et al., 2017; Mollow, 2013; Reid, 2016; Siebers, 2013; Wood, 2017), as efficient but inadequate and harmful. Many of the RDs appeared to respond similarly when confronted with the individualized experiences of stated student needs that fell into conflict with systems of accommodations.

Many RDs also connected this focus to their understandings of disability stigma and barriers to the accommodation process. They discussed their knowledge that some students with disabilities choose not to register and seek accommodations through the DS offices on their campuses. Campus peer and faculty reactions, as well as socioeconomic documentation barriers were among the most frequently referenced reasons the RDs discussed. Their perceptions of these barriers supported their interests in taking students at their word. The RDs explained that they wanted to provide students with the things that they said they needed, because the RDs were not in a position to know if these things were needed, and that the formal disability accommodation process might not support all of the students with such needs.

Implicit in RDs' stated beliefs of their students' needs was also a questioning of the formal accommodations process. As addressed later in the Generalists Operating Between Silos of Expertise theme, the RDs acknowledged a limited expertise in issues of disability, particularly 
as compared to administrators who worked in DS offices. Nonetheless, when describing the tension between students' needs and accommodations processes, RDs articulated belief in, and support of, their students. Although it was not discussed by a large number of RDs, several spoke about the live-on nature of the RD position in ways that suggest a connection to their belief of students and doubt of institutional systems. The RD position is one that lives on campus, and is part of a 24-hour on-call system. RDs discussed responding to mental health crises in the early morning hours, when very few other campus staff or administrators are available. It appeared that the interactions that occurred during these on-call experiences were highly individual and personalized in nature. Robin described experiences of working with students with disabilities while on-call, "We do have a DS department, but we live here, and we're here all the time. And we're here in the middle of the night when the student does something, or has a certain reaction." Similarly, Maeve explained:

I'm often the one helping walk them through [the disability accommodation process]. I'm the one here late at night while they're struggling to study, or where they're stressed, and they don't know how to get the help that they need. They don't know who to go to. So I'm kind of like the listening ear as they struggle with it.

These highly personalized experiences invite an understanding of RD support of the individual students over that of the accommodations systems, as related to the individualized nature of the types of support that RDs provide by virtue of their unique live-on, 24-hour supportive role.

The RDs who held this perspective appeared more willing, as demonstrated by Scotty, to take students at their word even if that meant that some students might somehow take inappropriate advantage of that situation. However, not all of the RD participants shared this perspective. Although it was a minor aspect of the concept, several RDs discussed concerns 
related to providing or facilitating certain things for students. Their concerns were rooted in questions of whether these students were attempting to secure accommodations in a manner that was not warranted. These concerns were particularly concentrated around the approval of ESAs. They also frequently involved student requests to be exempted from the standard roommate mediation process and allowed to move housing assignments in response to roommate conflicts. More than a disagreement with the accommodation, in these instances the RDs appeared to express suspicion regarding the existence of the disability for which the accommodation was requested. Joshua articulated that there are certain moments in working with students where he becomes suspicious of these requests:

When I get suspicious is when I'm sitting with a student who says, "You know, I can't stand my roommate. There's so many issues. They're not willing, they don't do anything." And I ask, "Well, have you talked to them? No. Okay. Well, can we talk to them?" "Well, I just want to move out." "Okay. Well, you know, we can't really do that. We have this process. We want to make sure that we have this conversation." And then they're like, "Well, I have anxiety, I can't do that. So I need to get a disability accommodation for that, because I can't do that." Those are the ones that I'm usually suspicious of.

Joshua's description of his suspicion highlighted the manner in which a student's stated need - in this example, to not engage in a mediated discussion with their roommate - became cause for Joshua not only to question the need itself, but to question the existence of the disability for which the student was claiming the need.

A similar suspicion appeared among a number of RDs regarding ESAs. Common among these suspicions or concerns was that they existed in ways that were directly connected to questions of accommodations. In the case of ESAs, the suspicion was that the student did not 
need the accommodation, and was improperly seeking it - implicitly, by lying about a disability - in order to circumvent residence hall policies that prevented students from having pets in the halls. Much like the previous example, RD suspicions of illegitimate ESAs did not stop at whether the ESA as an accommodation was warranted or appropriate; they appeared to extend to a question of whether the student had a disability.

The challenge that emerged in these responses of RD suspicion is that the suspicion treated disability and accommodation requests as propositions that appeared together, in either appropriate or inappropriate ways. These expressions seemingly did not leave space for a student to have a disability, and still make a request in a way that was inconsistent with departmental expectations or operations. There did not appear to be space in these responses for the possibility that a student may have a disability, even if a particular accommodation was not needed or not appropriate. Such a paradigm risks furthering all-or-nothing propositions in the ways in which disability is understood. These propositions fuel understandings of disability in which the perception of an accommodation request as legitimate confirms disability, whereas the perception of an accommodation request as suspicious leads to a questioning of disability identity.

\section{Legal Requirements}

Beyond a focus on needs and accommodations that appeared to preempt a focus on disabilities, the tensions that appeared to surround RD notions of student needs and documentation requirements were also framed by RD understandings of legal requirements and liability. Disability as a legally protected class, with associated regulations and institutional obligations were referenced by a majority of the RDs interviewed. The legal aspect of disability was noted, and frequently cited as something with which RDs had a cursory familiarity, but in 
which they lacked expertise. Several RDs explained that this understanding led them to defer to others' instruction out of concern for legal compliance. As Carmen explained, "Because of the legal components, it's kind of like, well, we do what they say." These references to legal requirements often began with a focus on maintaining compliance or not running afoul of the law.

Meanwhile, the ways that RDs reported responding in moments of suspicion regarding disability were deferential to the administrators or offices with greater legal expertise. Perry noted that he had encountered instances where he believed that an accommodation was not warranted, or was not helpful. However, he explained that he was not in the best position to make those determinations, and as such would not deny an approved accommodation. He also acknowledged that a system that relied on such individualized determinations would likely not support sound decision-making, as he noted, "I think the system that is in place is probably better than every individual professor just being able to choose who gets accommodations." Similarly, Joshua explained that there have been instances in which he did not believe a particular accommodation should have been assigned, but that in such instances he always implements them, because he is not the person who makes the accommodations decisions. As discussed in the Generalists Operating Between Silos of Expertise theme, in some instances, RDs followed these decisions even when they disagreed with them. In others, they followed them, while simultaneously attempting to find ways around the system to support students when possible.

In some instances, RDs described working to provide support to students outside of what they perceived as administrative, legally-focused decisions. Gwen described moving a student into a space that had a bathroom, after the student had been denied a bathroom as an accommodation. This specific experienced is explored in greater depth later in the present theme. 
However, such instances did not appear with frequency among the RDs interviewed. Rather, the majority of RDs described their role as one in which they carried out the administrative decisions of others, even when they did not agree with those decisions. They explained that this created a tension for them in their role. Megan discussed this tension, explaining, "I have to really balance that I am representing the institution, and I can't be like, 'well the institution was wrong.' That's never good. So that is very tricky.” Megan's statement was representative of many RDs, who reported experiencing moments of disagreement with others at their institution, but frequently found themselves implementing decisions with which they may have disagreed, in part out of concerns for legal compliance.

\section{Assisting Students Through the DS Process}

The last element that made up the tension between stated needs and documentation requirements theme involved the work that RDs described in supporting students through the disability accommodation process. Similar to the previous components of this theme, a tension appeared among RD responses, regarding the ways in which they supported students through

these processes. For nearly all of the RDs interviewed, the documentation process was something coordinated by individuals in another office, and with a different area of expertise. Referral to the DS office for students to complete the accommodation request process was a common step that RDs reported taking when working with students who disclosed disabilities or expressed interests in accommodations. The most commonly requested accommodations that the RDs received from students included single rooms, rooms with private bathrooms or kitchens, or the approval of an ESA in on-campus housing. In describing this step, several RDs explained that appropriate documentation was necessary for students to secure accommodations, and that the 
DS office was responsible for receiving and evaluating that documentation. Joshua elaborated on the ways that he approaches these conversations:

My number one thing is to pass the disability accommodations request to [DS]. That is $95 \%$ of what I would do. So it would be "Here is the disability accommodations request.

You need to fill this out.' I can walk them through that. I can show where they need to fill out all the information. They need to provide their supportive documentation, who to contact afterwards, their supports. I usually show them the disability accommodations website. Both our residence life one and the disability accommodations department website. So that's like $95 \%$ of it.

Joshua highlighted the degree to which his work is focused on guiding students through the accommodation process by referring them to DS and explaining the DS process. Joshua and other RDs explained how generally, the DS process involved a student meeting with a staff member in the DS office to document their disability, and on the basis of the documentation and the functional limitations of their disability, work with the staff member to identify reasonable accommodations that the DS office would then approve and communicate to the appropriate faculty or staff member responsible for implementation.

However, other RDs discussed tensions that occurred within these types of referrals; particularly when students communicated their needs to the RDs, but the RDs were unable to act on those needs because the documentation and accommodation processes had not yet been engaged in or completed. Mac and Noelle each provided examples of these experiences. While discussing a specific student request for a single room, Mac said:

I can't make that call. And the student shared her documentation with me. And, you know, quite frankly, I was taken aback. I was like "Wow this is, you know, this is a great. 
You are inviting me into a very private aspect of your life and I'm honored and flattered that you would trust me in that way. And yet I'm still not the person that you should be giving this to." And so, initially when I first got that after working with her for about two weeks trying to resolve the roommate issue I was like, "This is deeply private information." And it was one of those things where like, I need to point you to somebody who's qualified to review this and make informed decisions on this.

These types of RD frustrations highlight the tension that emerged between student needs and documentation requirements. RDs like Noelle appeared frustrated that they could not directly meet student needs. For many RDs, this frustration was discussed in ways that related to the advocacy role that RDs described. The RDs articulated a desire to advocate for students with disabilities, but also found themselves balancing this desire against their understandings of their institutional responsibilities.

Several RDs, including Angela, enthusiastically identified themselves as advocates for students: "I love being an advocate for students. When I can advocate, 'Hey, that wasn't enough, we're not doing enough for these students.' They're asking for some basic stuff and we're not doing that. Those are some good times." However, many of the RDs described having limited positional agency with which to engage in this advocacy. Carmen explained that to her, advocating for students, "Doesn't feel like real control or real change. At the end of the day it's just me being like, 'please do the right thing." These accounts supported what appeared to be a point of tension for RDs, between a desire to advocate for students, and a limitation dictated by their position at their institutions.

Further, several RDs described their desire to advocate for students as at odds with the departmental structures and processes within which they worked. Gwen described disagreeing 
with a departmental decision about a bathroom accommodation request, and explained how she responded by working outside of the system that she perceived to be an adversarial one for the student:

I have a student with a larger dog as an ESA and some unrelated hip problems. The student has PTSD panic attacks and the dog is a really helpful grounding tool.... She asked to have a room with an attached bathroom so she could bathe her dog, because larger dogs need to be bathed from time to time. She's a college student with limited funds and it's a pandemic. So, going to a grooming salon makes no sense. And we say you can't shower your dog in the common bathroom, which also makes sense. So, in my brain, if the physician says she needs this dog, and then she says "Great, I have the dog, the dog needs this." Then we should be doing that so she can care for her animal. But the committee said that the doctor didn't say she needed an attached bathroom so we're not going to provide one. Someone else might need an attached bathroom. And I get they're trying to balance stuff, but it also seems like a reasonable logic to follow. Student needs dog, dog needs this, we have a room available, give the student a room, right? And so I had the ability to just move that student into an open room with a bath, that someone had just vacated, but I don't think it should be on me to do the back door. Right? And it's weird to have that formal and informal process, navigated simultaneously. And then I feel like I have to fight for the student, and it shouldn't be an adversarial process. And I think that's how it's framed for staff and for students.

At times, however, RD frustration was not always explicitly connected to firsthand RD knowledge that the students they were working with had disabilities. In some cases, RDs relied on their own interpretations of student behaviors to conclude that a disability may have been 
present. This appeared most frequently as RDs discussed students who they believed may have been on the autism spectrum. Juli described one such assumption she had made:

What if there's something else? So then when I spoke to their RA, and they told me the qualities that this individual had, I was like, got it. It kind of clicked for me. But again, I'm assuming that.... When I personally met this individual, I saw qualities, that allowed me to feel confident that that's what they had. But I couldn't ask them because that's not allowed. Like that's not within our control.... But it led me think of how I navigate with this individual.... And see if I can adapt things little by little, and see if I can work with that student.

In other cases, however, RD frustration around documentation and the accommodation process appeared less connected to a conclusion that a student had a disability. Instead, several RDs problematized the necessity of disability documentation and verification requirements. They questioned why they were prevented from supporting students in meeting their stated needs, irrespective of a documented disability. For Bea, some of these challenges were connected to the type of disability in question:

Especially when we ask Disability Services to validate a student's disability so that they can move into a certain room. If it's not as visible, not having that privilege of getting documentation. So we don't know if we can make that happen if you don't have the documentation.

Bea also shared concerns about socio-economic barriers to documentation, stating, "I think it's just the structural challenges. How do we navigate that? They need documentation, but is it really equitable for us to ask? Or for them to provide that if they don't have the resources?" These discussions of economic barriers primarily revolved around financial barriers to meeting 
with medical providers in order to obtain documentation, including in ways that might be limited by students' access to health insurance. They were also discussed as related to the financial resources that RDs understood might be involved in securing transportation to or from an offcampus medical appointment.

These expressions of concern demonstrated the tension between student needs and documentation requirements. It appeared that RDs developed their awareness and concern in part through the process of referring students to the DS accommodation process. They shared with students what they knew about the DS process or provided them with instructions for how to initiate the process. They supported students in completing forms, tracking down documentation, and in some cases, physically walking with them to the DS office. Then, they heard back from those students about the challenges they faced within the accommodations process.

Throughout the RD interviews, an active tension appeared in the interest that RDs articulated regarding taking students at their word about the things that they needed, and the documentation that was required for the provision of accommodations. The tension was informed by RD understandings of the legal limitations of their positions, or the requirements of the RD position to refer to DS offices before accommodations could be provided. RDs recognized that the referral was in support of managing legal liability, and appeared to appreciate that there were others on campus who had expertise to make disability-related decisions. Simultaneously, however, frustration appeared around RD acknowledgement that referral to these experts was necessary in order to provide the supports to students that the students stated they needed. 


\section{Questioning Accommodations}

Disability accommodations were frequently discussed by nearly all of the RDs. Most of the RDs spoke directly about accommodations, despite interview questions that did not specifically name them, or address the concept. Many RDs referenced accommodations very early in their interviews. They explained that providing or facilitating accommodations was one of the primary ways in which disability appeared in their roles. Across the interviews, RDs used the word accommodation in a number of different ways. Most frequently, it was used to reference formal disability accommodations that students requested or that DS offices approved through a DS interactive process. Occasionally it was also used to discuss aspects of Universal Design that RDs considered or implemented. For the purposes of this discussion, the theme of questioning accommodations emerged related to the specific things that DS offices identified, or that students with disabilities requested, for the purposes of affording them equal access to the education environment.

The RDs also discussed student need for accommodations as a defining characteristic of disability. While talking about their definitions of disability the RDs spoke about their awareness of a range of accommodations that was broader than those that directly involved housing and residence life. For example, in speaking about the first things that she thinks of with respect to disability, Emily said, "in terms of my role within disabilities I would say classroom accommodations come to mind." Although the RDs were not directly involved in the process of providing or facilitating academic accommodations, they were aware of them. They reported meeting with students who were struggling academically, and aware of potentially helpful accommodations. Aaron described this when he explained the ways that disability shows up in his daily interactions with students: 
A lot of it is academic struggles. Like a failed test that shows up in distress and dismay and anxiety. That usually gets brought to either my RAs' attention or my attention. And it's often either an undiagnosed disability, or something that they thought was under control. Or they just kind of wanted to see, like, they went through high school, and they kind of wanted to see if they can make it through college without the support systems they had in high school. And then they realize, no, they can't. And so then we need to figure out what that looks like here.

In this way, even though the RDs were not directly related in the provision of academic accommodations, they were aware of them, and they framed their understandings of disability and the types of interactions they had with students with disabilities.

When discussing their work, RDs spoke about accommodations as part of a process. They explained that their involvement occurs at the beginning of the process and at the end. They described that when students come to them with questions or requests for accommodations, they refer them to the DS office, and that office processes the requests. When accommodations are approved by DS offices, RDs explained that they are notified of particular accommodations that they may be asked to provide or facilitate - such as moving a student to a single room, talking with a student about the expectations of ESAs in the building, or working with the facility department to ensure the installation of an automatic door opener.

Despite general statements of support for accommodations, there were several ways in which the RDs appeared to call accommodations into question. These questions were not as common as the RDs' generic statements of support. However, certain aspects of these questions emerged in specific ways that warrant consideration. There were three types of questions that RDs appeared to raise regarding disability accommodations. One involved student development 
and self-advocacy. The type of questions addressed in this element were those that questioned whether student development, including the development of self-advocacy skills, was impeded by disability accommodations. The element of accommodations and RA employment involved explorations of the essential components of the RA position. This element addressed RD consideration of whether students with disabilities were qualified to be RAs; whether and what types of accommodations were possible within the context of the position. The final element was identity privilege and limited resources. This element captured questions that the RDs raised about the efficacy of the accommodations process. Specifically, these questions targeted the implications of disparate amounts of social and economic capital on students' abilities to secure accommodations.

\section{Student Development and Self-Advocacy}

RDs appeared to question disability accommodations by asking whether there were aspects of the residential experience on which students with disabilities may miss out, as a result of certain accommodations. Primarily, RDs focused these questions on matters of student growth and development. They noted that interpersonal interactions, particularly those in moments of conflict, provide important student development opportunities. The RDs expressed concern regarding requests from students for accommodations that would allow them to avoid these interactions. They worried that if students were removed from these interactions, they would miss out on the developmental opportunities that are afforded to students as part of the residential experience.

Several RDs spoke about the intentional efforts of their departments to create contexts that encouraged student development. Gwen held that residence hall living should involve a certain degree of discomfort, suggesting that students should, "be reasonably uncomfortable... 
baseline living in a residence hall is not a comfortable experience, and it's kind of designed to be a little uncomfortable because you're supposed to be learning and growing." The RDs appeared to ascribe positive associations to some amount of student discomfort in a way that aligns with Sanford's (1966) discussion of challenge and response. Within the field of Student Affairs, Sanford's work on change and development theory appears in cornerstone professional texts as discussions of challenge and support (e.g., Patton et al., 2016; King, 2005). Sanford suggested that optimal learning occurs within an environment that is both challenging and supportive; development does not happen without some degree of push towards discomfort, but individuals must be supported in meeting that challenge, lest the developmental moment be lost to overwhelm. The notion of challenge and support was referenced by several RDs, particularly as they described aspects of the residential environment that students find uncomfortable. The RDs appeared to view peer conflict and discomfort, such as that which arises in roommate conflicts, as aligned with this theory. Perry identified a similar value within his department:

"It's why we have a process of mediation for students. It's why we require roommates for students. It makes so much more work for us, honestly. But that's part of the struggle. We talk about challenge and support as those classic Residence Life things. We constantly try to balance the challenge and the support."

These references to student struggle were articulated by the RDs as important opportunities for all students to develop self-advocacy skills. RD interest in wanting students to have these experiences seemingly encouraged the RDs to question whether accommodations might limit these developmental moments for students with disabilities. 
Joshua spoke directly to his belief that these moments of interpersonal conflict were important for all students, including those with disabilities, and his belief that accommodations should not impede educational moments, such as roommate mediations:

Our number one thing is to get them to a place where they can have a conversation with their roommate, about whatever. Even if they had an accommodation, I think that would always be our goal. Because that's an important developmental process, in my personal opinion, to be able to confront issues and confront one another, and to manage and navigate that. I think that's an important skill to learn. No matter what, even if you had a disability accommodation. We would at least try to do that.

Similarly, Adrian discussed a concern with how quickly certain students were moved out of uncomfortable residential situations:

Are we actually overlooking students' self-efficacy sometimes? You know, student's ability to solve? And I'm not talking about those hard accommodations of sickle cell, and wheelchairs. Definitely not that. But thinking about the anxiety and depression or other mental health disorders that we are widely aware of. Is the best answer in the overall human development of this student to just move them to a different room? And I think that's what I mull over a little bit. Because we do. It's like, "Oh you feel uncomfortable in this space? Alright, there's a space in the next building over let's get you over there. And if you can't move today we'll at least put you in a temp room." It's like we have the answer and the sub answer ready for the students.

Adrian's concern implied a belief that certain students were asking to move prematurely because of a disability. It also highlighted a tension between notions of the purpose of student housing. For Adrian and the majority of the RDs, residence life offered important moments for the 
development of student social and conflict resolution skills; a perspective that at times appeared to run counter to student or family expectations of the residence halls as a totality of amenities designed to allow students to access and engage in their academic programs. Elizabeth also articulated an implicit assertion that aligned with Adrian. She described past experiences in which she believed students had identified their disabilities as factors in limited personal growth or development:

I feel like students sometimes, not all the time, but students will have a diagnosis of insert something here - depression, ADHD. And they will be - they're so quick to - sometimes so quick to say, "Oh well I'm not good at that because of my ADHD." Or "I can't focus because of my ADHD."

Importantly, the questions that arose related to the potential impact that accommodations might have on student development were exclusive to non-physical disabilities. This is not a novel finding, and is consistent with the literature across Disability Studies. As noted above, Adrian explicitly stated that his concerns did not extend to "hard accommodations." This assertion is demonstrative of greater social awareness and acceptance of physical disabilities, which is well established by prior research (e.g., Beilke \& Yssel, 1999; Humphrey, 2000; Jensen et al., 2004; Samuels, 2013). Consistent with this research, RDs appeared to be more willing to question the impacts of accommodations specifically related to disabilities that were less easily visible. Additionally, the RDs did not appear to engage in consideration of the implications of student disabilities on the developmental opportunities that they identified. They deployed ideas of challenge and support theory to support students in leaning into discomfort. However, they did not appear to consider whether certain disabilities may present a student with an environment in which the situational challenge is too great, and the learning opportunity is therefore lost. 
Lastly, these questions appeared to invite consideration of the learning outcomes from the departments in which the RDs worked. The questions that RDs appeared to raise surrounding the implications of quickly removing students from roommate conflicts or other residential tensions suggest that greater consideration of RDs in the accommodations process may be warranted. In the academic context, a component of the determination of reasonable accommodations requires collaboration with faculty, particularly regarding the academic objectives of the course in question. The questions that RDs raised regarding student development and accommodations appeared to parallel the academic question that is asked in the context of classroom accommodations. In considering questions of student development and accommodations, the RD perspective, or that of another residence life staff member, may be valuable in assisting with the determination of residential accommodations. Their ability to engage the accommodations process, as the administrator familiar with the intended educational outcomes of their department's roommate conflict mediation process, or RA programming model, would support departmental learning objectives while also making those environments accessible to students with disabilities.

\section{Accommodations and RA Employment}

The RDs also raised questions regarding accommodations related to their RAs. Many of the RDs had experience supervising RAs with disabilities. Similar to their consideration of the impact of accommodations on the residential experience, RDs questioned the impact and feasibility of certain accommodations on the RA position.

The questions that RDs posed regarding the RA position appeared to demonstrate an interest in providing some amount of flexibility. However, this interest was balanced against a 
position that certain components of the RA role were required and could not be altered. Aaron demonstrated this approach when discussing RA accountability:

When [disability] butts up with employment, where I'm trying to hold [the RA] accountable. And I'm like, "You need to do your job, but also, you need accommodations." And so trying to hold both of those is never super great. Because I'm trying to balance that, "I need to hold you accountable to some standards, I get that they don't need to be exactly like your peers. But there needs to be some accountability still, because you have a job to do." But also trying to figure out those best accommodations to allow you to do your job with a similar effort that your peers are doing. Tricky to navigate.

Aaron's focus on maintaining a role that was similar to that of the RA's peers was a consideration expressed by multiple RDs. Parker shared a similar account about an experience working with an RA with a physical disability. However, Parker's example had an additional implication within it, because the job requirement of doing rounds was limited by the fact that the institution had multi-floor residence halls that were not physically accessible:

Thinking through, "How are you going to do rounds as an RA on duty? We need you to check the third floor. What do you think that's going to look like?" And he would always get a resident to help him or get another RA to help him. He would walk up the stairs, but they would carry like his portable wheelchair. And then they would go around and do that with him. And I think that was probably my closest working with disability experience or noticing it and then realizing just exactly how ableist-centric some of our practices were. Rather than a focus on peer role similarity, Parker articulated certain aspects of the RA role as inflexible, without directly acknowledging the challenge of holding an RA accountable to a job 
responsibility that was limited by the physical environment, rather than by the student. Gwen spoke of these as "the baseline of [the RA] job that aren't negotiable."

The questions that RDs posed regarding RA disability accommodations were similar to those they posed related to the overall residential experience. The RDs demonstrated a desire to be flexible in some ways, and to some degree, but within a framework that did have certain fixed RA role requirements. When the RDs encountered the portions of the RA role that they found to be necessary or inflexible, they responded with questions that were similar to those previously discussed, regarding accommodations implications for student learning and development. Unfortunately, these appeared to be limited to finding isolated creative solutions. The RDs did not fully confront the inherent conflicts in requiring as job components certain physical tasks that some applicants would be unable to complete due to the limitations of the residential buildings.

\section{Identity Privilege and Limited Resources}

RDs appeared to question accommodations that they believed might change the nature of student development opportunities, or fundamentally alter required components of the RA job description. These questions focused primarily on the impact of accommodations. In addition to impact-related questions, the RDs also questioned the DS accommodation process. These process-related questions concentrated on issues of equity. The RDs questioned whether and how DS accommodation processes functioned to the benefit or detriment of students, based on individual students' access to resources and other forms of socio-cultural capital. These questions most frequently centered around concerns related to low SES and first-generation college students, and their abilities to access accommodations through institutional DS processes. Multiple RDs articulated concerns about the burdens they perceived that DS accommodation processes placed on students. Specifically, these concerns questioned the 
requirements of accommodation processes. Particular sensitivity was expressed related to the resources necessary for the documentation of a disability. The RDs described documentation requirements as a typical component of DS processes; as a way for a DS office to verify a student's disability. Based on these understandings, they questioned the potential for disparate impacts among students, as dictated by different resources to which these students may or may not have access. The RDs connected their apprehension over individual student resources to the abilities of those students to obtain the documentation necessary to secure disability accommodations. They expressed concern that for some students, securing the necessary documentation was very easy, while for multiply marginalized students, who may be in the greatest need of support, the process was much more challenging.

The RDs' concerns also appeared to be rooted in beliefs that students who had excesses of resources were often able to more easily obtain accommodations. The most commonly identified resource abundances were financial, and familial - specifically having family members who understood systems of higher education and had the available means to call administrators and advocate for their students. Murphy explored this disparity, explaining:

I think navigating systems in general is one of those things where, if you have good social capital, you will navigate systems exceptionally well. And I think that is the case for disability stuff as well. If you have mom or dad who will call in and yell enough, or who will go get the documentation for you - who will do that stuff like that - you're going to have a much easier time than someone who does not have that. Or someone who hasn't had access to a therapist until they were in college, as compared to students who've been in therapy or have worked with psychologists for most of their lives. They're just coming at this differently. 
While Murphy articulated concern for disparities between students of different access and means, Corey explored the idea while describing previously encountered student frustrations that were rooted in the lack of access:

I have heard from many students that their biggest barrier when it comes to accommodations is feeling like they can even access the ability to get the documents they require. Many of them come from low SES families where they've had the documentation because it was provided through districts that have really great and robust systems. But then when they come to college, it's not good enough, and it's not relevant enough or new enough. I think DS has tried to expand upon that by providing different monetary resources or opportunities for students to apply for funding. But it's just one more barrier because you already have a student who now doesn't have the documentation they need. You're telling them they need to find an off-campus provider, and more often than not they don't have a car. So now they have to find this person, apply for the funding, and then somehow make it all work. So I think a lot of our students just get really discouraged.

Similar to Corey, Bea pointedly asked whether there is an equity issue wrapped up in requiring documentation from students: "I think it's just the structural challenges. How do we navigate that? They need documentation, but is it really equitable for us to ask? Or for them to provide that if they don't have the resources?" In these instances, the RDs did not suggest that the documentation requirement should not exist at all. Rather, they problematized it by raising questions about the impacts that it has on students, particularly those with limited resources.

Finally, the RDs appeared to intersect questions of equitable access to documentation with questions of accommodations as limited resources. The RDs discussed certain 
accommodations as unlimited resources, while others were understood to be scarce. For example, although nearly all of the RDs spoke about a rise in ESAs in their halls, none of them were concerned about a student's ability to be approved for an ESA based on whether other students had, or needed, the same accommodation. Meal plan exemptions and RA programming adjustments - such as captions on videos, or large-font advertisements - were thought of in a similar manner. However, certain accommodations, particularly those that involved the physical characteristics of the residential buildings, were understood to be complicated by resource availability.

Questions about accommodations availability were most frequently raised at the intersection of documentation requirements and residence hall configurations or amenities. RDs discussed student requests for apartment-style housing, in-unit kitchens, and single rooms as accommodations that were limited resources within their buildings. Vanessa articulated the tension that she experiences at the intersection of documentation requirements and limited accommodations resources:

[Students] have to provide documentation of some sort. And then DS looks through it, and then they send us back, "Yeah, they're approved." Or, "This is what they need." And then we try to accommodate as best as we can. But it's never guaranteed. They can go through the process and then it's disappointing because they can go through the process but it's not like it'll be guaranteed, necessarily. Which is really disappointing when I find out about that. My job is to try to be as accommodating as possible but it's really disappointing when they go through all this process, they've already been vulnerable in the space and provided all these details, a lot about themselves to get what they actually 
need to be successful, to not get what they actually need to thrive in the space. And that's just been very difficult.

Vanessa also connected this to her consideration of the impact of student access to resources:

[Students] need to provide documentation, and they need to prove it. It's literally based on proving that they have it, and why they need it. So I get that that's the process in place but it does become a really draining and long process that feels like it's inaccessible.

Vanessa continued:

And we always have the disclaimer of "We can't guarantee that you're going to have the space, if you go through the process." And it and it does become disappointing and it does become exhausting. I only have empathy for that student that gets disappointed. Through these questions, the RDs seemingly noticed differential impacts on students with disabilities based not only on their abilities to access documentation - as supported by family resources or dominant identities - but also on whether the accommodations that they were seeking were available. Within these questions, the RDs expressed optimism that over time their residential buildings would be renovated or rebuilt in ways that incorporated principles of universal design, which they noted would hopefully alleviate the some of the current accommodations scarcity they had observed. In the meantime, they described the importance of taking it upon themselves to know the available spaces within their buildings, as well as the students who reside there, so that they could provide support and advocacy for students when individualized issues arose.

\section{Generalists Operating Between Silos of Expertise}

The RDs in this study worked at highly residential colleges and universities. Within this institutional context, the student experience is one that is not necessarily defined by the specific 
setting in which a discrete interaction occurs. Rather, students experience the campus as an amalgam of their classroom, co-curricular, residential, and social experiences (Dillon, 2003; Kuh, 2003; Seifert et al., 2008). The RDs frequently referenced the interactive nature of the classroom cocurricular, and housing settings. They described their RD roles as ones that at times include providing support and coaching for students who are struggling academically, attending to specific needs of student athletes, or working with students as they navigate social circles and explore their identities. They also described their roles as central hubs for crisis response and student support. The RDs stated that they receive reports of student concerns from a wide array of sources - including faculty, roommates, or family members. The RDs explained that they interact with students in housing, but do so across topics that span students' broad campus experiences.

When discussing the ways in which RDs interacted with issues of disability, the RDs identified a similarly wide range of contexts that frame the RDs' work with students. Frequently, RDs discussed supporting students with disabilities as they navigate the DS registration and accommodation process, particularly to secure classroom accommodations. Responding to faculty and family concerns was another commonly referenced point of interaction with students with disabilities. Collaborating with their DS office to provide housing accommodations, and supporting their RAs to facilitate accessible residential programs were two other frequently discussed areas. Across all of these interactions, the RDs framed themselves as generalists having broad knowledge regarding the student experience and student support, but without specific expertise in areas such as disability or disability services. They also described ways in which they perceived disability support to operate in a manner that was siloed from the residence life department. The notion of functional silos in Student Affairs has been established through 
research into higher education organization management (e.g., Kleemann, 2005; Kuk, 2016; Ousley, 2006). Silos have been used as an analogy to describe offices or departments that function in relative isolation across college and university campuses - each with an area of functional expertise. Within these systems, students move from silo to silo, seeking assistance based on the specialization of each office. For example, the financial aid office assists with scholarships, the registrar's office manages course enrollments, and the DS office supports disability accommodations. Although this is not the only organizational model available within Student Affairs, it was the one that the RDs most closely described as they discussed their interactions with the DS offices on their campuses.

Through these discussions, and with consideration of the institutional contexts as described above, a theme of RDs as generalists operating between silos of expertise emerged. One element of this theme included autonomy within my building, which captured the RD perspectives regarding their authority and control with respect to the management of their residential communities. Specialized knowledge of disability is not needed, addressed the ways that RDs spoke about their relatively limited knowledge of disability, particularly as compared to their DS colleagues. Lastly, managing liability by following instruction, was an element that included RD references to their perceptions of legal risk associated with issues of disability, and the ways in which RDs acted in order to mitigate that risk.

\section{Autonomy Within My Building}

Overwhelmingly, when RDs discussed their involvement or levels of control over the programmatic and interpersonal aspects of their work that involved disability or students with disabilities, they drew distinctions between things that occurred within their buildings, and things that took place beyond them. The RDs identified this distinction as a primary factor in their 
levels of autonomy. They explained that they often had high degrees of control over the things that took place within their buildings. In contrast, they reported little control, or ability to operate with the same amount of autonomy, outside of their building or across the broader campus community.

They identified high degrees of autonomy to supervise and provide professional development to their RAs, in support of the RAs' work with students with disabilities. Bea noted that support for students with disabilities was something that she took upon herself, calling her RAs to consider it as they engage in community-building activities with their residents:

Incorporating [disability awareness] into staff meetings and talking about it. Giving them training on community builders, "Your community builders are coming up, make sure you're thinking about these things." And then talking about it in our one on ones as well. Aaron similarly identified the work he does within his buildings as that over which he had the most control in terms of supporting students with disabilities. He noted that this also included the ability to provide direct support, so long as it was of minimal cost:

Programs, meetings, student conduct, all of those things where either I directly control it, or I'm helping RAs do it, and it's either no cost or minimal cost, both in terms of time and labor. When it is, "We just have to buy this quick little software that is able to put captions on this video? Easy peasy."

Captioning of videos, in the context of residential programs, as Aaron described, was a common example that RDs shared. They described it as something over which they had direct control, was of little financial expense, and they were able to easily implement. The RDs explained that low-cost supports were part of their in-building autonomy because they were able to make decisions about low-cost items within their buildings by themselves. They contrasted these 
decisions to those for larger budget items, which had to be passed along to their supervisor or department.

The RDs also spoke about having autonomy in their interactions with students and the ways in which they provided interpersonal support. Noelle and Darren both shared examples of such interactions. Noelle spoke broadly about students who disclose disabilities to her:

I choose how I can best support them in that moment. Obviously, we have a lot of resources but there's kind of a counseling-like component that you're offering a student. So, you have to make choices of how to best support the student. Darren described one specific instance of providing this type of student support. The situation occurred at the intersection of disability, roommate conflict and social connections. It highlighted the control that Darren had in the way he worked with the students:

I don't have autonomy over the accommodation, or moving someone. I don't have autonomy in what they're charged for their room. But I do have direct and immediate ownership of the social environment. I've spoken about having to talk with students about hygiene. I had to work with that student directly to create a plan to make them aware of that issue.... And how that student is feeling connected to other people - it's on me. I have to do the introductions. I have to do the platonic matchmaking at a program. I have to dig and discover their interests and learn. Oh, my gosh, you like Settlers of Catan? So does this guy, right?... That's really where I have the most autonomy in my work with students with disabilities. It's helping them connect.

Darren's description of the role he played in supporting student social connection was something that many of the RDs noted as part of their role, and within their scope of control for all of their residents. Within the context of disability, as Darren noted, the RDs appeared to support students 
with disabilities in manners that were similar to the support they provided all of their residents, but with additional levels of care or attention, if they perceived students to be in need of additional support.

A final aspect of RDs' in-building autonomy involved the freedom that they articulated they had with respect to their decisions. Although they perceived that they had little, if any, influence on larger campus-wide disability issues or initiatives, many RDs described tremendous freedom, with little, if any, oversight regarding the things they did within their buildings. This freedom was most clearly captured by Parker:

In Residence Life we have autonomy over what type of programs we want to run in our buildings. So, could I put on a monthly panel about a different diversity inclusion topic? One hundred percent. And it would definitely not be questioned at all. It'd be like, "Oh, yeah, he's just doing that panel and we trust him to do that panel." And could I do a training with my RAs around like ability or disability? And could it include experiential learning elements? Totally. And I think those are aspects where in terms of programming and training, I don't know if I've ever really run against a place where a supervisor has said, "You can't do that."

Parker's description was consistent with how the majority of the RDs discussed their autonomy within their buildings regarding issues of disability. It was also representative of the aspirational manner in which most of the RDs discussed disability-related programming. Many of the RDs indicated that they had the freedom to host disability-related programs in their communities, and noted that doing so would be beneficial for the community. However, these programmatic examples were rarely rooted in things that the RDs had done. Parker noted that while he had the freedom to run a diversity inclusion series that included disability, it was not something he had 
previously done. In contrast, Lynn described the limitations of campus-wide programming she expected she would encounter if she attempted to hold such an event:

I probably have the most control over my building and the least control over anything outside of my building. I can't do something campus wide unless all of the RDs collaborated. And I think if we did that, then it would stand out that we are trying to do something campus wide, and we'd probably have to talk to someone.

Lynn's description served to further underscore the in-building autonomy described by Parker and other RDs. The perception of additional administrative barriers that would be encountered if one was to program at a campus-wide level invites RDs to view their buildings as space with high degrees of flexibility and autonomy in how they support students with disabilities.

\section{Specialized Knowledge of Disability is Not Needed}

Understandings of the RD position as a generalist role appeared to have a relationship with the ways in which the RDs understood their levels of disability-specific knowledge. The RDs described themselves as having foundational understandings of disability. For many of the RDs, these understandings straddled the medical and social models of disability. The medical model appeared to frame RD considerations of disability accommodation processes. When they discussed what they knew of the accommodation process, they described it as one that was reliant upon medical diagnosis, verification, and documentation, in order to secure accommodations. Alternatively, when the RDs discussed accessibility and inclusion related to residential programming, RA conversations, or other social interactions, they appeared to operate from a standpoint more rooted in a social model of disability. 
Expertise in disability was not the only way in which the RDs viewed themselves as generalists. They saw themselves as generalists relative to a number of specialized roles at their institutions. Elizabeth noted this, explaining:

I tell my students all the time, it's like my tagline in conversations that I have with them, "I'm not the person who has all the answers, but I'm usually the person who can get you to someone who does." I just see myself as this person that takes the chess piece and I'm like, "Okay, you're there." And then I get the other one and I'm like, "You, go over there." Very rarely am I doing the direct service. Unless it's just motivational interviewing or coaching. But I'm not the person with the social work degree, or the person that's the expert in academic planning, or that kind of stuff.

When the RDs discussed their reactive work in supporting students with disabilities, they appeared to engage with a medical model of disability in a way that reinforced their generalist role. They indicated that their referral of students to DS was in part due to specialized knowledge of disability, held by DS administrators, that they did not have as generalists. Carmen shared an example of the way she has described this to students:

I'll say, "So, you can go to the accessibility office, and you can talk to them about that and get an accommodation." And then I usually say, "I don't know a lot, but they are the experts and they know. They can talk to you about your options that maybe will help you manage both your depression and the impact that your depression is having on your schoolwork."

Carmen further elaborated on her role as a generalist, describing what she understood to be some of the risks associated with stepping outside of this role: 
Especially in housing, we try to play these roles that really are not our strengths, or not our training. And that's borderline malpractice. I'm not a therapist, I can't work with you on your depression. And to insinuate that you come to your one-on-one every week, and I'm going to check in on you and your depression and help you manage that is not great. But I think that happens a lot in Residence Life, not maybe with residents, but I think with student staff. I think about that a lot. So I would say I try to help people and I try to give resources, but I'm mostly trying to triage because it's really not an area of expertise, and I want to own that.

Murphy described a similar reaction when receiving disability-related information or materials from students:

A lot of times I'll get an email from a student, and it's a very long email about all their medical or mental health reasons that they need a room change. And what's tricky there is oftentimes that'll happen, and I can't make a decision. I can't say, "Yes, your medical, reason is a good reason to have that accommodation, great." So, once someone discloses that the first thing I'll do is say, "Okay, it sounds like you need to connect with DS. So, that's the first thing that I do. I think oftentimes, students think if they disclose enough to me that they'll get something. I don't want students to have to disclose things to me, because I'm not going be able to get them all the support that they need for that specific disability. That's not my expertise.

Similar to the previous examples, Murphy not only outlined the limits of their positional authority, but also connected those limits to a lack of expertise relative to other administrators on campus. 
Throughout the interviews, the RDs discussed their limited roles in the disability accommodation process, and their referrals to DS offices upon receiving student questions or disclosures. However, as the previous excerpts demonstrate, the RDs also appeared to understand their referrals to DS as consistent with their role as generalists. The RDs took on this generalist role in part due to the nature of their job responsibilities. The 24-hour on-call portion of their role, combined with the live-in nature of close proximity to their RAs and residents appeared to result in the RDs being a first point of contact for students across all manner of issues. In this way, the RD position called them to engage in triage across a broad range of social and academic topics, and route concerns to more specialized campus resources. The RDs acknowledged that they may be well positioned to triage student issues related to disability, but that they do not have the disability-specific expertise appropriate to make decisions related to the provision of accommodations.

\section{Managing Legal Liability by Following Instruction}

The final aspect of this theme involved the role that legal liability appeared to play in RD perspectives on the role as generalists and the varied silos of expertise that exist at their institutions. Many of the RDs referenced disability as a matter that involved legal compliance, and by extension, liability. In conjunction with the other aspects of this theme, the RDs appeared to perceive a legal complexity related to the support of students with disabilities and acknowledge that they lacked specific expertise in this area. These perceptions and acknowledgments are useful in understand the RDs' deferral of disability-related matters to others on campus as a way to manage liability. Gwen described this tendency as she talked about why she views disability as an aspect of her role where she asserts little control or makes few decisions: 
I think that there is a legitimate legal standing [associated with disability]. It is sometimes state level, sometimes federal level. And I don't have an understanding of all of that intimately. So, I think it's less that I don't have autonomy and more just "there be dragons." I don't know how to navigate that part so I don't.

Carmen described a similar outlook:

I think because ability has a legal component to it, I think it is more black and white than other social identities, like racism, or sexism. I think that RDs almost get a pass in terms of ability justice. Of course, we want to put students in accessible buildings so that they have a good experience. Whatever it is that they need. I mean, when I think of people who have gotten housing accommodation approvals through disability services, it is everything from mold to the need for light. So as much as I think those are things that we should be thinking about, and we should want to put people in those buildings or not in those buildings, because it's the right thing to do, we also legally have to do that. And I think that component takes away some of the, I don't want to say the need to think about it, because I think that there still is some need.... But, yeah, because of the legal components, it's kind of like, "Well, we do what they say."

There were numerous instances when the RDs described disagreeing with certain disabilityrelated decisions, or believed that accommodations processes were not meeting the needs of students. However, in most of these instances, the RDs described following instructions, or advocating for students, but only to certain degrees. Their own understandings of their roles as generalists, combined with their understandings of disability-related legal complexity and liability inform the interpretation of these responses. While the RDs may have found themselves in situations where they disagreed with the decisions of DS offices or departmental leadership, 
their acknowledgement of their limited knowledge of the disability-related legal landscape,

coupled with their desires to mitigate risk, invited them to take a deferential stance and carry out the decisions made by others. 


\section{CHAPTER 5: DISCUSSION}

The present study aimed to contribute to the literature on disability in higher education within the context of residence life. A review of the literature on co-curricular college and university experiences revealed a dearth of research surrounding campus housing. While limited research had attended to the experiences of students with disabilities in campus housing, there was an absence of work that explored the ways in which campus housing staff members engage with topics of disability. The present study utilized constructivist grounded theory to explore these experiences in order to address this gap in the research, and contribute to knowledge related to the RD position and notions of disability within campus housing. Through a constructivist grounded theory analysis, four themes emerged. The themes were (1) developing an understanding of the breadth and individualization of disability, (2) addressing disability reactively, (3) tension between stated needs and documentation requirements, (4) questioning accommodations, and (5) generalists operating between silos of expertise. Common across these themes was a dynamic tension regarding matters of disability in which the RDs appeared bound.

Frequently, RD commitments to diversity and social change-focused approaches to disability appeared at odds with their job requirements and institutional responsibilities. Many of the RDs expressed desires to understand and work with issues of disability as matters of diversity. However, the institutional systems within which they operated - and their entry-level positions within those systems - limited their abilities to engage in such work. These institutional systems also appeared to compel the RDs to approach disability as an individual matter, framed by legal liability. The tensions that were uncovered in the previous chapter are more fully explored in this chapter. Following a review of the research questions, this chapter discusses the 
findings, and presents implications for student affairs practice, limitations, and considerations for future research.

\section{Review of Research Questions}

The primary research question for this study was:

- In what ways do RDs from small, private, liberal arts colleges and universities think about and work with issues and concepts of disability in the context of campus housing?

The question was further informed by four sub-questions:

- In what, if any, ways do RDs consider disability identities in their creation and support of their residential communities?

○ In what, if any, ways do RDs consider disability as a component of diversity that intersects with other marginalized identities?

○ In what, if any, ways do RDs work to provide accommodations to residential students with disabilities?

○ In what, if any, ways do RDs support resident assistants in working with students with disabilities?

The findings begin to generate answers to these questions through the themes that emerged. When the previously presented themes are put into conversation with each other, the persistence of tension across the ways in which RDs understand and work with issues and concepts of disability becomes apparent.

\section{Framing Active Tensions Across Identified Themes}

Across the themes, the RDs discussed navigating a number of disability-related issues. Tensions emerged as the RDs found themselves in the middle of individuals and systems that had competing interests, definitions, or values regarding disability. In certain institutional 
contexts, such as the disability accommodation process, the RDs were literally in the middle of various stakeholders or participants. They connected students with disabilities to DS administrators, while they simultaneously managed their own desires to support students beyond the bounds of those very processes. The RDs were also tasked to deliver disability or accommodations-related decisions back to students. In some cases, they were delivering this information without any knowledge of the basis upon which, or by whom, the decisions were made. In other instances, the RDs appeared to be figuratively in the middle, as they navigated their own understandings of how best to think about or respond to disability. They demonstrated multi-layered understandings of disability, as something that was both a legally protected category and an important facet of diversity and student identity.

The ways in which these tensions appeared throughout the themes varied. However, a common element was the presence of tension between a focus on disability at the level of individuals and a focus on disability at the level of systems. Locating and contextualizing this tension is necessary in order to fully consider the implications for RDs and students with disabilities in campus housing.

Based on the emergence of the themes, the social and medical models of disability are valuable in considering the distinct ideological directions in which the RDs were pulled. These models are detailed in the following sections. The models serve as large cultural anchors regarding the ways in which societies think about disability (e.g., Brantlinger, 1997; Ferri, 2008; Kliewer \& Drake, 1998; Siebers, 2013). They permeate societal interactions, beliefs, and ways of understanding related to disability. To the extent that the models serve as ideologies, they are ingrained into cultural interactions such that they not only ground the ways in which disability is understood, but they support such understandings without requiring the full consciousness of 
those operating within them. The RDs in the study did not create these models, and in many instances did not directly reference them. Rather, the RDs engaged in their understandings of disability in ways that were influenced by their personal, political, and social experiences; and the tensions created suggest conflict between multiple disability ideologies.

The RDs experienced tensions in ideological understandings of disability within the context of the RD position. These tensions emerged in the particular ways that they did due to the organizational contexts within which they were set. The RDs navigated their personal understandings of disability alongside their positional responsibilities as entry-level employees within complex institutions of higher education. Organizational structures framed the expectations that RDs had regarding the responsibilities of their positions. These systems informed the ways in which the RDs understood their available options as they navigated organizational policy, procedure, and politics. They understood disability and aimed to support students with disabilities within the organizational frames of their institutions, their residence life departments, and their specific RD positions.

\section{Medical Model of Disability}

The medical model of disability understands disability as personal affliction that requires treatment, or exclusion from society (Straus, 2013). Within this framework, disabilities are understood as individual conditions. They are viewed as abnormalities which, depending on hegemonic society's understanding of their severity, may disqualify individuals from participation in society. Treatment of disability is thus a benevolent aim of the medical model; to remediate deficiencies so as to allow individuals to participate in society. In focusing on treatment, the model elides the fact that society is not built to meet the needs of these individuals. Further, the services that are generated from this standpoint are often provided in restrictive ways 
that are limited in offerings or inferior in quality (Linton, 1998). By framing disability as a matter of individual deviancy, the medical model insulates normate society and its systems of operation from critique (Garland-Thomson, 1997). Focus is placed on individuals who do not fit the social system, as opposed to the system that does not work for all members of society.

The medical model has previously been identified as a prevailing framework through which disability is understood within higher education (e.g., Evan et al., 2017; Lewis, 2017). Medical language appeared throughout the RD descriptions of their work with students with disabilities. Such language appeared with the greatest frequency when the RDs discussed disability accommodation processes. The deployment of this language was not surprising. Accommodation processes, and the legal framework upon which they are built, understand disability and higher education access largely as matters of individual rights. Federal laws protect students with disabilities from discrimination, and afford them equal access to education (Evans et al., 2017). However, in order for students to secure such protection or access they must meet legal definitions as qualified individuals with disabilities (ADA, 1990). These determinations are made on individualized bases and primarily result in solutions that are similarly specific and isolated to the individual student in question.

When the RDs discussed working with students with disabilities, they frequently referenced specific individuals. The RDs described students who disclosed their disabilities to them, or asked them questions about certain accommodations or the accommodation process. The RDs also discussed interacting with students with disabilities while the RDs were on-call; primarily as they responded to mental health emergencies. These interactions were largely explained in terms of medical model language. Further, this language was frequently used to 
identify the boundaries of the RD role or their personal knowledge or expertise regarding definitions, diagnoses, or legal issues related to disability.

The RDs identified their limited technical expertise by naming medical concepts of disability, and their inability to do things, such as make determinations about whether students had disabilities. They explained this as they noted the importance of referring students to the offices or administrators who had more expertise in these areas. As Cathryn stated, "If [disability] comes up and on my end I just send the student somewhere else. I'm nice to them and talk to them and I refer them to someone who knows more than I do." Legal liability, limited technical expertise, and minimal institutional agency were elements that emerged from the RDs that are informed by deploying a medical model of disability framework in understanding issues and concepts of disability in the campus housing environment.

\section{Social Model of Disability}

In contrast to the medical model, the social model of disability engages disability at the level of societies, rather than the level of individuals (Shakespeare, 2013). The social model contends that individuals may have impairments, but posits that it is the interactions between societies and systems that disable individuals through the creation and maintenance of exclusionary structures. An example of this framework appeared among the RDs as they discussed their responsibilities for managing older multi-floor residence halls that lack elevators. They acknowledged that the halls were built at a time when higher education did not consider individuals with mobility impairments among the potential students who would be enrolling and living in these buildings. As a result, the buildings have disabling effects on students who are unable to fully access the spaces in ways similar to their peers. 
In addition to understanding the location or cause of disability, the social model also differs from the medical model in the solutions that it suggests. While medical model solutions target individual students, social model solutions focus on broader changes to systems of interaction or operation (Guzman \& Balcazar, 2010; Hadley \& Archer, 2017). When applied to the example of an inaccessible residence hall, a traditional medical model would ask how an individual with a mobility impairment can be provided equal access to the building, or to a comparable building. Meanwhile, the social model would ask how the entire building can be made accessible to all individuals, including those with mobility impairments. Further, the social model asks these questions through a broader consideration of the ways in which the building might be used and experienced. Several RDs lamented the impacts of inaccessible buildings on students' families. They expressed concerns that some students have less-positive experiences during the move-in process because members of their families who bring them to college are unable to see their rooms, or help them move in. A legal compliance framework does not require that institutions provide full access for family members in these circumstances. In contrast, the wide view of a social model lens allows for a consideration of the broader societal benefits and experiences that may come from supporting the full participation of these family members.

The social model was also present in the RDs' discussions of Universal Design. Many of the RDs referenced Universal Design as one way to think about both the physical and social spaces within their communities. The RDs articulated an awareness of the benefits of systems that are structured for maximum access and flexibility of use. They described their understandings of Universal Design in ways that were consistent with a social model framing of disability; moving beyond legal compliance to facilitate as much access for as many students as possible. 
It is important to note that the social model of disability has also been critiqued, particularly for furthering an oversimplistic consideration of disability in a manner that otherwise presumes dominant identities (Shakespeare, 2013). The emergence of DisCrit in response to these critiques has established an important perspective in which disability is considered at the intersection of race, gender, religion, and other identities that shape both individual and social expectations, understandings, and experiences (e.g., Annama et al., 2018; Mendoza et al., 2016). For the purposes of the present discussion, the contributions that DisCrit provides are crucial in understanding the tensions that the RDs experienced.

The RDs spoke extensively about their commitments to social justice, and their desires to approach community-building in ways that did not treat singular identities as monoliths or in isolation. In considering the tensions that emerged from the themes, greater friction appeared between the medical model and social model - inclusive of DisCrit theory, than between the social model and critical disability theories. It is for this reason that the social model was identified in this section as a primary ideology, positioned in contrast to the medical model. However, the principles of DisCrit, and similar critical approaches that regard disability as an element of diversity, are vital to a rich consideration of the tensions found across the themes that emerged from the RDs.

\section{Systems and Structures of Student Affairs in Higher Education}

In addition to the medical and social models of disability as ideologies that framed the tensions that appeared in the themes, the context of these tensions must also be considered. The RDs in this study worked at small and medium private colleges and universities that were rooted in liberal arts traditions. The RDs also overwhelmingly had graduate preparation in higher education administration. Within higher education, institutional cultures vary considerably. Even 
between institutions that appear similar in size, student makeup, or stated mission, differences in institutional culture may be substantial. Despite these differences, there are aspects of structure, operation, and leadership that are common within campus housing and student affairs. These structural commonalities provide a context within which the RDs experiences and understandings should be considered.

While there are examples of college or university organizational structures that are flat and interconnected, the prevailing models in student affairs are hierarchical and vertical in nature (Keeling et al., 2007; Keezar, 2012; Kuk \& Banning, 2009). Within offices, organizational charts commonly distribute decision-making authority through vertical reporting lines. Student-facing functions are typically carried out by those in entry-level positions, while larger policy or budgetary decisions are made at director, dean, and/or vice president levels. As decisions are made at upper levels of organizational charts, directions are provided and actions are carried out at lower levels. The RDs provided examples of these types of organizational structures as they discussed receiving instructions about policy implementation. Several RDs described receiving policy-related instructions without any prior opportunity for input. Further, in some instances, they described not having any direct knowledge of which institutional leaders were involved in arriving at the policy decisions in question. The RDs were tasked to implement policies, or report decisions to students, without knowing how, or in some cases why, these decisions were made.

The vertical organization and decision-making also leaves many functional area-specific decisions to be made at departmental levels. Although the RDs discussed having little autonomy or decision-making power in larger institutional decisions, they also explained that they have high degrees of control, and little oversight, with respect to the daily operations of their residential communities. These observations are consistent with vertical leadership structures in 
which institution-level decisions are made by those at the top of the organizational chart, and are carried out through the daily operations that entry-level employees are tasked to manage. The entry-level employees are provided the autonomy to make decisions specific to their functional areas, and tasked to do so in ways that are consistent with the larger institutional mission, vision, policies, and priorities.

In addition to hierarchical organization, the vertical nature of differentiated student affairs offices also tends towards high degrees of specialization. In these systems, different student affairs offices provide specific services to students, and students navigate campus from one office to another in order to have all of their differentiated needs met (Ousley, 2006). Campus housing and DS are both examples of such offices. Overwhelmingly, the RDs spoke of little if any collaborative efforts between their office and the DS office on their campus. Such descriptions were consistent with previous studies that noted a similar dearth of interdepartmental collaboration (Vaccaro \& Kimball, 2019). Within student affairs these individual functional areas often have their own professional associations that are devoted to development and knowledge-sharing related to particular services or supports. Most pertinent to the present study, are the professional associations for campus housing (Association of College and University Housing Officers - International, n.d.) and DS (Association on Higher Education and Disability, n.d.). These areas of specialization, and the professional development support systems that are associated with them, underscore the technical work that the RDs referenced throughout the study. However, critiques of these models have pointed to the silo-ing effects of specialization as a potential impediment to cross-campus collaboration (Keeling et al., 2007). 


\section{Tensions of Community and Diversity}

The themes that emerged in this study uncover a number of tensions when they are examined by applying the medical and social models of disability. Many of the job responsibilities that the RDs discussed related to medical model-oriented disability accommodations and service provision. However, the RDs simultaneously discussed their responsibilities for the care of their communities and the creation of inclusive spaces. Particularly when describing community-building efforts in their residence halls, the RDs articulated strong commitments to issues of diversity and inclusion that highlighted key aspects of a social model of disability. The RDs frequently spoke about the importance of making hall events accessible. They noted that it was important to do this proactively, because they were not always aware of who might attend a program or what specific supports might be needed. Unlike their discussions of disability accommodations, which primarily involved specific knowledge of individual students, the community-focused discussions involved consideration of unknown disability; they aimed for the support of communities in ways that were designed to be preemptively inclusive, rather than reactively accommodating.

The presence of social model thinking around disability is consistent with the professional backgrounds of the RDs as student affairs administrators. One of the focuses of student affairs and graduate programs in higher education administration over the past decade has been on efforts in inclusion, equity, and social justice. These efforts have been identified by professional organizations (e.g., Eanes \& Perillo, 2015) and many graduate programs have devoted coursework to this area (e.g., Claremont Graduate University, 2021; Lewis and Clark, 2021; Oregon State University, 2021). The social model of disability is consistent with a social 
justice orientation to students' identities, and therefore well aligned with recent areas of emphasis within student affairs.

The RDs described thinking through aspects of disability in ways that were similar to their thinking regarding other marginalized identities. Jessica discussed the importance of supporting knowledge development and awareness-raising across the residential community as a way of supporting students with disabilities:

Addressing the stigma that just because someone is in a wheelchair, that they need your help.... Bringing that awareness, and for students to be educated. People come from all different backgrounds, especially their first year and I house first year students. They may come from a background where they've never seen anyone in a wheelchair. They don't know how to react.... So, making sure people know that you don't just go and push somebody - you don't put your hands on their wheelchair. It's creating that space for students who identify, or who decide to share, their experience or their story - so that people will listen, and respect.

Several RDs also identified experiences that they had related to other marginalized identities as central to their thinking around disability. Darren described seeking out intersectional lectures, as a way to apply a familiar lens of feminism to issues of disability:

I have attended some like lectures on campus from a faculty member who works in our Women's and Gender Studies program. And she talks about the intersection of feminism and disability. And so that felt like a very approachable way for me to learn more about that topic because I could already kind of understand the perspective through feminism. The RDs described working within departments and institutions that did not position disability as an aspect of diversity similar to other identities, such as race, ethnicity, gender, or sexuality. 
However, the RDs did appear to think about disability in this way, and demonstrated a familiarity with ideas consistent with a social model of disability in doing so.

Tensions are visible around this thinking, however, when contrasted with the RDs discussions and understandings that focused on disability accommodations. While their student affairs graduate preparation may have equipped them to engage topics of diversity, research has suggested that specific training related to disability continues to be lacking in these programs (Vaccaro \& Kimball, 2017). The absence of disability-specific training was raised by many of the RDs. They also suggested that it was an area for improvement at both personal and departmental levels. It thus appears that the RDs found themselves in the middle of legallyminded individualized accommodations processes, for which the RDs received little training and over which they were quick to cede responsibility, and broader community understandings of disability as an aspect of diversity. They appeared to be more prepared to understand disability as an element of diversity at the level of the community, but were limited by their training, and the systems within which they operate, in their application of these principles to their support of specific students with disabilities.

\section{Tensions of Individualization}

Another source of tension across the themes appeared to be driven by the nature of the RD role and responsibilities. Specifically, various aspects of their role straddled different approaches to understanding disability, as well as other identities. The RDs described the nature

of campus housing as work that was in some ways quite customer service-oriented. The notion of customer service may not readily appear aligned with any particular approach to disability. However, to the extent that customer service is rooted largely within individualized experiences, 
it may be more consistent with an individualized medical model consideration of disability, as opposed to one focused on social constructs.

Within their positions, the RDs were simultaneously tasked to approach disability in rigid, individualized, legalistic ways, as well as in social justice-minded ways. As previously discussed, the social-justice minded ways appeared more closely associated with community building and support, while the individualized ways were connected with the facilitation of DS accommodations processes. The RDs were bound by accommodations process limitations regarding when and what could be provided to students with disabilities. Given the positions from which they operated, they perceived their authority to be limited, particularly when they were instructed to do something with which they disagreed. Meanwhile, they were committed to supporting RAs and communities in ways that were inclusive. They supported the programmatic elements of their residential communities in ways that furthered inclusion; at times separate from the needs of any particular student.

The RDs valued a social model approach to disability, but perceived themselves to be limited in the extent to which they could make decisions that would further inclusion for all of their residents. They perceived that disability inclusion was not a high institutional priority, while indicating that they had very little agency in setting these priorities. All the while, they interacted with individual students with disabilities in ways that informed their broader understandings of disability identity. While they may have gone into these interactions tasked with legal compliance and accommodations process referral, the cumulative impact of these experiences appeared to support the RDs in their abilities to dispel their own previously held disability stereotypes. Through the individualized nature of their interactions with students, they learned from students about the intersectional impacts of marginalizing systems. They engaged 
in these exchanges with students with prior awareness of issues of diversity and social justice, and heard from students about the ways that their multiply marginalized identities created barriers for them in disability accommodations processes. Tensions were created within the RDs, as they came away from individual interactions with insights they might apply across their communities, but in ways that were limited by the medical model frameworks of the systems within which they function.

\section{Tensions of Residence Life Learning Outcomes}

A common sentiment among the RDs was a desire to take students at their word with respect to their disability-related needs. The RDs' interest in doing so was itself in tension with departmental procedures related to disability accommodations processes. The tension the RDs described was undergirded by legal requirements and associated liabilities. The RDs recognized individual student circumstances and articulated equity concerns on the basis of those circumstances. They elaborated on particular concerns regarding intersectional identities and limited resource access for multiply marginalized students with disabilities. Bearing these concerns in mind, they expressed desires to at times forego legally-driven procedure and associated bureaucratic red tape in order to provide students with what the students stated they needed. The RDs were limited, however, in their abilities to act upon these desires, by the systems within which they worked. Both the limited authority of their position and the concern of legal compliance emerged as factors they weighed in these decisions.

However, the departments or institutions within which the RDs worked were not the only sources of tension surrounding the desire to take students at their word. Taking students at their word also involved tensions in differences across RD understandings of students' requests. RD questions regarding the legitimacy of a disability or concerns surrounding the ways in which 
accommodations requests intersected with the educational or developmental goals and objectives of their residence life departments created internal conflict for the RDs. Tension appeared particularly when students' requests had implications for educational elements of the residential experience. The RDs questioned students' disability-related needs that were connected to core elements of campus living - such as navigating a difficult or uncomfortable roommate conversation. They took similar positions when considering what adjustments to the required components of the RA position description could, or could not, be made for RAs with disabilities.

The tensions that emerged surrounding the nature of accommodations requests and the perceived legitimacy of student disabilities may have in part been connected to the RDs understandings of the learning outcomes of their campus housing departments. Keeling et al. (2007) suggested that one of the organizational challenges faced by student affairs divisions is their struggle to codify and demonstrate their educational value. Astin (2016) similarly suggested that within the United States, the perceived value of the educational experience - including the cocurricular components - has come under increased scrutiny in recent decades. The legal requirements related to disability accommodations do not compel institutions to provide accommodations that would fundamentally alter the nature of their education programs (Rothstein, 2015). However, Astin (2016) noted that many of the cocurricular elements of higher education do not have clearly articulated educational objectives or outcomes. The RDs appeared to raise concerns about the possibility of residential learning outcomes being fundamentally altered by certain DS accommodations. However, the absence of communication and collaboration between the RDs and their DS colleagues served as a barrier to such an outcome. Instead, it appeared that the RDs were isolated from the accommodations decisions that were 
being made relative to the residential experiences that they were tasked to manage. Such circumstances put the RDs in positions wherein they wanted to support students with disabilities, particularly when they believed they could provide something that a student needed. Yet, they were skeptical of certain accommodations, especially those that impacted what they understood to be beneficial outcomes of the campus housing experience. In both instances, the RDs seemed to arrive at these beliefs based more on their interactions with students, rather than on information from, or collaboration with, their DS offices.

\section{The Medical-Social Continuum}

Of final note, the social model and medical model of disability did not emerge in ways that supported an understanding of individual RDs as primarily reliant upon one model over the other. Rather, the RDs consistently demonstrated a utilization of both models simultaneously. As the RDs discussed navigating DS offices and accommodations processes, the medical model was generally more visible in their responses. The relationship between these aspects appeared to be driven by the individualized nature of the medical model, and of aspects of the themes that involved accommodations, areas of expertise, legal implications, and entry-level positional authority. Meanwhile, as the RDs described their support of their residential communities, or of notions of disability within their communities of which they were unaware, the social model was more readily apparent.

Despite many of the tensions in this discussion being framed as matters of conflicting positions, the ways in which they appeared in the RD understandings and experiences of disability were not dualistic. Individual RDs did not engage the topic of disability solely through a medical or a social model of disability. Rather, they described their thoughts and interactions in ways that demonstrated a range of experiences across a spectrum. Similarly, the tensions that the 
RDs experienced in their understandings of disability, their available resources and responses, the ways in which they questioned students and systems, and their roles within their institutions, were not ones that appeared only on the poles of disability continuums. Rather, the RDs articulated perspectives that were reflective of being in the middle of these continuums. The individual and the social were intermingled and bumped into each other within and across RDs notions of disability. Jessica provided an example of this, as she articulated a desire for individual student disability information, which she wanted in order to consider how best to support her larger residential community:

So, you know, we celebrated pride. My RAs were like, "I have seven residents who have said that they identify in the LGBT community, and I want them to have a safe space." We cater to our residents. So I think having this knowledge, I want to be able to let my RAs know, "Here's all these different things that that are going on." From breast cancer to autism. Just having that information. We have passive programs on bulletin boards. So maybe one month, I could have done some type of program, depending on what it was. Like, if it was autism, maybe we focus on something like that. Because the more the more people are educated, the more they're able to be aware.

Jessica's response simultaneously articulated a desire to engage in social-level education; a desire to develop community awareness at a systems-level in a way that would support students with disabilities. However, it was rooted in a desire to connect this to specific individuals within the community who would benefit from this type of community education. Implicit in this notion was that such awareness raising would not be necessary if there were not students with disabilities present in the community. The attachment to an individual focus created a tension that may have prevented a more robust socially-minded understanding of disability. 


\section{Limitations}

There were multiple limitations identified in this study. One involved participant selection, and another involved the context of the data collection. The RDs who were identified as possible study participants worked at colleges and universities on the West Coast of the United States. The institutions were also private, primarily residential, small and medium in size, and rooted in liberal arts traditions. While these criteria narrowed the scope of the study, there were other institutional characteristics for which the study was not controlled. Religious affiliation was one of these characteristics. Several RDs spoke about their understandings of disability through a religious lens in a way that was impacted by working at institutions with strong religion affiliations. Additionally, there was limited racial diversity among the RDs, and the study did not include any RDs from an Historically Black College or University. Lastly, RDs opted into the study, leaving the possibility that those who elected not to respond to the recruitment emails did so because of differently held understandings of disability than what emerged from the participants.

In addition to institution type and RD diversity, recruitment and interviews occurred during the summer and fall of 2020 - in the midst of the coronavirus pandemic, and in the wake of national response to the murder of George Floyd. The adjustments that colleges and universities made to address the pandemic impacted the experiences that RDs had with their residents. Large scale social programs could not happen, and students were experiencing higher reported rates of mental health concerns (Boettcher, 2020; Brown \& Kafka, 2020). At many institutions students were isolated in single occupancy residence hall rooms, with limited opportunity for traditional socializing and community building. These factors may have invited the RDs to focus on student mental health as an element of disability to a greater degree than 
they would have under different conditions. Likewise, when discussing disability as an element of diversity, many of the RDs framed diversity as connected to, or primarily a matter of, racial diversity. They cited the killing of George Floyd and the national reaction as a prevailing factor in this understanding. The RDs articulated their understandings of intersectional disability in ways that they explicitly connected to larger dialogues on race. For some RDs, these dialogues underscored the need to consider disability as intersectional. For other RDs, the national dialogues on race were a reason to place less emphasis on issues of disability in the present moment. The RDs varied greatly in the degrees to which they engaged disability as intersectional. However, across this variation was a clear connection to national conversations regarding race, specifically Blackness, in the United States. It is likely that RD understandings of mental health and intersectional disability may have emerged from the data differently, had data collection taken place under a different set of recent national events.

\section{Implications}

The implications of this study primarily involve the support of RDs in their work with issues and concepts of disability. The RDs frequently held personal understandings of disability that approached disability as an element of diversity, and were more inclusion-oriented, as compared to their perceptions of the systems of disability across the institutions at which they worked. These tensions have direct implications for how the RD position is understood, with respect to concepts and issues of disability. Tensions across the themes that emerged suggest that those who supervise RDs need to be aware of the various ways in which issues of disability conflict in the daily work of RDs. The directors or assistant directors of campus housing offices who supervise RDs may themselves not necessarily be in positions of institutional authority to resolve these tensions. However, an awareness of them would allow supervisors to provide 
intentional support and development opportunities to the RDs related to their understandings of disability and their positional responsibilities. Such an awareness may also equip campus housing leadership to better articulate the need for a prioritization of collaboration between campus housing and DS offices.

Another implication that arises from the persistence of tensions across the themes relates to the ubiquitous nature of conflicting notions of disability within higher education. Tensions were identified across many levels in this study. They were found both within and between individuals, offices, departments, communities, and institutions. The tensions that the RDs experienced were connected to their campus housing environments. However, the interactions of these tensions with DS offices, faculty, or institutional leadership support the existence of similar incongruities across numerous contexts within higher education. For example, the tension between individualized accommodations and broad accessibility-focused systems change appears at the core of research related to Universal Design in higher education classrooms (e.g., Black et al., 2015; Fornauf \& Erickson, 2020; Johnstone \& Edwards, 2020).

The RDs in this study experienced conflicts in their work related to differing disability ideologies. These ideological differences appeared across the various contexts within which the RDs worked. Therefore, while research into specific positional knowledge, attitudes, or actions may lead to suggestions for ongoing training and support, this study also serves to temper the expectations that should be paired with such recommendations. The tensions uncovered in this study are a reminder that higher education was not originally designed with the inclusion of students with disabilities in mind. The resulting staff experiences and conflicting understandings that emerge as they support these students are unlikely to be resolved solely through individual or departmental professional development, training, or collaboration. Long term, institutional 
shifts will be required in order to achieve the type of inclusion imagined by proponents of critical social and intersectional models of disability.

\section{Recommendations for Future Research}

Limited research exists on the ways in which campus housing administrators in higher education think about and support students with disabilities. The present study has contributed to this gap by beginning to generate emergent themes in this area. Preliminarily, these themes are marked by tensions that exist and are navigated by campus housing administrators. However, this is a nascent analysis. Additional research is needed in order to add analytical depth to the experiences and understandings of campus housing administrators regarding issues of disability.

The present study focused on small and medium private colleges and universities on the West Coast of the United States. Additional research involving RDs at public institutions, large institutions, or professionally-focused colleges and universities would aid in understanding whether relationships exist between RD understandings and perspectives and institutional types. Simultaneously, such relationships should also be explored through a narrowing of institutional criteria. As previously discussed as a limitation of the study, institutional criteria and categories are numerous; those selected for this study still left for a great deal of institutional variety among the colleges and universities from which the RDs drew their experiences. As a result, future research that focuses on additional criteria may bring greater nuance to understandings of RD notions of disability.

Based on the findings of this study, two institutional criteria may be of particular interest for future research. These criteria are institutional religious affiliation, and percentage of high financial need students. Multiple RDs in this study worked at institutions with strong religious affiliations. These RDs spoke about their own religious perspectives of disability. They also 
discussed the ways in which these perspectives were similar to larger departmental or campus religious beliefs and the influences of these beliefs on broader campus conversations about disability. Future research that explores institutional and personal religious affiliation and disability may lead to increased support for students with disabilities at these institutions. Similarly, many of the RDs discussed concerns regarding student access to the documentation necessary to obtain disability accommodations. Frequently, the RDs framed this access concern as one of socio-economic status and financial means. Meanwhile, they expressed frustration that students with substantial financial means were potentially able to purchase documentation with far less difficulty. There are a number of factors to be researched at this intersection of disability, documentation, and RD concern. One future approach may include research that explores RD understandings of disability across institutions with varied levels of student financial need.

\section{Conclusion}

Understanding the ways in which student affairs staff think about and work with concepts of disability is vital to overall efforts to support students with disabilities in higher education. On the basis of these understandings, institutional and departmental leadership may better engage their student-facing administrators in furthering inclusive practices related to disability and in approaching disability as an aspect of diversity. The present study sought to contribute to this research by exploring the ways in which RDs think about and work with issues and concepts of disability in their roles as campus housing administrators. Following a constructivist grounded theory methodology, the study analyzed interviews from 32 RDs. The analysis resulted in the emergence of five themes. The preliminary themes suggested: (1) that RDs developed greater understandings of the breadth of disability through their personal experiences; (2) that they worked with and conceived of disability in largely reactive ways; (3) that they experienced 
conflict between the stated needs of students with disabilities and institutional accommodations processes; (4) that they questioned disability accommodations in ways that were simultaneously critical of both students and institutional systems; and (5) that their work with students with disabilities was limited by their roles as generalists who referred students to campus disability experts.

Across the five themes an element of tension was identified. The RDs appeared to understand concepts of disability that were in dynamic tension with each other. The RDs also worked with tension across what they perceived at times to be the competing interests of the institutions by whom they were employed, and the students in their residential communities they aimed to support. These findings are limited to the specific RDs involved in the study. However, the tensions identified are valuable in supporting additional research in this area. A greater understanding of the ways in which disability is understood among RDs will allow for campus housing departments to better equip the administrators responsible for providing service and support to students with disabilities in campus housing. 


\section{REFERENCES}

Abes, E. S., \& Wallace, M. M. (2018). "People see me, but they don't see me": An intersectional study of college students with physical disabilities. Journal of College Student Development, 59(5), 545-562. https://doi.org/10.1353/csd.2018.0052

Abes, E. S., \& Wallace, M. M. (2020). Using crip theory to reimagine student development theory as disability justice. Journal of College Student Development, 61(5), 574-592. https://doi.org/ 10.1353/csd.2020.0056

Americans With Disabilities Act of 1990, 42 U.S.C. $§ 12101$ et seq. (1990). https://www.ada.gov/pubs/adastatute08.htm

Annamma, S. A. (2015). "It was just like a piece of gum": Using an intersectional approach to understand criminalizing young women of color with disabilities in the school-to-prison pipeline. In D. J. Connor, J. W. Valle, \& C. Hale (Eds.), Practicing disability studies in education: Acting toward social change (pp. 83-102). Peter Lang.

Annamma, S. A., Ferri, B. A., \& Connor, D. J. (2018). Disability Critical Race Theory: Exploring the intersectional lineage, emergence, and potential futures of DisCrit in education. Review of Research in Education, 42, 46-71. https://doi.org/10.3102/0091732X18759041

Annamma, S. A., \& Handy, T. (2019). DisCrit solidarity as curriculum studies and transformative praxis. Curriculum Inquiry, 49(4), 442-463. https://doi.org/10.1080/03626784.2019.1665456

Anderson, C., \& Butt, C. (2017). Young adults on the autism spectrum at college: Successes and stumbling blocks. Journal of Autism and Developmental Disorders, 47, 3029-3039. https://doi.org/10.1007/s10803-017-3218-x 
Anderson, A. H., Carter, M., \& Stephenson, J. (2018). Perspectives of university students with autism spectrum disorder. Journal of Autism and Developmental Disorders, 48, 651-665. https://doi.org/10.1007/s10803-017-3257-3

Aquino, K. C., \& Bittinger, J. D. (2019). The self-(un)identification of disability in higher education. Journal of Postsecondary Education and Disability, 32(1), 5-19. https://files.eric.ed.gov/fulltext/EJ1217454.pdf

Ashbaugh, K., Koegel, R. L., \& Koegel, L. K. (2017). Increasing social integration for college students with autism spectrum disorder. Behavioral Development Bulletin, 22(1), 183196. https://doi.org/10.1037/bdb0000057

Association of College and University Housing Officers - International. (n.d.). Regional associations. https://www.acuho-i.org/partners/regions

Association on Higher Education and Disability. (n.d.). Home. https://www.ahead.org/home

Astin, A. W. (1977). Four critical years: Effects of college on beliefs, attitudes, and knowledge. Jossey-Bass Publishers.

Astin, A. W. (2016). Are you smart enough? How colleges' obsession with smartness shortchanges students. Stylus.

Barnard-Brack, L., Lechtenberger, D., \& Lan, W. Y. (2010). Accommodation strategies of college students with disabilities. Qualitative Report, 15(2), 411-429. https://eric.ed.gov/?id=EJ875262

Barnhill, G. P. (2016). Supporting students with Asperger syndrome on college campuses: Current practices. Focus on Autism and Other Developmental Disabilities, 31(1), 3-15. https://doi.org/10.1177/1088357614523121 
Barragan, E., \& Nusbaum, E. A. (2017). Perceptions of disability on a post-secondary campus: Implications for oppression and human love. In S. L. Kerschbaum, L. T. Eisenman, \& J. M. Jones (Eds.), Negotiation disability: Disclosure and higher education (pp. 39-55). University of Michigan Press.

Bauman, M., Davidson, D. L., Sachs, M. C., \& Kotarski, T. (2013). Service, comfort, or emotional support? The evolution of disability law and campus housing. Journal of College \& University Student Housing, 40(1), 142-157.

https://www.nxtbook.com/nxtbooks/acuho/journal_vol39no2/index.php\#/p/142

Beilke, J. R., \& Yssel, N. (1999). The chilly climate for students with disabilities in higher education. College Student Journal, 33(3), 364. https://link.gale.com/apps/doc/A62839444/AONE?u=oregon_oweb\&sid=googleScholar $\& \mathrm{xid}=05 \mathrm{df} 3 \mathrm{c} 09$

Belch, H. A., \& Marshak, L. E. (2006). Critical incidents involving students with psychiatric disabilities: The gap between state of the art and campus practice. NASPA Journal, 43(3), 464-483. https://doi.org/10.2202/1949-6605.1679

Belch, H. A., \& Mueller, J. A. (2003). Candidate pools or puddles: Challenges and trends in the recruitment and hiring of resident directors. Journal of College Student Development, 44(1), 29-46. https://doi.org/10.1353/csd.2003.0001

Berg, S. A., \& Brown, C. G. (2019). An examination of the supervision and job satisfaction factors of residence directors and resident assistants. The Journal of College and University Student Housing, 46(1), 30-45. https://www.nxtbook.com/nxtbooks/acuho/journal_vol46no1/index.php\#/p/29 
Berger, J. B., \& Milem, J. F. (1999). The role of student involvement and perceptions of integration in a causal model of student persistence. Research in Higher Education, 40(6), 641-664. https://link.springer.com/content/pdf/10.1023/A:1018708813711.pdf

Bialka, C. S., Morro, D., Brown, K., \& Hannah, G. (2017). Breaking barriers and building bridges: Understanding how a student organization attends to the social integration of college students with disabilities. Journal of Postsecondary Education and Disability, 30(2), 157-172. https://files.eric.ed.gov/fulltext/EJ1153574.pdf

Birks, M., \& Mills, J. (2012). Grounded theory: A practical guide. Sage Publications.

Birks, M., Chapman, Y., \& Francis, K. (2008). Memoing in qualitative research: Probing data and processes. Journal of Research in Nursing, 13(1), 68-73. https://doi.org/10.1177/1744987107081254

Black, R. D., Weinberg, L. A., \& Brodwin, M. G. (2014). Universal Design for Instruction and Learning: A pilot study of faculty instructional methods and attitudes related to students with disabilities in higher education. Exceptionality Education International, 24(1), 4864. https://ir.lib.uwo.ca/eei/vol24/iss 1/5

Black, R. D., Weinberg, L. A., \& Brodwin, M. G. (2015). Universal Design for Learning and Instruction: Perspectives of students with disabilities in higher education. Exceptionality Education International, 25(2), 1-26. http://ir.lib.uwo.ca/eei/vol25/iss2/2/

Boettcher, M. L. (2020, August 11). When home is where work is. Inside Higher Ed. https://www.insidehighered.com/views/2020/08/11/residence-hall-staff-are-experiencingmore-work-and-stress-colleges-reopen-opinion 
Bolt, S. E., Decker, D. M., Lloyd, M., \& Morlock, L. (2011). Students' perceptions of accommodations in high school and college. Career Development for Exceptional Individuals, 34(3), 165-175. https://doi.org/10.1177/0885728811415098

Bowen, G. A. (2006). Grounded theory and sensitizing concepts. International Journal of Qualitative Methods, 5(3), 12-23. https://doi.org/10.1177\%2F160940690600500304

Brantlinger, E. (1997). Using ideology: Cases of nonrecognition of the politics of research and practice in education. Review of Educational Research, 67(4), 425-459. https://doi.org/10.3102/00346543067004425

Brown, N., \& Leigh, J. (2018). Ableism in academia: Where are the disabled and ill academics? Disability \& Society, 33(6), 985-989. https://doi.org/10.1080/09687599.2018.1455627

Brown, S., \& Kafka, A. C. (2020, May 11). Covid-19 has worsened the student mental-health crisis. Can resilience training fix it? The Chronicle of Higher Education. https://www.chronicle.com/article/covid-19-has-worsened-the-student-mental-healthcrisis-can-resilience-training-fix-it/

Bryant, A., \& Charmaz, K. (2007). Grounded theory in historical perspective: An epistemological account. In A. Bryant \& K. Charmaz (Eds.), The SAGE handbook of grounded theory (pp. 31-57). Sage Publications.

Burgstahler, S., \& Moore, E. (2009). Making student services welcoming and accessible through accommodations and universal design. Journal of Postsecondary Education and Disability, 21(3), 155-174. https://files.eric.ed.gov/fulltext/EJ831433.pdf

Burgstahler, S., \& Russo-Gleicher, R. J. (2015). Applying universal design to address the needs of postsecondary students on the autism spectrum. Journal of Postsecondary Education and Disability, 28(2), 199-212. https://files.eric.ed.gov/fulltext/EJ1074670.pdf 
Camarena, P. M., \& Sarigiani, P. A. (2009). Postsecondary educational aspirations of highfunctioning adolescents with autism spectrum disorders and their parents. Focus on Autism and Other Developmental Disabilities, 24(2), 115-128. https://doi.org/10.1177/1088357609332675

Carlson, S., \& Friga, P. N. (2020, June 2). 'This is an existential time for higher ed': An interview with Gordon Gee. The Chronicle of Higher Education. https://www.chronicle.com/article/This-Is-an-Existential-Time/248907?cid=cp275 Carnegie Classification of Institutions of Higher Education. (2018). 2018 update: Facts \& figures. Center for Postsecondary Research. https://carnegieclassifications.iu.edu/downloads/CCIHE2018-FactsFigures.pdf

Carter, A. M., Catania, R. T., Schmitt, S., \& Swenson, A. (2017). Bodyminds like ours: An autoethnographic analysis of graduate school, disability, and the politics of disclosure. In S. L. Kerschbaum, L. T. Eisenman, \& J. M. Jones (Eds.), Negotiating disability: Disclosure and higher education (pp. 95-113). University of Michigan Press.

Cawthon, S. W., \& Cole, E. V. (2010). Postsecondary students who have a learning disability: Student perspectives on accommodations access and obstacles. Journal of Postsecondary Education and Disability, 23(2), 112-128. https://files.eric.ed.gov/fulltext/EJ906696.pdf

Charmaz, K. (2008). Grounded theory as an emergent method. In S. N. Hesse-Biber, \& P. Leavy (Eds.), Handbook of emergent methods (pp. 155-172). The Guilford Press.

Charmaz, K. (2014). Constructing grounded theory (2nd ed.). Sage Publications. Claremont Graduate University School of Educational Studies. (2021). Student affairs \& educational justice: MA in Education. Retrieved October 15, 2021, from https://www.cgu.edu/academics/program/student-affairs-educational-justice/ 
Colclough, M. N. (2017). Exploring the social experiences of college students who have autism spectrum disorders. Journal of Student Affairs, 26, 21-32. https://sahe.colostate.edu/wpcontent/uploads/sites/10/2017/04/csu304611-SAHE-journal-2017-www.pdf\#page=22

Corbin, J. (2009). Taking an analytic journey. In J. M. Morse, P. N. Stern, J. Corbin, B. Bowers, K. Charmaz, \& A. E. Clarke (Eds.), Developing grounded theory: The second generation (pp. 35-54). Routledge.

Council for the Advancement of Standards in Higher Education. (2015). Housing and residential life programs (pp. 288-300). In CAS professional standards for higher education (9th ed.).

Cox, B. E., Thompson, K., Anderson, A., Mintz, A., Locks, T., Morgan, L., Edelstein, J., \& Wolz, A. (2017). College experiences for students with autism spectrum disorder: Personal identity, public disclosure, and institutional support. Journal of College Student Development, 58(1), 71-87. https://doi.org/10.1353/csd.2017.0004

Crenshaw, K. (1989). Demarginalizing the intersection of race and sex: A black feminist critique of antidiscrimination doctrine, feminist theory, and antiracist politics. University of Chicago Legal Forum, 139-168.

https://heinonline.org/HOL/P?h=hein.journals/uchclf1989\&i=143

Cullen, J. A. (2015). The needs of college students with autism spectrum disorders and Asperger's syndrome. Journal of Postsecondary Education and Disability, 28(1), 89-101. https://files.eric.ed.gov/fulltext/EJ1066322.pdf

DaDeppo, L. M. (2009). Integration factors related to the academic success and intent to persist of college students with learning disabilities. Learning Disabilities Research \& Practice, 24(3), 122-131. https://doi.org/10.1111/j.1540-5826.2009.00286.x 
Davidson, D. L., \& Bauman, M. (2013). Addressing the needs of residential students with disabilities. The Journal of College and University Student Housing, 40(1), 136-140. https://www.nxtbook.com/nxtbooks/acuho/journal_vol39no2/index.php\#/p/136

Davis, L. J. (2013). Introduction: Disability, normality, and power. In L. Davis (Ed.), The disability studies reader (4th ed., pp. 1-14). Routledge.

Denhart, H. (2008). Deconstructing barriers: Perceptions of students labeled with learning disabilities in higher education. Journal of Learning Disabilities, 41(6), 483-497. https://doi.org/10.1177/0022219408321151

Dillon, J. J. (2003). Bringing counseling to the classroom and the residence hall: The university learning community. The Journal of Humanistic Counseling, Education and Development, 42(2), 194-208. https://doi.org/10.1002/j.2164-490X.2003.tb00006.x

Dowrick, P. W., Anderson, J., Heyer, K., \& Acosta, J. (2005). Postsecondary education across the USA: Experiences of adults with disabilities. Journal of Vocational Rehabilitation, 22, 41-47. https://content.iospress.com/articles/journal-of-vocationalrehabilitation/jvr00272

Eanes, B. J., \& Perillo, P. A. (Co-chairs). (2015). Professional competency areas for student affairs educators. Washington, DC: ACPA-College Student Educators International and NASPA-Student Affairs Administrators in Higher Education. https://www.naspa.org/images/uploads/main/ACPA_NASPA_Professional_Competencie s_FINAL.pdf

Evans, N. J., Broido, E. M., Brown, K. R., \& Wilke, A. K. (Eds.). (2017). Disability in higher education: A social justice approach. Jossey-Bass. 
Ferri, B. A. (2008). Changing the script: Race and disability in Lynn Manning's Weights. International Journal of Inclusive Education, 12(6), 497-509. https://doi.org/10.1080/13603110802377524

Fornauf, B. S., \& Erickson, J. D. (2020). Toward an inclusive pedagogy through Universal Design for Learning in higher education: A review of the literature. Journal of Postsecondary Education and Disability, 33(2), 183-199. https://eric.ed.gov/?id=EJ1273677

Francis, G. L., Duke, J. M., Fujita, M., \& Sutton, J. C. (2019). “It's a constant fight:” Experiences of college students with disabilities. Journal of Postsecondary Education and Disability, 32(3), 247-261. https://files.eric.ed.gov/fulltext/EJ1236871.pdf

Frymier, A. B., \& Wanzer, M. B. (2003). Examining differences in perceptions of students' communication with professors: A comparison of students with and without disabilities. Communication Quarterly, 51(2), 174-191. https://doi.org/10.1080/01463370309370149

Gabel, S. L. (2010). A disability studies framework for policy activism in postsecondary education. Journal of Postsecondary Education and Disability, 23(1), 63-71. https://files.eric.ed.gov/fulltext/EJ888645.pdf

Gabel, S. L., Reid, D. P., \& Pearson, H. (2017). Disability, diversity, and higher education: A critical study of California State University's websites. In E. Kim, \& K. C. Aquino (Eds.), Disability as diversity in higher education: Policies and practices to enhance student success (pp. 171-184). Routledge.

Gardner, L. (2020, June 7). Why colleges' plans for the fall are like 'nailing Jell-O to the wall.' The Chronicle of Higher Education. https://www.chronicle.com/article/Why-CollegesPlans-for-Fall/248937?cid=cp275 
Gelbar, N. W., Shefcyk, A., \& Reichow, B. (2015). A comprehensive survey of current and former college students with autism spectrum disorders. Yale Journal of Biology and Medicine, 88, 45-68. https://doi.org/10.1016/j.compedu.2013.02.021

Glaser, B., \& Strauss, A. (1967). The discovery of grounded theory: strategies for qualitative research. Aldine Publishing Company.

Goegan, L. D., \& Harrison, G. L., (2017). The effects of extended time on writing performance. Learning Disabilities: A Contemporary Journal, 15(2), 209-224. https://files.eric.ed.gov/fulltext/EJ1160642.pdf

Goffman, E. (1963). Stigma: Notes on the management of spoiled identity. Simon \& Schuster Inc.

Graham, P. A., Hurtado, S. S., \& Gonyea, R. M. (2018). The benefits of living on campus: Do residence halls provide distinctive environments of engagement? Journal of Student Affairs Research and Practice, 55(3), 255-269. https://doi.org/10.1080/19496591.2018.1474752

Gray, R., Vitak, J., Easton, E. W., \& Ellison, N. B. (2013). Examining social adjustment to college in the age of social media: Factors influencing successful transitions and persistence. Computers \& Education, 67, 193-207. https://doi.org/10.1016/j.compedu.2013.02.021

Grigal, M., Hart, D., Smith, F. A., Domin, D., Sulewski, J., \& Weir, C. (2014). Think College National Coordinating Center: Annual report on the transition and postsecondary programs for students with intellectual disabilities (2012-2013). University of Massachusetts Boston, Institute for Community Inclusion. https://thinkcollege.net/sites/default/files/files/resources/ARYR3_F.pdf 
Guzman, A., \& Balcazar, F. E. (2010). Disability services' standards and the worldviews guiding their implementation. Journal of Postsecondary Education and Disability, 23(1), 48-62. https://files.eric.ed.gov/fulltext/EJ888644.pdf

Hadley, W., \& Archer, D. E. (2017). College students with learning disabilities: An at-risk population absent from the conversation of diversity. In E. Kim \& K. C. Aquino (Eds.), Disability as diversity in higher education: Policies and practices to enhance student success (pp. 75-88). Routledge.

Harbour, W. S. (2009). The relationship between institutional unit and administrative features of disability services offices in higher education. Journal of Postsecondary Education and Disability, 21(3), 138-154. https://files.eric.ed.gov/fulltext/EJ831432.pdf

Harbour, S. W., Boone, R., Heath, E. B., \& Ledbetter, S. G. (2017). “Overcoming” in disability studies and African American culture. In S. L. Kerschbaum, L. T. Eisenman, \& J. M. Jones (Eds.), Negotiation disability: Disclosure and higher education (pp. 149-169). University of Michigan Press.

Haynes, C. S. (2019). There's no place like home? African American women in the residence halls of a predominantly white Midwestern university. Gender and Education, 31(4), 525-542. https://doi.org/10.1080/09540253.2018.1484430

Hernández-Saca, D. I., Gutmann Kahn, L., \& Cannon, M. A. (2018). Intersectionality dis/ability research: How dis/ability research in education engages intersectionality to uncover the multidimensional construction of dis/abled experiences. Review of Research in Education, 42, 286-311. https://doi.org/10.3102/0091732X18762439 
Hong, B. S. (2015). Qualitative analysis of the barriers college students with disabilities experience in higher education. Journal of College Student Development, 56, 209-226. https://doi.org/10.1353/csd.2015.0032

Hong, B., Haefner, L., \& Slekar, T. (2011). Faculty attitudes and knowledge toward promoting self-determination and self-directed learning for college students with and without disabilities. International Journal of Teaching and Learning in Higher Education, 23(2), 175-185. https://eric.ed.gov/?id=EJ946142

Humphrey, J. C. (2000). Researching disability politics, or, some problems with the social models in practice. Disability \& Society, 15(1), 63-86. https://doi.org/10.1080/09687590025775

Hurtado, S., \& Carter, D. F. (1997). Effects of college transition and perceptions of the campus racial climate on Latino college students' sense of belonging. Sociology of Education, 70(4), 324-345. https://www.jstor.org/stable/pdf/2673270

Hutcheon, E. J., \& Wolbring, G. (2012). Voices of “disabled” post secondary students: Examining higher education "disability" policy using an ableism lens. Journal of Diversity in Higher Education, 5(1), 39-49. https://doi.org/10.1037/a0027002

Jackson, S. L., Hart, L., Brown, J. T., \& Volkmar, F. R. (2018). Brief report: Self-reported academic, social, and mental health experiences of post-secondary students with autism spectrum disorder. Journal of Autism and Developmental Disorders, 48, 643-650. https://doi.org/10.1007/s10803-017-3315-X

Jaggers, D., \& Iverson, S. V. (2012). “Are you as hard as 50 Cent?” Negotiating race and masculinity in the residence halls. The Journal of College and University Student 
Housing, 39(1), 186-199.

http://www.nxtbook.com/nxtbooks/acuho/journal_vol39no1/\#/188

Jensen, J. M., McCrary, N., Krampe, K., \& Cooper, J. (2004). Trying to do the right thing:

Faculty attitudes toward accommodating students with learning disabilities. Journal of Postsecondary Education and Disability, 17(2), 81-90. https://eric.ed.gov/?id=EJ876004

Johnstone, C., \& Edwards, P. (2020). Accommodations, accessibility, and culture: Increasing access to study abroad for students with disabilities. Journal of Studies in International Education, 24(4), 424-439. https://doi.org/10.1177/1028315319842344

Kattari, S. K. (2015). Examining ableism in higher education through social dominance theory and social learning theory. Innovative Higher Education, 40, 375-386. https://doi.org/10.1007/s10755-015-9320-0

Ketterlin-Geller, L. R., \& Johnstone, C. (2006). Accommodations and universal design: Supporting access to assessments in higher education. Journal of Postsecondary Education and Disability, 19(2), 163-172. https://eric.ed.gov/?id=EJ844632

Kim, W. H., \& Lee, J. (2015). The effect of accommodation on academic performance of college students with disabilities. Rehabilitation Counseling Bulletin, 60(1), 40-50. https://doi.org/10.1177/0034355215605259

Kimball, E., Vaccaro, A., \& Vargas, N. (2016). Student affairs professionals supporting students with disabilities: A grounded theory model. Journal of Students Affairs Research and Practice, 53(2), 175-189. https://doi.org/10.1080/19496591.2016.1118697

King, P. M. (2005). Theories of college student development: Sequences and consequences. In M. E. Wilson \& L. E. Wolf-Wendel (Eds.), ASHE reader on college student development theory (pp. 43-53). Pearson. 
Kitchin, R. (2000). The researched opinions on research: Disabled people and disability research. Disability \& Society, 15(1), 25-47. https://doi.org/10.1080/09687590025757

Kleemann, G. L. (2005). Weaving silos - A leadership challenge: A cross-functional team approach to supporting web-based student services. New Directions for Student Services, 112, 89-101. https://www.learntechlib.org/p/73958/

Kliewer, C., \& Drake, S. (1998). Disability, eugenics and the current ideology of segregation: A modern moral tale. Disability \& Society, 13(1), 95-111. https://doi.org/10.1080/09687599826939

Knott, F., \& Taylor, A. (2014). Life at university with Asperger syndrome: A comparison of student and staff perspectives. International Journal of Inclusive Education, 18(4), 411426. https://doi.org/10.1080/13603116.2013.781236

Knoll, K. R. (2009). Feminist disability studies pedagogy. Feminist Teacher, 19(2), 122-133. https://www.jstor.org/stable/40546086

Kroeger, S., \& Kraus, A. (2017). Changing the narrative around disability on college campuses. In E. Kim \& K. C. Aquino (Eds.), Disability as diversity in higher education: Policies and practices to enhance student success (pp. 216-229). Routledge.

Kuh, G. D. (2003). What we're learning about student engagement from NSSE: Benchmarks for effective educational practices. Change: The Magazine of Higher Learning, 35(2), 24-32. https://doi.org/10.1080/00091380309604090

Kuh, G. D., Kinzine, J., Buckley, J. A., Bridges, B. K., \& Hayek, J. C. (2007). Piecing together the student success puzzle: Research, propositions, and recommendations. Jossey-Bass. 
Kuk, L. (2016). Organizational and administrative models within student affairs. In G. S. McClellan \& J. Stringer (Eds.), The handbook of student affairs administration (4th ed., pp. 367-388). Wiley.

Kurth, N., \& Mellard, D. (2006). Student perceptions of the accommodation process in postsecondary education. Journal of Postsecondary Education and Disability, 19(1), 7184. https://files.eric.ed.gov/fulltext/EJ844625.pdf

Leake, D. W., \& Stodden, R. A. (2014). Higher education and disability: Past and future of underrepresented populations. Journal of Postsecondary Education and Disability, 27, 399-408. https://eric.ed.gov/?id=EJ1059990

Leonardo, Z., \& Broderick, A. A. (2011). Smartness as property: A critical exploration of intersections between whiteness and disability studies. Teachers College Record, 113, 2206-2232. https://www.tcrecord.org/content.asp?contentid=16431

Lewis, B. (2017). Narrating and navigating mental difference and disability. In S. L. Kerschbaum, L. T. Eisenman, \& J. M. Jones (Eds.), Negotiation disability: Disclosure and higher education (pp. 191-209). University of Michigan Press.

Lewis \& Clark Graduate School of Education and Counseling. (2021). Graduate catalog: Student affairs administration. Retrieved October 15, 2021, from https://docs.lclark.edu/graduate/educationalleadership/studentaffairs/\#coursestext Linton, S. (1998). Claiming disability: Knowledge and identity. New York University Press. Lombardi, A., Murray, C., \& Dallas, B. (2013). University faculty attitudes toward disability and inclusive instruction: Comparing two institutions. Journal of Postsecondary Education and Disability, 26(3), 221-232. https://eric.ed.gov/?id=EJ1026882 
López Gavira, R., \& Moriña, A. (2015). Hidden voices in higher education: Inclusive policies and practices in social science and law classrooms. International Journal of Inclusive Education, 19(4), 365-378. https://doi.org/10.1080/13603116.2014.935812

Lovett, B. J., Lewandowski, L. J., \& Carter, L. (2019). Separate room testing accommodations for students with and without ADHD. Journal of Psychoeducational Assessment, 37(7). 852-862. https://doi.org/10.1177/0734282918801420

Lynch, R. T., \& Gussel, L. (2011). Disclosure and self-advocacy regarding disability-related needs: Strategies to maximize integration in postsecondary education. Journal of Counseling \& Development, 74, 352-357. https://doi.org/10.1002/j.15566676.1996.tb01879.x

Madriaga, M. (2010). 'I avoid pubs and the student union like the plague': Students with Asperger syndrome and their negotiation of university spaces. Children's Geographies, 8(1), 39-50. https://doi.org/10.1080/14733280903500166

Mamiseishvili, K., \& Koch, L. C. (2011). First-to-second-year persistence of students with disabilities in postsecondary institutions in the United States. Rehabilitation Counseling Bulletin, 54(2), 93-105. https://doi.org/10.1177/0034355210382580

Marshak, L., Van Wieren, T., Ferrell, D. R., Swiss, L., \& Dugan, C. (2010). Exploring barriers to college student use of disability services and accommodations. Journal of Postsecondary Education and Disability, 22, 151-165. https://eric.ed.gov/?id=EJ906688

Marshall, C., \& Rossman, G. B. (2016) Designing qualitative research (6th ed.). Sage. Matthews, N. (2009). Teaching the 'invisible' disabled students in the classroom: Disclosure, inclusion and the social model of disability. Teaching in Higher Education, 14(3), 229239. https://doi.org/10.1080/13562510902898809 
Mayhew, M. J., Rockenbach, A. B., Bowman, N. A., Seifert, T. A., \& Wolniak, G. C. (2016). How college affects students: 21 st century evidence that higher education works (Vol. 3). Jossey-Bass.

McKeon, B., Alpern, C. S., \& Zager, D. (2013). Promoting academic engagement for college students with autism spectrum disorder. Journal of Postsecondary Education and Disability, 26(4), 353-366. https://files.eric.ed.gov/fulltext/EJ1026894.pdf

McLeod, J. D., Meanwell, E., \& Hawbaker, A. (2019). The experiences of college students on the autism spectrum: A comparison to their neurotypical peers. Journal of Autism and Developmental Disorders, 49, 2320-2336. https://doi.org/10.1007/s10803-019-03910-8

Megivern, D., Pellerito, S., \& Mowbray, C. (2003). Barriers to higher education for individuals with psychiatric disabilities. Psychiatric Rehabilitation Journal, 26(3), 217-231. https://doi.org/10.2975/26.2003.217.231

Mendoza, E., Paguyo, C., \& Gutiérrez, K. (2016). Understanding the intersection of race and dis/ability: Common sense notions of learning and culture. In D. J. Connor, B. A. Ferri, \& S. A. Annamma (Eds.), DisCrit: Disability studies and critical race theory in education (pp. 71-86). Teachers College Press.

Meyer, A., Thornton, M., \& Funckes. (n.d.). The professional's guide to exploring and facilitating access. AHEAD: Association on Higher Education and Disability. https://www.ahead.org/professionalresources/accommodations/documentation/professional-resources-accommodationsprofessional-guide-access

Miele, A. N., Hamrick, F. A., \& Kelley, J. W. (2018). Different is not deficient: Addressing student conduct concerns among residential college students with autism spectrum 
disorder. Journal of College and University Student Housing, 44(3), 30-45.

https://www.nxtbook.com/nxtbooks/acuho/journal_vol44no3/index.php\#/p/30

Miller, R. A. (2015). "Sometimes you feel invisible": Performing queer/disabled in the university classroom. The Educational Forum, 79(4), 377-393. https://doi.org/10.1080/00131725.2015.1068417

Miller, R. A. (2017). "My voice is definitely strongest in online communities": Students using social media for queer and disability identity-making. Journal of College Student Development, 58(4), 509-525. https://doi.org/10.1353/csd.2017.0040

Miller, R. A., Wynn, R. D., \& Webb, K. W. (2017). Queering disability in higher education: Views from the intersections. In E. Kim \& K. C. Aquino (Eds.), Disability as diversity in higher education: Policies and practices to enhance student success (pp. 31-44). Routledge.

Mills, J., Birks, M., \& Hoare, K. (2014). Grounded theory. In J. Mills \& M. Birks (Eds.), Qualitative methodology: A practical guide (pp. 107-121). Sage.

Mollow, A. (2013). "When Black women start going on Prozac..." The politics of race, gender, and emotional distress in Meri Nana-Ama Danquah's Willow Weep for Me. In L. Davis (Ed.), The disability studies reader (4th ed., pp. 411-431). Routledge.

Murray, C., Flannery, B. K., \& Wren, C. (2008). University staff members' attitudes and knowledge about learning disabilities and disability support services. Journal of Postsecondary Education and Disability, 21(2), 73-90.

https://files.eric.ed.gov/fulltext/EJ822095.pdf 
Murray, C., Lombardi, A., \& Wren, C. T. (2011). The effects of disability-focused training on the attitudes and perceptions of university staff. Remedial and Special Education, 32(4), 290-300. https://doi.org/10.1177/0741932510362188

Murray, C., Wren, C. T., Stevens, E. B., \& Keys, C. (2009). Promoting university faculty and staff awareness of students with learning disabilities: An overview of the Productive Learning u Strategies (PLuS) project. Journal of Postsecondary Education and Disability, 22(2), 117-129. https://eric.ed.gov/?id=EJ868136

NASPA - Student Affairs Administrators in Higher Education. (n.d.). Regions and areas. https://www.naspa.org/communities/regions-and-areas/regions-and-areas

Newman, L., Wagner, M., Cameto, R., Knokey, A. M., \& Shaver, D. (2010). Comparisons across time of the outcomes of youth with disabilities up to 4 years after high school. (A report of findings from the National Longitudinal Transition Study (NLTS) and the National Longitudinal Transition Study-2 [NLTS-2; NCSER 2010-3008]). SRI International. https://files.eric.ed.gov/fulltext/ED512149.pdf

Newman, L., Wagner, M., Knokey, A. M., Marder, C., Nagle, K., Sharver, D., \& Wei, X. (2011). The post-high school outcomes of young adults with disabilities up to 8 years after high school. (A report from the National Longitudinal Transition Study-2 [NLTS2; NCSER 2011-3005]). SRI International. https://ies.ed.gov/ncser/pubs/20113005/pdf/20113005.pdf

Nuss, E. M. (2003). The development of student affairs. In S. R. Komives, D. B. Woodard, Jr., \& Associates (Eds.), Student services: A handbook for the profession (4th ed., pp. 65-88). Jossey-Bass. 
Oliver, D. G., Serovich, J. M., \& Mason, T. L. (2005). Constraints and opportunities with interview transcription: Towards reflection in qualitative research. Social Forces, 84(2), 1273-1289. https://doi.org/10.1353/sof.2006.0023

Olney, M. F., \& Brockelman, K. F. (2003). Out of the disability closet: Strategic use of perception management by select university students with disabilities. Disability \& Society, 18(1), 35-50. https://doi.org/10.1080/713662200

O’Neil Green, D., Willis, H., Green, M. D., \& Beckman, S. (2017). Access Ryerson: Promoting disability as diversity. In E. Kim \& K. C. Aquino (Eds.), Disability as diversity in higher education: Policies and practices to enhance student success (pp. 200-215). Routledge.

Oregon State University College of Liberal Arts. (2021). College Student Services Administration Curriculum Overview. Retrieved October 15, 2021, from https://liberalarts.oregonstate.edu/slcs/cssa/about-cssa-program/cssa-curriculum-overview

Ousley, M. (2006). The Luke Principle: Counting the costs of organizational change for one-stop service models in student affairs. The College Student Affairs Journal, 26(1), 45-63. https://eric.ed.gov/?id=EJ902802

Parry, K. (1998). Grounded theory and social process: A new direction for leadership research. Leadership Quarterly, 9(1), 85-106. https://doi.org/10.1016/S1048-9843(98)90043-1

Patton, L. D., Renn, K. A., Guido, F. M., \& Quaye, S. J. (2016). Student development in college: Theory, research and practice (3rd ed.). Jossey-Bass.

Pearson, H., \& Samura, M. (2017). Using a spatial lens to examine disability as diversity on college campuses. In E. Kim \& K. C. Aquino (Eds.), Disability as diversity in higher education (pp. 89-103). Routledge. 
Perry, S. P., \& Franklin, K. K. (2006). I'm not the gingerbread man! Exploring the experiences of college students diagnosed with ADHD. Journal of Postsecondary Education and Disability, 19(1), 94-109. https://files.eric.ed.gov/fulltext/EJ844627.pdf

Preece, J. E., Roberts, N. L., Beecher, M. E., Rash, P. D., Shwalb, D. A., \& Martinelli, E. A. (2007). Academic advisors and students with disabilities: A national survey of advisors' experiences and needs. NACADA Journal, 27(1), 57-72. https://doi.org/10.12930/0271$9517-27.1 .57$

Quaye, S. J., Harper, S. R., \& Pendakur, S. L. (Eds.). (2020). Student engagement in higher education: Theoretical perspectives and practical approaches for diverse populations (3rd ed.). Routledge.

Rehabilitation Act of 1973, Pub. L. No. 93-112, 29 U.S.C. §793, 34 C.F.R. §104.3(k)(3).

Reid, D. P. (2016). Tensions experienced as a visually impaired African American student negotiated identities in the pursuit of education: A mother's influence. In S. Danforth \& S. L. Gabel (Eds.), Vital questions facing Disability Studies in Education (2nd ed., pp. 117-139). Peter Lang.

Reynolds, A. L. (2017). Counseling and helping skills. In J. H. Schuh, S. R. Jones, \& V. Torres (Eds.), Student services: A handbookfor the profession (6th ed., pp. 452-465). JosseyBass.

Roessler, R. T., Hennessey, M. L., \& Hogan, E. M. (2009). Career assessment and planning strategies for postsecondary students with disabilities. Journal of Postsecondary Education and Disability, 21(3). 126-137. https://files.eric.ed.gov/fulltext/EJ831431.pdf

Rothstein, L., (2015). The Americans with Disabilities Act and higher education 25 years later: An update on the history and current disability discrimination issues for higher education. 
Journal of College and University Law, 41(3), 531-588.

https://ssrn.com/abstract=2629306

Salzer, M. S., Wick, L. C., \& Rogers, J. A. (2008). Familiarity with and use of accommodations and supports among postsecondary students with mental illnesses. Psychiatric Services, 59(4), 370-375. https://doi.org/10.1176/appi.ps.59.4.370

Samuels, E. (2013). My body, my closet: Invisible disability and the limits of coming out. In L. Davis (Ed.), The disability studies reader (4th ed., pp. 316-332). Routledge.

Sanford, N. (1966). Self \& society: Social change and individual development. Atherton Press.

Schudde, L. T. (2011). The causal effect of campus residency on college student retention. The Review of Higher Education, 34(4), 581-610. https://muse.jhu.edu/article/439958/pdf

Seifert, T. A., Goodman, K. M., Lindsay, N., Jorgensen, J. D., Wolniak, G. C., Pascarella, E. T., \& Blaich, C. (2008). The effects of liberal arts experiences on liberal arts outcomes. Research in Higher Education, 49, 107-125. https://doi.org/10.1007/s11162-007-9070-7

Shakespeare, T. (2013). The social model of disability. In L. Davis (Ed.), The disability studies reader (4th ed., pp. 214-221). Routledge.

Shallish, L. (2017). A different diversity? Challenging the exclusion of disability studies from higher education research and practice. In E. Kim \& K. C. Aquino (Eds.), Disability as diversity in higher education: Policies and practices to enhance student success (pp. 1930). Routledge.

Shepler, D. K., \& Woosley, S. A. (2012). Understanding the early integration experiences of college students with disabilities. Journal of Postsecondary Education and Disability, 25(1), 37-50. https://eric.ed.gov/?id=EJ970018 
Shushok, F., Scales, T. L., Sriram, R., \& Kidd, V. (2011). A tale of three campuses: Unearthing theories of residential life that shape the student learning experience. About Campus, 16(3), 13-21. https://doi.org/10.1002\%2Fabc.20063

Siebers, T. (2013). Disability and the theory of complex embodiment - for identity politics in a new register. In L. Davis (Ed.), The disability studies reader (4th ed., pp. 278-297). Routledge.

Skaff, L. F., Kemp, J. N., Sternesky McGovern, L. A., \& Fantacone, J. M. (2016). Educator and parent views of the effectiveness of individualized learning plans for students with disabilities. Career Development and Transition for Exceptional Individuals, 39(2), 6878. https://doi.org/10.1177/2165143414546131

Smith, C. P. (2007). Support services for students with Asperger's syndrome in higher education. College Student Journal, 41(3), 515-531. https://link.gale.com/apps/doc/A169306797/AONE?u=chap_main\&sid=AONE\&xid=b16 290ca

Sniatecki, J. L., Perry, H. B., \& Snell, L. H. (2015). Faculty attitudes and knowledge regarding college students with disabilities. Journal of Postsecondary Education and Disability, 28(3), 259-275. https://eric.ed.gov/?id=EJ1083837

Snyder, T. D., de Brey, C., \& Dillow, S.A. (2019). Digest of education statistics 2018. National Center for Education Statistics, Institute of Education Sciences, U.S. Department of Education. https://nces.ed.gov/pubs2020/2020009.pdf

Snyder, T. D., \& Dillow, S.A. (2010). Digest of education statistics 2009. National Center for Education Statistics, Institute of Education Sciences, U.S. Department of Education. https://nces.ed.gov/pubs2010/2010013.pdf 
Squires, M. E., Burnell, B. A., McCarty, C., \& Schnackenberg, H. (2018). Emerging adults: Perspectives of college students with disabilities. Journal of Postsecondary Education and Disability, 31(2), 121-134. Retrieved from https://eric.ed.gov/?id=EJ1192068

Stapleton, L. (2015). When being deaf is centered: d/Deaf women of color's experiences with racial/ethnic and d/Deaf identities in college. Journal of College Student Development, 56(6), 570-586. https://doi.org/10.1353/csd.2015.0061

Stein, K. F. (2013). DSS and accommodations in higher education: Perceptions of students with psychological disabilities. Journal of Postsecondary Education and Disability, 26(2), 145-161. https://eric.ed.gov/?id=EJ1026925

Straus, J. N. (2013). Autism as culture. In L. Davis (Ed.), The disability studies reader (4th ed., pp. 460-484). Routledge.

Strayhorn, T. L. (2012). Satisfaction and retention among African American men at two-year community colleges. Community College Journal of Research and Practice, 36(5), 358375. https://doi.org/10.1080/10668920902782508

Stumbo, N. J., Hedrick, B. N., Weisman, C., \& Martin, J. K. (2010). An exploration into the barriers and facilitators experienced by university graduates with disabilities requiring personal assistance services. Journal of Science Education for Student with Disabilities, 14(1), 1-24. https://doi.org/10.14448/jsesd.03.0001

Terenzini, P. T., Pascarella, E. T., \& Blimling, G. S. (1999). Students' out-of-class experiences and their influence on learning and cognitive development: A literature review. Journal of College Student Development, 40(5), 610-623.

Tinto, V. (1993). Leaving college: Rethinking the causes and cures of student attrition (2nd ed.). University of Chicago Press. 
Urquhart, C., Lehmann, H., \& Myers, M. D. (2010). Putting the 'theory' back into grounded theory: Guidelines for grounded theory studies in information systems. Information Systems Journal, 20(4), 357-381. https://doi.org/10.1111/j.1365-2575.2009.00328.x

Vaccaro, A., Daly-Cano, M., \& Newman, B. M. (2015). A sense of belonging among college students with disabilities: An emergent theoretical model. Journal of College Student Development, 56, 670-686. https://doi.org/10.1353/csd.2015.0072

Vaccaro, A., \& Kimball, E. (2017). “It's a very deep, layered topic” Student affairs professionals on the marginality and intersectionality of disability. In E. Kim \& K. C. Aquino (Eds.), Disability as diversity in higher education: Policies and practices to enhance student success (pp. 138-152). Routledge.

Vaccaro, A. \& Kimball, E. (2019). Navigating disability in campus housing: An ecological analysis of student affairs work. Journal of Student Affairs Research and Practice, 56(2), 168-180. https://doi.org/10.1080/19496591.2018.1490307

Vaccaro, A., Kimball, E. W., Moore, A., Newman, B. M., \& Troiano, P. F. (2018). Narrating the self: A grounded theory model of emerging purpose for college students with disabilities. Journal of College Student Development, 59(1), 37-54. https://doi.org/10.1353/csd.2018.0003

Vaccaro, A., Moore, A., Kimball, E., Troiano, P. F., \& Newman, B. M. (2019). "Not gonna hold me back": Coping and resilience in students with disabilities. Journal of Student Affairs Research and Practice, 56(2), 181-193. https://doi.org/10.1080/19496591.2018.1506793

Van Hees, V., Moyson, T., \& Roeyers, H. (2015). Higher education experiences of students with autism spectrum disorders: Challenges, benefits and support needs. Journal of Autism 
and Developmental Disorders, 45, 1673-1688. https://doi.org/10.1007/s10803-014-23242

Watson, E., Bartlett, F., Sacks, C., \& Davidson, D. L. (2013). Implementing Universal Design: A collaborative approach to designing campus housing. The Journal of College and University Student Housing, 40, 158-171. https://www.nxtbook.com/nxtbooks/acuho/journal_vol39no2/index.php\#/p/158

Wessel, R. D., Wentz, J., \& Markle, L. L. (2011). Power soccer: Experiences of students using power wheelchairs in a collegiate athletic club. Journal of Postsecondary Education and Disability, 24(2), 147-159. https://files.eric.ed.gov/fulltext/EJ943701.pdf

West, M., Kregel, J., Getzel, E. E., Zhu, M., Ipsen, S. M., \& Martin, E. D. (1993). Beyond Section 504: Satisfaction and empowerment of students with disabilities in higher education. Exceptional Children, 59(5), 456-467. http://citeseerx.ist.psu.edu/viewdoc/download?doi=10.1.1.968.6147\&rep=rep1\&type=pdf

Wilke, A. K., Evans, N. J., Varland, C. E., Brown, K. R., \& Broido, E. M. (2019). Access and integration: Perspectives of disabled students living on campus. The Journal of College and University Student Housing, 46(1), 46-61. https://www.nxtbook.com/nxtbooks/acuho/journal_vol46no1/index.php\#/p/45

Winston, R. B., Jr. (2003). Counseling and helping skills. In S. R. Komives, D. B. Woodard, Jr., \& Associates (Eds.), Student services: A handbook for the profession (4th ed., pp. 484506). Jossey-Bass.

Wood, T. (2017). Rhetorical disclosures: The stakes of disability identity in higher education. In S. L. Kerschbaum, L. T. Eisenman, \& J. M. Jones (Eds.), Negotiating disability: Disclosure and higher education (pp. 75-91). University of Michigan Press. 
Yanni, C., \& Taylor, H. (2020, June 12). The question of living spaces. Inside Higher Ed. https://www.insidehighered.com/views/2020/06/12/architecture-expert-and-bioethicistexplore-problem-residence-halls-duringpandemic?fbclid=IwAR0_5vJ5ola6iEUPo4CxDeOoyqF6gGCMTSErNHROjrLFzGhV31 Im8veit2g

Young, K. S. (2016). How student teachers (don’t) talk about race: An intersectional analysis. Race Ethnicity and Education, 19(1), 67-95. https://doi.org/10.1080/13613324.2013.831826 


\section{Appendix A}

Summary of reviewed literature methods and samples

\begin{tabular}{|c|c|c|c|}
\hline Author(s) \& Year & Setting & Methodology & Sample \\
\hline Abes \& Wallace (2018) & $\begin{array}{l}\text { Not institution } \\
\text { specific }\end{array}$ & Qualitative; interviews & 13 students \\
\hline Anderson \& Butt (2017) & $\begin{array}{l}\text { Not institution } \\
\text { specific }\end{array}$ & Qualitative; interviews & $\begin{array}{l}18 \text { pairs of students } \\
\text { and parents }\end{array}$ \\
\hline Anderson et al. (2018) & $\begin{array}{l}8 \text { universities in } \\
\text { Australia }\end{array}$ & Quantitative; survey & 48 students \\
\hline Aquino \& Bittinger (2019) & $\begin{array}{l}\text { Not institution } \\
\text { specific }\end{array}$ & $\begin{array}{l}\text { Quantitative; NCES data } \\
\text { analysis }\end{array}$ & $\begin{array}{l}1,670 \text { students; } \\
1,820 \text { students }\end{array}$ \\
\hline Ashbaugh et al. (2017) & $\begin{array}{l}\text { Not institution } \\
\text { specific }\end{array}$ & $\begin{array}{l}\text { Quantitative; intervention } \\
\text { \& surveys }\end{array}$ & 3 students \\
\hline Barnard-Brak et al. (2010) & $\begin{array}{l}\text { Large public } \\
\text { university }\end{array}$ & Qualitative; interviews & 5 students \\
\hline Barnhill (2016) & 30 institutions & Quantitative; survey & $\begin{array}{l}30 \text { disability service } \\
\text { office staff members }\end{array}$ \\
\hline
\end{tabular}

Belch \& Marshak (2006) Not institution Qualitative; questionnaire 62 senior student

specific affairs officers

Bialka et al. (2017) Private Qualitative; interviews 5 students

university

Burgstahler \& Moore (2009) Large public Qualitative; focus groups 53 students

university 72 staff members 


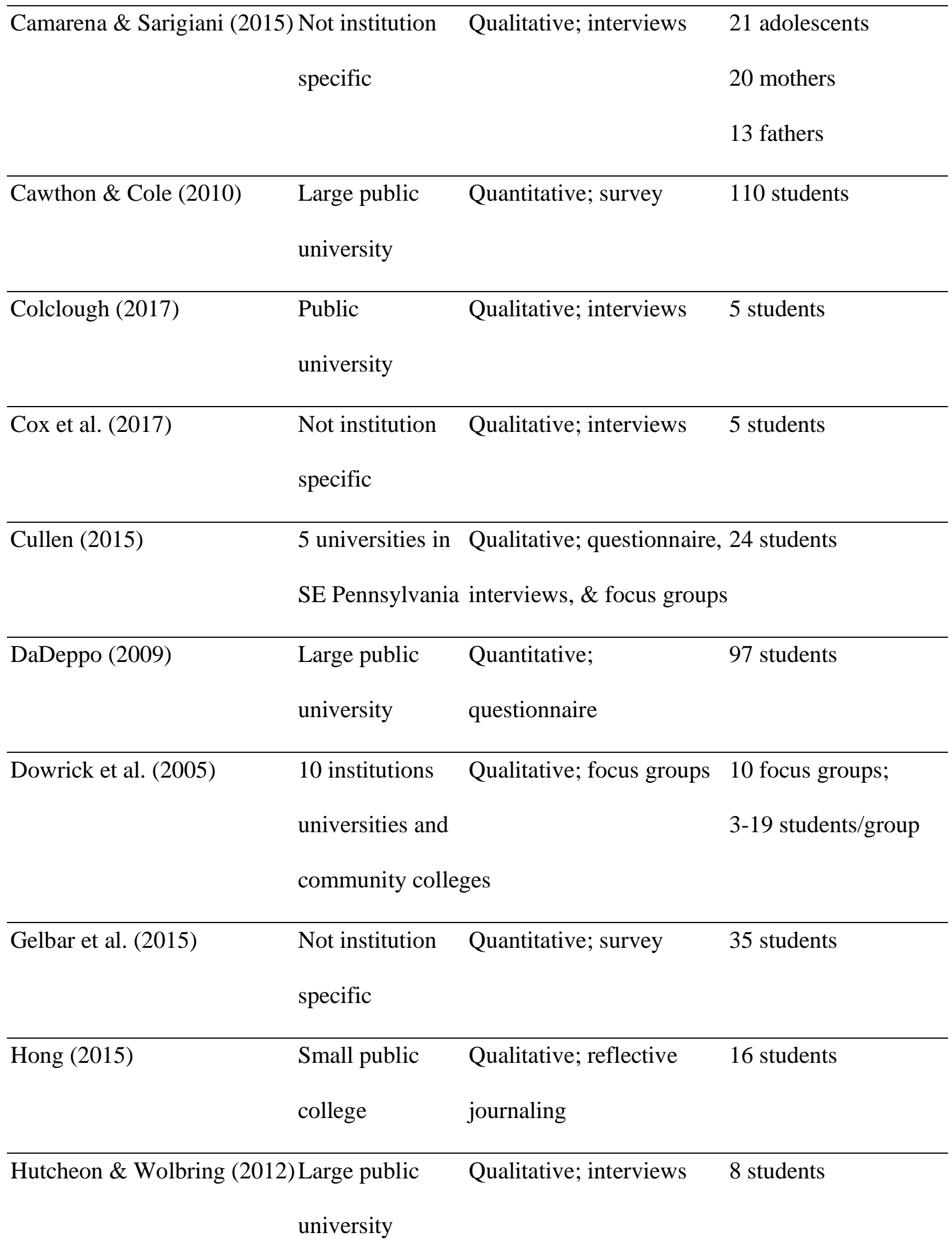




\begin{tabular}{|c|c|c|c|}
\hline Jackson et al. (2018) & $\begin{array}{l}\text { Not institution } \\
\text { specific }\end{array}$ & Quantitative; survey & 56 students \\
\hline Kimball et al. (2016) & $\begin{array}{l}21 \text { institutions, } \\
\text { New England }\end{array}$ & Qualitative; focus groups & $\begin{array}{l}31 \text { staff members } \\
4 \text { students }\end{array}$ \\
\hline Knott \& Taylor (2014) & $\begin{array}{l}\text { Large UK } \\
\text { university }\end{array}$ & Qualitative; focus groups & $\begin{array}{l}9 \text { staff members } \\
4 \text { students }\end{array}$ \\
\hline Kurth \& Mellard (2006) & $\begin{array}{l}15 \text { community } \\
\text { colleges, in } 3 \\
\text { states }\end{array}$ & $\begin{array}{l}\text { Mixed methods; survey \& } \\
\text { focus groups }\end{array}$ & $\begin{array}{l}108 \text { students surveyed } \\
104 \text { in focus groups }\end{array}$ \\
\hline Madriaga (2010) & $\begin{array}{l}\text { Multiple } \\
\text { institutions }\end{array}$ & Qualitative; life-histories & 8 students \\
\hline Marshak et al. (2010) & $\begin{array}{l}\text { Mid-sized public } \\
\text { university }\end{array}$ & Qualitative; interviews & 16 students \\
\hline McLeod et al. (2019) & $\begin{array}{l}\text { All } 14 \text { public } \\
\text { institutions } \\
\text { in Indiana }\end{array}$ & Quantitative; survey & 3073 students \\
\hline Megivern et al. (2019) & $\begin{array}{l}\text { Not institution } \\
\text { specific }\end{array}$ & Qualitative; interviews & 35 former students \\
\hline Murray et al. (2008) & $\begin{array}{l}\text { Large private } \\
\text { university }\end{array}$ & Quantitative; survey & 70 staff members \\
\hline Olney \& Brockelman (2003) & $\begin{array}{l}\text { Large public } \\
\text { university }\end{array}$ & $\begin{array}{l}\text { Qualitative; interviews } \\
\text { and focus groups }\end{array}$ & 25 students \\
\hline
\end{tabular}




\begin{tabular}{|c|c|c|c|}
\hline Preece et al. (2007) & $\begin{array}{l}\text { Not institution } \\
\text { specific }\end{array}$ & Quantitative; survey & $\begin{array}{l}1500 \text { academic } \\
\text { advisors }\end{array}$ \\
\hline Perry \& Franklin (2006) & $\begin{array}{l}1 \text { small private } \\
\text { university; } \\
1 \text { small public } \\
\text { university }\end{array}$ & Qualitative; interviews & 10 students \\
\hline Smith (2010) & $\begin{array}{l}\text { Sample of } \\
\text { AHEAD member } \\
\text { institutions }\end{array}$ & Quantitative; survey & $\begin{array}{l}29 \text { disability service } \\
\text { office staff members }\end{array}$ \\
\hline Squires et al. (2018) & $\begin{array}{l}\text { Public liberal } \\
\text { arts college }\end{array}$ & $\begin{array}{l}\text { Qualitative; surveys \& } \\
\text { interviews }\end{array}$ & $\begin{array}{l}541 \text { students surveyed } \\
45 \text { students } \\
\text { interviewed }\end{array}$ \\
\hline Stumbo et al. (2010) & $\begin{array}{l}\text { Large public } \\
\text { university }\end{array}$ & Qualitative; interviews & 13 former students \\
\hline Vaccaro \& Kimball (2019) & $\begin{array}{l}21 \text { institutions, } \\
\text { New England }\end{array}$ & Qualitative; focus groups & 31 staff members \\
\hline Vaccaro et al. (2015) & $\begin{array}{l}\text { Mid-sized public } \\
\text { university }\end{array}$ & Qualitative; interviews & 8 students \\
\hline Van Hees et al. (2015) & $\begin{array}{l}\text { Not institution } \\
\text { specific }\end{array}$ & Qualitative; interviews & 23 students \\
\hline West et al. (1993) & $\begin{array}{l}\text { Public and } \\
\text { private institution } \\
\text { in Viroinia }\end{array}$ & $\begin{array}{l}\text { Quantitative; survey } \\
\text { Is }\end{array}$ & 761 students \\
\hline
\end{tabular}


Wilke et al. (2019)

4 small, liberal Qualitative; case studies 24 students

arts colleges 


\section{Appendix B}

\section{Recruitment Email: First Contact}

\section{Dear [Name]:}

I hope this email finds you safe, and as well as one might expect given the collective circumstances of higher education amid a global pandemic. My name is Chris Toutain, and I am the Title IX \& 504 Coordinator at Reed College, and a doctoral candidate in Chapman University's Attallah College of Educational Studies.

I am emailing you today to ask if you would be willing to participate in my dissertation research study that I am conducting on the ways that Resident Directors conceive of and engage with notions of disability in their campus housing work. Participation will involve a 60-90 minute video or phone interview, with up to two potential brief follow-up interviews. If you are interested in participating in this study please reply to this email, or email me at ctoutain@chapman.edu. Participation in the study is entirely voluntary. Minimal risks similar to those experienced in daily life have been identified, and steps are being taken throughout the study to minimize these risks.

If you have any questions, and/or are interested in participating in this study, please let me know, and we can schedule a time to talk.

Thank you very much for your time and consideration during these unprecedented times.

Sincerely,

-Chris

Chris Toutain, M.A., M.Ed.

Doctoral Candidate

Attallah College of Educational Studies

Chapman University

ctoutain@chapman.edu 


\section{Recruitment Email: Consent Following Recruitment}

\section{Dear [Name]:}

Thank you for contacting me indicating an interest in participating in my research study on the ways that Resident Directors conceive of and engage with notions of disability in their campus housing work. I have attached the consent sheet for this study to this email. If you agree to participate in the study, we can arrange to review the consent sheet via a Zoom or phone call prior to your participation in your interview. If you would like to arrange a meeting to discuss the consent sheet before scheduling an interview, we can find a time for a Zoom or phone call to do so. We can also schedule an interview, and review the consent sheet prior to beginning the interview. In either case, you will have an opportunity to review the consent information, and have any questions answered, prior to signing and returning the form.

If you remain interested in participating in this study, please let me know what days and/or times would be most convenient for us to meet over Zoom or phone, and we can schedule a meeting.

Again, my sincerest thanks for your time and interest during a remarkable fall for higher education.

Chris Toutain

Doctoral Candidate, Chapman University Attallah College of Educational Studies ctoutain@chapman.edu 


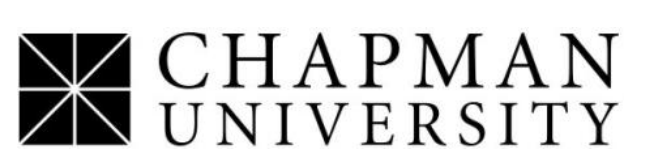

Appendix C

\section{ADULT INFORMED CONSENT TO PARTICIPATE IN RESEARCH}

Title of Study:

Housing Professionals and Disability: A Grounded Theory Exploration of Resident Directors'Understandings of Disability

\section{Members of the Research Team}

Student Researcher: Christopher Toutain, MA, MEd

Lead Researcher: Scot Danforth, Ph.D.

email: ctoutain@chapman.edu

email: danforth@chapman.edu

\section{Key Information}

You are being asked to take part in a research study. Research studies include only people who choose to take part. A member of the research team will explain the study to you and will answer any questions you might have. You should take your time in deciding whether or not you want to participate.

If you agree to participate in this study, the project will involve:

- Individuals over the age of 18

- Procedures will include semi-structured interviews, which will be audio-recorded and transcribed

- Interviews will be conducted over Zoom or a similar video conference platform

- There will be one primary interview, with the possibility of two follow-up interviews

- These interviews will take between 1.5-3 hours total

- There are not risks associated with this study that exceed what would typically be encountered in daily life

- You will be provided a copy of this consent form

\section{Invitation}

You are invited to take part in this research study. The information in this form is meant to help you decide whether or not to participate. If you have any questions, please ask.

Why are you being asked to be in this research study?

You are being asked to be in this study because you are a Resident Director with at least one year of experience at a small or medium private, not-for-profit, liberal arts college or university that houses at least $25 \%$ of undergraduate students in on-campus housing. You must be 18 years of age or older to participate.

\section{What is the reason for doing this research study?}

Resident Directors (RDs) are responsible for the overall operation of the residential programs and students within the buildings to which they are assigned. Operational policies and procedures, along with staff member responses have been identified as critical to the campus experiences of students with disabilities. This research is designed to better understand the ways 
in which RDs conceive of and think about the concept of disability, and the ways in which they work with students with disabilities in their buildings.

\section{What will be done during this research study?}

You will be asked to complete an in-person, semi-structured interview. The interview will be audio-recorded and transcribed. The researcher will analyze the transcripts in order to identify themes that commonly emerge across study participants. You may also be asked to participate in up to two follow up interviews. It is anticipated that the initial interview will last approximately 90 minutes, and in total your participation time will be between 1.5-3 hours. All interviews will occur via Zoom or a similar web conference platform, from a location of your choosing.

\section{What are the possible risks of being in this research study?}

As with any study involving collection of data, there is the possibility of breach of confidentiality of data. Other risks in this research include possible emotional and/or psychological distress similar to that which may be encountered in daily life related to the discussion of sensitive topics.

It is possible that other rare side effects could occur that are not described in this consent form. It is also possible that you could have a side effect that has not occurred before.

\section{What are the possible benefits to you?}

You are not expected to get any direct benefit from being in this study.

\section{What are the possible benefits to other people?}

The benefits to higher education and/or society may include a better understanding of how to support the knowledge, training, and professional development of RDs in ways that are supportive of students with disabilities in higher education campus housing.

\section{What will participating in this research study cost you?}

There is no cost to you to be in this research study.

\section{Will you be compensated for being in this research study?}

You will not be compensated for your participation in this research study.

\section{What should you do if you have a problem during this research study?}

Your welfare is the major concern of every member of the research team. If you have a problem as a direct result of being in this study, you should immediately contact one of the people listed at the beginning of this consent form.

\section{How will information about you be protected?}

Reasonable steps will be taken to protect your privacy and the confidentiality of your study data.

The interview recordings will be stored electronically through a secure cloud server and will only be reviewed by the research team during the study, until the study is complete. De-identified transcripts of the interviews will be created and stored in password protected files on a password 
protected laptop, or a secure cloud server and will only be reviewed by the research team during the study and for seven years following the completion of the study.

The only people who will have access to your research records are the members of the research team, the Institutional Review Board (IRB), and any other person, agency, or sponsor as required by law. Information from this study may be published in education journals or presented at education meetings but the data will be reported in summary form in order to maintain individual anonymity. Where quotations from individuals are used to demonstrate data summaries they will be presented using pseudonyms and your identity will be kept strictly confidential. We cannot guarantee total privacy.

\section{What are your rights as a research subject?}

You may ask any questions about this research and have those questions answered before agreeing to participate in the study or during the study.

For study related questions, please contact the investigator(s) listed at the beginning of this form.

For questions concerning your rights or complaints about the research, contact the Institutional Review Board (IRB) at (714) 628-2833 or irb@ chapman.edu.

\section{What will happen if you decide not to be in this research study or decide to stop participating once you start?}

You can decide not to be in this research study, or you can stop being in this research study (i.e., "withdraw") at any time before, during, or after the research begins for any reason. Deciding not to be in this research study or deciding to withdraw will not affect your relationship with the investigator or with Chapman University. You will not lose any benefits to which you are entitled.

\section{Documentation of informed consent}

You are voluntarily deciding whether or not to be in this research study. Signing this form means that (1) you have read and understood this consent form, (2) you have had the consent form explained to you, (3) you have had your questions answered, and (4) you have decided to be in the research study. You will be given a copy of this consent form to keep.

Printed Name of Participant or Legal Guardian

Signature of Participant or Legal Guardian

Date 


\section{AUDIO RECORDING:}

I have received an adequate description of the purpose and procedures for audio recording sessions during the course of the proposed research. I give my consent to allow myself to be audio recorded during participation in this study, and for those records to be reviewed by persons involved in the study, as well as for other professional purposes as described to me.

Yes, I agree to allow the research team to audio record my interview(s).

No, I do not wish to have my interview(s) audio recorded. 


\section{Appendix D}

\section{Participant Demographic Information}

\begin{tabular}{|c|c|c|c|c|c|c|}
\hline Name & Age & Gender Identity & Race/Ethnicity & Ability/Disability & $\begin{array}{l}\text { Years } \\
\text { Experience }\end{array}$ & Graduate School \\
\hline Aaron & 31 & Male & White & Able & 3 & $\begin{array}{l}\text { Masters - Higher } \\
\text { Ed. Admin. }\end{array}$ \\
\hline Adrian & 25 & Non binary & Asian & $\begin{array}{l}\text { Physically able, } \\
\text { diagnosed anxiety }\end{array}$ & 2 & $\begin{array}{l}\text { Masters - Higher } \\
\text { Ed. Admin. }\end{array}$ \\
\hline Angela & 25 & Female & Multi-ethnic & Able bodied & 2 & $\begin{array}{l}\text { Masters - College } \\
\text { Counseling }\end{array}$ \\
\hline Bea & 25 & Woman & Asian American & Type 1 diabetes & 1 & $\begin{array}{l}\text { Masters - Higher } \\
\text { Ed. Admin. }\end{array}$ \\
\hline Brooke & 27 & Female & White, Caucasian & Able bodied & 2 & $\begin{array}{l}\text { Masters - Higher } \\
\text { Ed. Admin.. }\end{array}$ \\
\hline Carmen & 27 & Woman & Biracial & Able & 4 & $\begin{array}{l}\text { Masters - Higher } \\
\text { Ed. Admin }\end{array}$ \\
\hline Cathryn & 27 & Female & White & No disabilities & 1 & $\begin{array}{l}\text { Masters - Higher } \\
\text { Ed. Admin. }\end{array}$ \\
\hline Corey & 26 & Male & White & Able bodied & 5 & MBA \\
\hline Damien & 28 & Cisgender male & African American & Able bodied & 1 & $\begin{array}{l}\text { Masters - Higher } \\
\text { Ed. Admin. }\end{array}$ \\
\hline Darren & 30 & Cisgender male & White, Caucasian & Able bodied & 4 & $\begin{array}{l}\text { Masters - Higher } \\
\text { Ed. Admin. }\end{array}$ \\
\hline Elizabeth & 29 & Female & White & I have a disability & 2 & $\begin{array}{l}\text { Masters - Higher } \\
\text { Ed. Admin. }\end{array}$ \\
\hline
\end{tabular}




\begin{tabular}{|c|c|c|c|c|c|c|}
\hline Name & Age & Gender Identity & Race/Ethnicity & Ability/Disability & $\begin{array}{l}\text { Years } \\
\text { Experi }\end{array}$ & Graduate School \\
\hline Emily & 30 & Woman & White, Caucasian & Able & 2 & $\begin{array}{l}\text { Masters - Higher } \\
\text { Ed. Admin. }\end{array}$ \\
\hline Frankie & 27 & Woman & White, Caucasian & Able & 2 & Masters \\
\hline Gwen & 27 & Cis Woman & White, Caucasian & Able & 2 & $\begin{array}{l}\text { Masters - Higher } \\
\text { Ed. Admin. }\end{array}$ \\
\hline$\overline{\text { Isa }}$ & 32 & Female & White, Caucasian & I have a disability & 3 & $\begin{array}{l}\text { Masters -College } \\
\text { Counseling }\end{array}$ \\
\hline Jessica & 31 & Female & Hispanic & Able & 2 & Masters \\
\hline Joshua & 29 & Male & White & No disabilities & 7 & $\begin{array}{l}\text { Doctorate - Higher } \\
\text { Ed. Leadership }\end{array}$ \\
\hline Juli & 26 & Female & Latina & $\begin{array}{l}\text { Temporarily } \\
\text { able bodied }\end{array}$ & 1 & $\begin{array}{l}\text { Masters - Higher } \\
\text { Ed. Admin. }\end{array}$ \\
\hline Kevin & 29 & Male & Biracial & Able & 4 & $\begin{array}{l}\text { Masters - Higher } \\
\text { Ed. Admin. }\end{array}$ \\
\hline Lynn & 24 & Female & White, Caucasian & No disabilities & 1 & None \\
\hline Mac & 28 & Male & White, Caucasian & Presently able & 2 & $\begin{array}{l}\text { Masters - Higher } \\
\text { Ed. Admin. }\end{array}$ \\
\hline Maeve & 27 & Female & White & Able & 6 & $\begin{array}{l}\text { Masters - Mental } \\
\text { Health \& Wellness }\end{array}$ \\
\hline Megan & 30 & Woman & White & I have a disability & 7 & $\begin{array}{l}\text { Masters - Higher } \\
\text { Ed. Admin. }\end{array}$ \\
\hline Murphy & 27 & Trans male & White & I have a disability & 5 & $\begin{array}{l}\text { Masters - Higher } \\
\text { Ed. Admin. }\end{array}$ \\
\hline$\overline{\text { Noelle }}$ & 25 & Cis woman & White & I have a disability & 1 & $\begin{array}{l}\text { Masters - Higher } \\
\text { Ed. Admin. }\end{array}$ \\
\hline
\end{tabular}




\begin{tabular}{|c|c|c|c|c|c|c|}
\hline Name & Age & Gender Identity & Race/Ethnicity & Ability/Disability & $\begin{array}{l}\text { Years } \\
\text { Experience }\end{array}$ & Graduate School \\
\hline Parker & 27 & Male & Asian American & Able bodied & 6 & $\begin{array}{l}\text { Masters - Higher } \\
\text { Ed. Admin. }\end{array}$ \\
\hline Perry & 24 & Male & White, Hispanic & Able & 3 & Masters - Theology \\
\hline Robin & 40 & Male & White & Able & 6 & Masters \\
\hline Rose & 23 & Female & White & No disabilities & 1 & None \\
\hline Scotty & 27 & Male & $\begin{array}{l}\text { Latino \& } \\
\text { Middle Eastern }\end{array}$ & Able bodied & 4 & Masters \\
\hline Theo & 26 & Male & LatinX & Able bodied & 2 & $\begin{array}{l}\text { Masters - Higher } \\
\text { Ed. Admin. }\end{array}$ \\
\hline Vanessa & & Woman & $\begin{array}{l}\text { Asian Pacific } \\
\text { Islander }\end{array}$ & Able & 2 & Masters \\
\hline
\end{tabular}




\section{Appendix E}

Institution Characteristics

The following details capture characteristics of the 17 colleges and universities from which the

32 RDs were recruited:

\begin{tabular}{lll} 
& Range & Average \\
\hline Undergraduate Headcount & $1,480-7,988$ & 3,488 \\
\hline Published Tuition \& Required Fees & $\$ 37,000-\$ 60,620$ & $\$ 49,442$ \\
\hline
\end{tabular}

Institutional Service:

\begin{tabular}{ll}
\hline Hispanic Serving Institutions (HSI) & Yes - 1
\end{tabular}

Historically Black Colleges and Universities (HBCU) No

Institutional Setting:

City, large - 5

City, midsized - 6

City, small - 1

Suburb, large - 2

Town, distant - 1

Town, fringe - 1

Rural, fringe - 1

Religious Affiliation:

Christian - 12

None - 5 


\section{Appendix F}

\section{Interview Guide (updated questions in italics)}

Thank you for agreeing to participate in my study about resident directors' understandings of disability. I would like to hear about your experiences as a resident director, particularly regarding the ways in which disability appears in the residential communities you supervise. I have some guiding questions for us, but they are not rigidly scripted - I may ask some follow-ups as we go, and I encourage you to elaborate on aspects or issues of your experiences as you find them important. I anticipate that our conversation will take around an hour. Before we begin, I want to remind you that in addition to being able to stop your participation at any time, you are also free to skip particular questions, or choose not to discuss anything that you may find uncomfortable. First, please read through the following consent form, and then we will begin.

- When you hear the term 'disability' - what comes to mind?

- Have you noticed or experienced disability in your current position?

- In what ways, if any, have your RD experiences impacted your definition of disability?

- In what ways, if any, does disability appear in your typical day as an RD? 
- Tell me about the ways, if any, that you work with students with disabilities in your residence hall - what do you do?

- Have you had some positive experiences working with students in the context of disability? If so, will you share some of those with me?

- Have you had some negative experiences working with students in the context of disability? If so, will you share some of those with me?

- As you reflect on working with students in the context of disability, are there particular things you have learned through these experiences?

- As you reflect on working with students in the context of disability, are there particular things you have found hopeful or exciting?

- As you reflect on working with students in the context of disability, are there particular things you have found discouraging? 
- Who, or what, have you found to be the most helpful in working with students with disabilities?

- What, if any, forms of supervisory support do you provide to RAs with respect to disability?

- What areas of campus do you think are the most friendly for students with disabilities?

- What areas of campus do you think are the least friendly for students with disabilities?

- In what ways, if any, do you associate concepts of disability with concepts of diversity?

- In what aspects of your work with students with disabilities do you have the most autonomy or control?

- In what aspects of your work with student with disabilities do you have the least autonomy or control? 
- Could you discuss how your views of disability, and the ways in which you work with students with disabilities, may have changed since you began working as an RD?

- Based on your experiences, what advice would you give to someone who is just starting their job as an RD about working with students with disabilities?

- What training or professional development, if any, have you received about students with disabilities?

- was this part of your graduate training?

$\circ$ is this something you sought out?

○ was it offered by your department?

- Is there something else you think I should know to understand the way your work engages disability? 
- Lastly, I have a series of demographic questions:

- How long have you worked as a Resident Director?

○ What, if any, graduate education have you completed?

$\circ$ What is your age?

- What is your gender?

○ How do you identify your race/ethnicity?

- How do you identify regarding ability/disability?

Thanks again for your time today. I'll be continuing with interviews and then will be typing up the transcripts and analyzing the interviews. I will be sharing my findings with you and the community once I have completed the analysis. If you have any questions or concerns in the meantime, please do not hesitate to contact me. 


\section{Appendix G}

\section{Coding Progression Example}

The following excerpt from Adrian's interview is provided as a demonstration of the coding progression that was carried out to analyze the data.

\section{Transcript Excerpt}

But it's an important thing with working with students who need accommodations per their disabilities, is that just because we have a certain answer doesn't mean that that's the prescription. Each student needs to be able to live out their own story. And no two students have the same story, and so, you know, kind of giving them, like, "Alright, here's our options," right? You know, "What looks good to you? What fits correctly?"

\section{Transcript Lines and Initial Codes}

\begin{tabular}{ll} 
Transcript & Initial Code \\
\hline But it's an important thing with working with students who need & Working with students who need accommodations \\
\hline accommodations per their disabilities, is that just because we have a & Having certain answers \\
\hline certain answer doesn't mean that that's the prescription. Each student needs & Having an answer doesn't mean it is a prescription \\
\hline to be able to live out their own story. And no two students have the & Allowing each student to live out their own story \\
\hline same story, and so, you know, kind of giving them, like, “Alright, here's & Knowing that no two students are the same \\
\hline our options," right? You know, "What looks good to you? What fits correctly?" & Asking about what fits \\
\hline
\end{tabular}




\section{Initial Codes and Focused Codes}

Initial Code

Focused Code

Working with students who need accommodations

Having certain answers

Having an answer doesn't mean it is a prescription

Allowing each student to live out their own story

Knowing that no two students are the same

Asking about what fits
Avoiding accommodation assumptions

Avoiding accommodation assumptions

Avoiding accommodation assumptions

Knowing that no two students are the same

Knowing that no two students are the same

Asking about what is working and what isn't

\section{Focused Codes and Categories}

Focused Code

Avoiding accommodation assumptions

Avoiding accommodation assumptions

Avoiding accommodation assumptions

Knowing that no two students are the same

Knowing that no two students are the same

Asking about what is working and what isn't

\section{Category}

Avoiding norms and assumptions

Avoiding norms and assumptions

Avoiding norms and assumptions

Avoiding norms and assumptions

Avoiding norms and assumptions

Avoiding norms and assumptions

\section{Category to Theme}

